University of Louisville

ThinkIR: The University of Louisville's Institutional Repository

Electronic Theses and Dissertations

$12-2017$

\title{
The knowledge economy : increasing human capital on the U.S. I-65 corridor.
}

Brandon S. McReynolds

University of Louisville

Follow this and additional works at: https://ir.library.louisville.edu/etd

Part of the Educational Sociology Commons

\section{Recommended Citation}

McReynolds, Brandon S., "The knowledge economy : increasing human capital on the U.S. I-65 corridor." (2017). Electronic Theses and Dissertations. Paper 2865.

https://doi.org/10.18297/etd/2865

This Doctoral Dissertation is brought to you for free and open access by ThinkIR: The University of Louisville's Institutional Repository. It has been accepted for inclusion in Electronic Theses and Dissertations by an authorized administrator of ThinkIR: The University of Louisville's Institutional Repository. This title appears here courtesy of the author, who has retained all other copyrights. For more information, please contact thinkir@louisville.edu. 
THE KNOWLEDGE ECONOMY:

INCREASING HUMAN CAPITAL ON THE U.S. I-65 CORRIDOR

By

Brandon Scott McReynolds

B.S., University of Louisville, 2012

M.A., University of Louisville, 2014

\author{
A Dissertation \\ Submitted to the Faculty of the \\ College of Arts and Sciences of the University of Louisville \\ In Partial Fulfillment of the Requirements \\ For the Degree of \\ Doctor of Philosophy \\ in Applied Sociology \\ Department of Sociology \\ University of Louisville \\ Louisville, Kentucky
}

December 2017 
Copyright 2017 by Brandon McReynolds

All rights reserved 



\section{THE KNOWLEDGE ECONOMY:}

INCREASING HUMAN CAPITAL ON THE U.S. I-65 CORRIDOR

$$
\text { By }
$$

Brandon Scott McReynolds

B.S., University of Louisville, 2012

M.A., University of Louisville, 2014

A Dissertation Approved on

November $14^{\text {th }}, 2017$

By the following Dissertation Committee:

Dissertation Director, Dr. Derrick Brooms

Dissertation Co- Director, Dr. Cynthia Negrey

Dr. Lauren Heberle

Dr. Jacob Gross

Dr. Aaron Rollins 


\section{DEDICATION}

This dissertation is dedicated to every teacher, professor, and mentor I have ever had. I am here today because of their commitment to knowledge and education. 


\section{ACKNOWLEDGMENTS}

I want to start by thanking Dr. Derrick Brooms for his mentorship, support, and guidance throughout this process. Additionally, I must thank Dr. Cynthia Negrey; her advice was instrumental to this dissertation. Also, I want to thank Dr. Lauren Heberle; she has served as more than just a committee member but also as an advisor and mentor. I would also like to thank Dr. Jacob Gross and Dr. Aaron Rollins for providing guidance in their respective specialties.

I wish to extend a special thank you to the Department of Sociology and School of Interdisciplinary and Graduate Studies for providing me this opportunity and their support.

Personally, I want to thank my parents, Scott and Jennifer McReynolds; they have always been my biggest supporters. I would never have gone this far in my education without them. I am also extremely grateful for Monali Haldankar, her friendship, love, and compassion have been amazing.

Last but not least, I want to thank my friends and colleagues. Especially, Adam Sizemore and Kent Pugh, who have been more than just colleagues in the same cohort but two of my greatest friends. Additionally, I must thank Katie Adamchik and Robin Weiss for their advice, support, and friendship. 


\section{ABSTRACT \\ THE KNOWLEDGE ECONOMY: \\ INCREASING HUMAN CAPITAL ON THE U.S. I-65 CORRIDOR}

Brandon S. McReynolds

November 14, 2017

In economics, the term growth often refers to the increase in economic activity between two points in time. Within the context of the United States of America, the language of growth has permeated beyond just economics and into other societal institutions due to spillover. As a result, growth is not just an economic term but rather a part of the culture of capitalism which impacts every area of society. The dissertation using growth machine theory and the global cities literature examines how in the knowledge economy, cities play a growing role in mediating the supply and demand for post-secondary attainment. The research recognizes that as the knowledge economy expands, cities, states, and nation states will look for new channels of meeting a precondition for growth: human capital. The study examines 58 cities and finds a great divergence taking place between high and low attainment cities in the United States. Additionally, the dissertation examines three case study cities on the U.S. I-65 interstate corridor: Indianapolis, Louisville, and Nashville.

The case studies examine how and why cities are working to raise the percentage of their populations with a college degree. Findings show that cities are working to raise 
attainment for the purposes of: economic development, economic competitiveness, and individual empowerment. To meet attainment goals each city's human capital system works to develop, retain, and attract individuals with at least a post-secondary degree. Additionally, the research discusses the long-term implications of using growth and competition as a rationale for increased higher educational attainment. In conclusion, the study questions and recommends future research on the changing purpose of higher education in the United States. 


\section{TABLE OF CONTENTS}

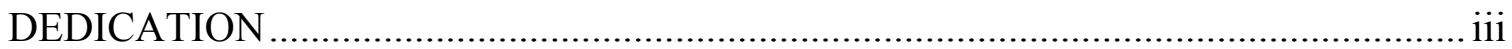

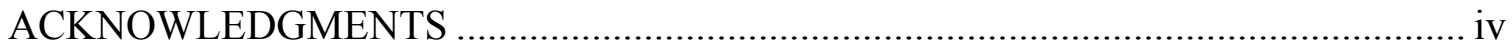

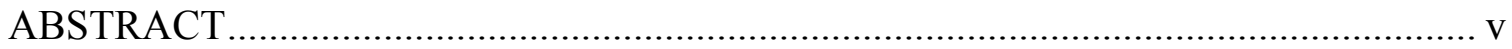

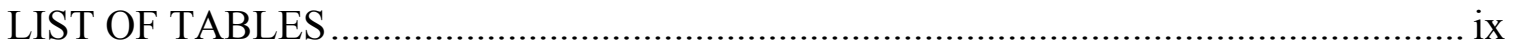

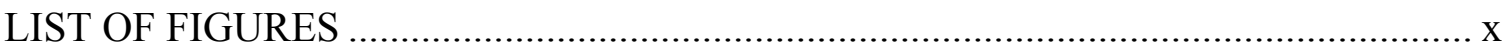

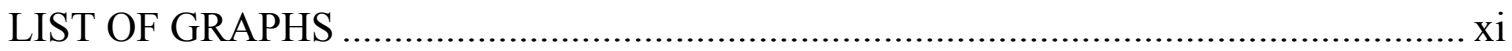

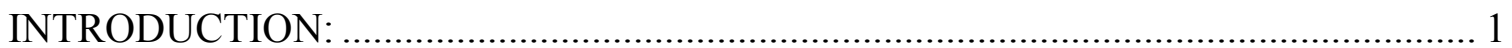

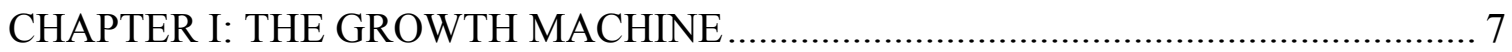

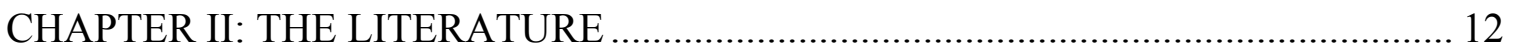

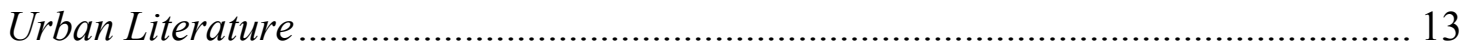

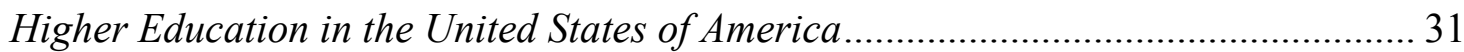

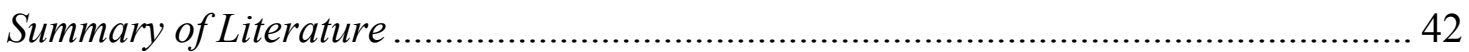

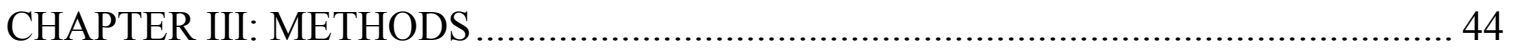

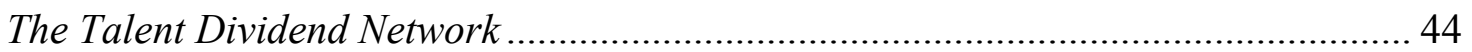

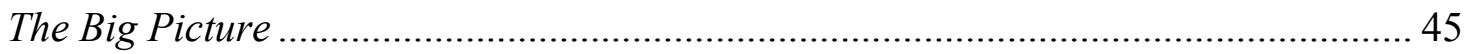

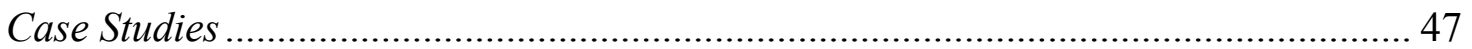

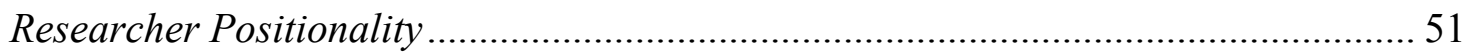

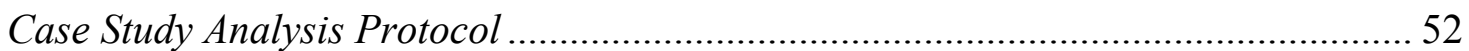

CHAPTER IV: THE GREAT DIVERGENCE ……………........................................ 54

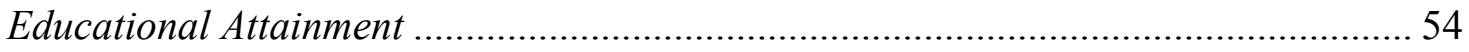

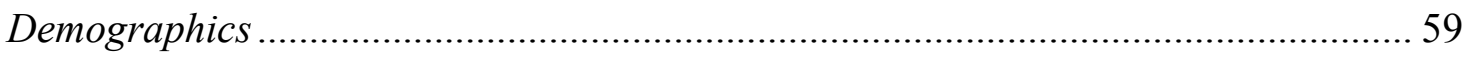

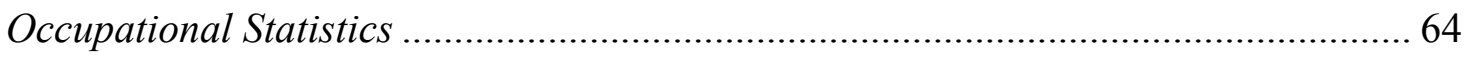

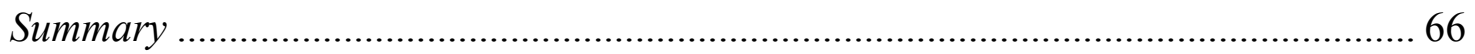

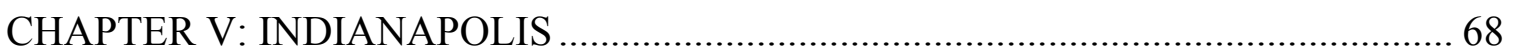

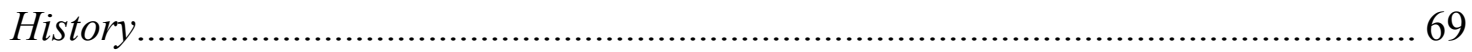

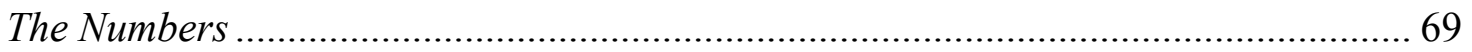

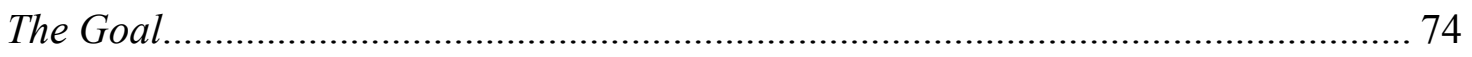

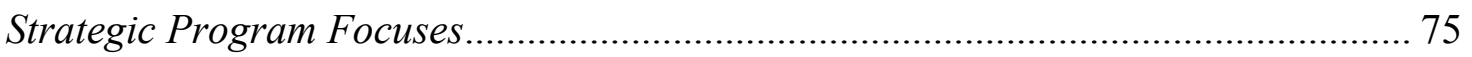

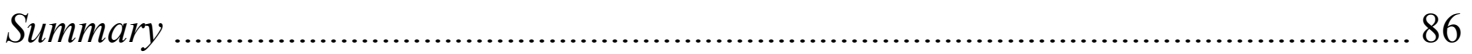




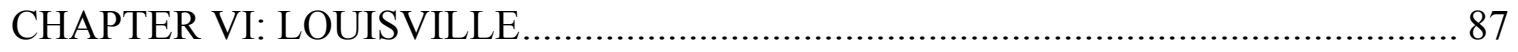

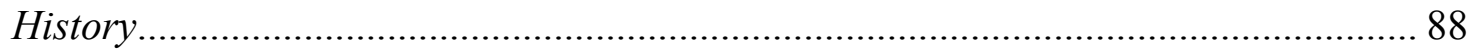

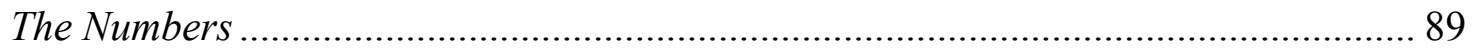

A City Committed to Fostering Educational Attainment ................................................ 94

Strategic Program Focuses.............................................................................. 96

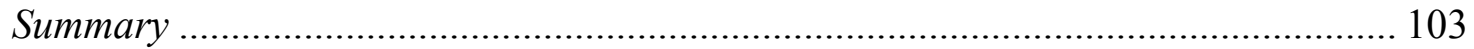

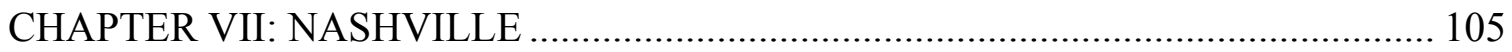

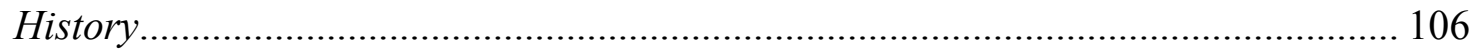

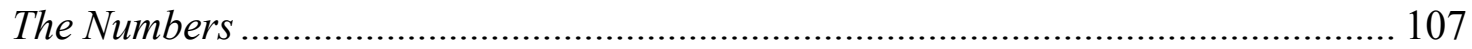

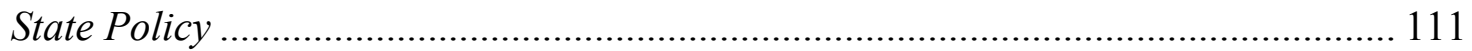

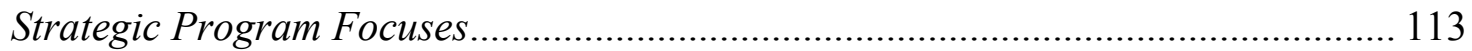

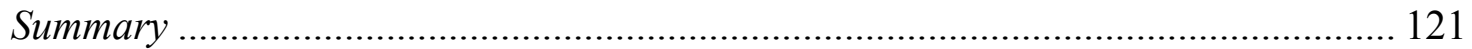

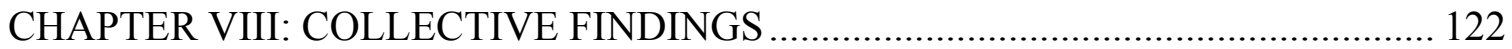

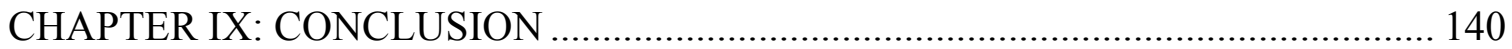

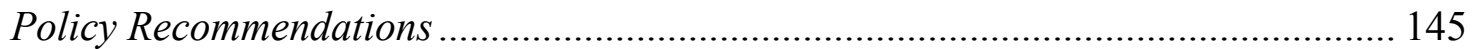

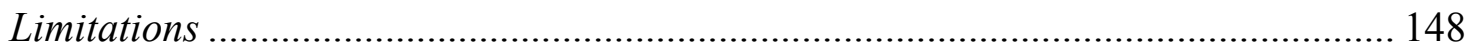

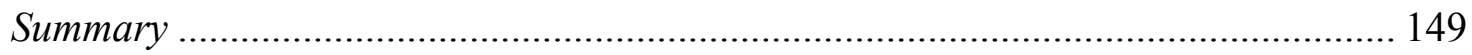

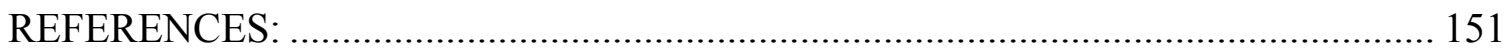

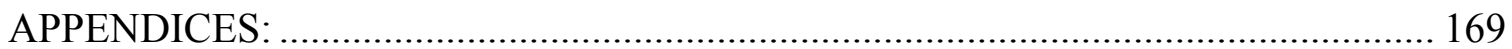

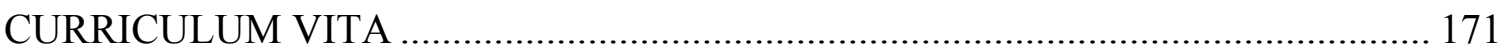




\section{LIST OF TABLES}

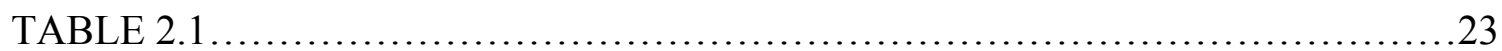

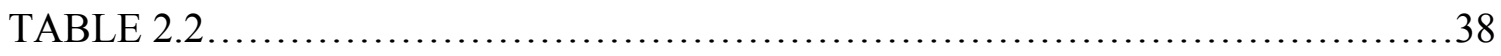

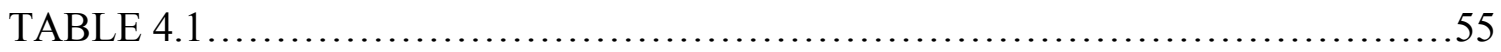

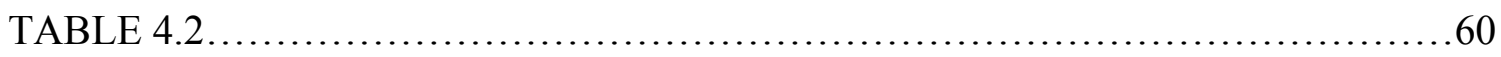

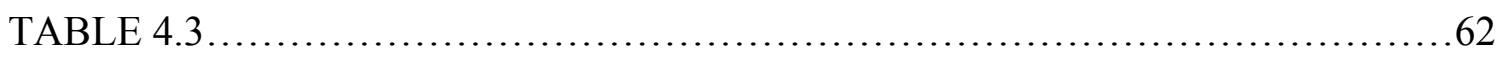

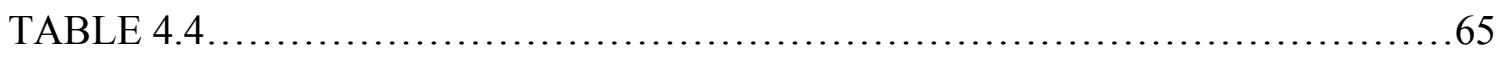

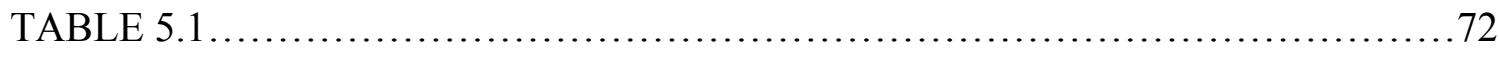

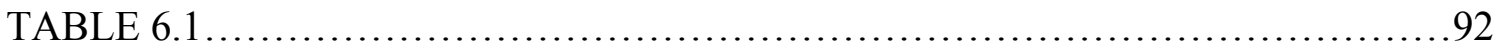

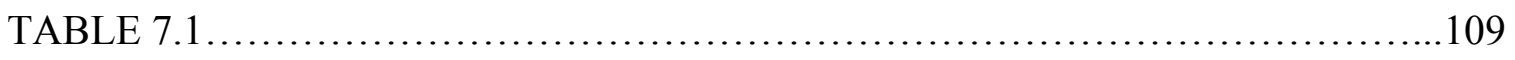




\section{LIST OF FIGURES}

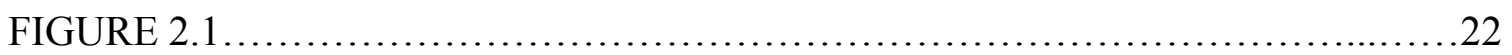

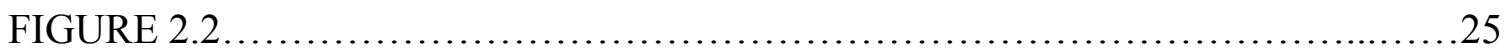

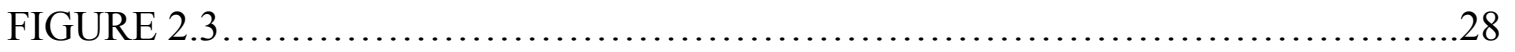

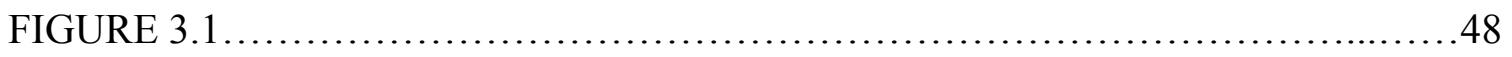

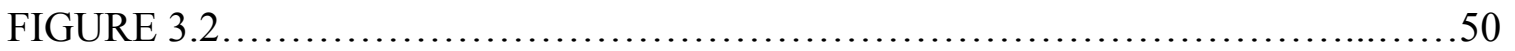

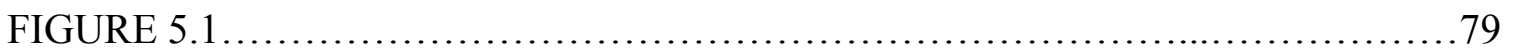

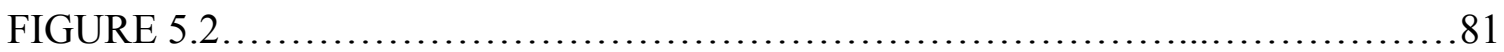

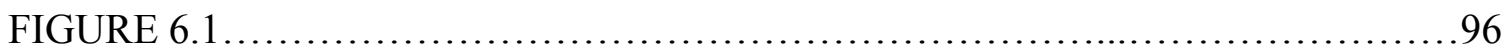

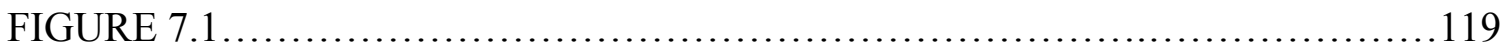

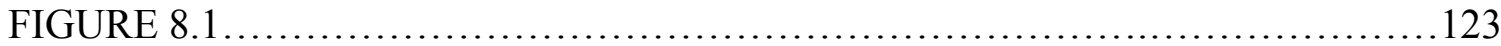

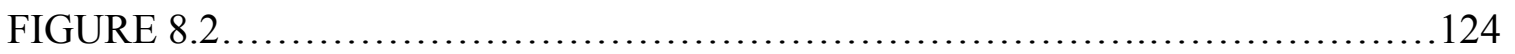




\section{LIST OF GRAPHS}

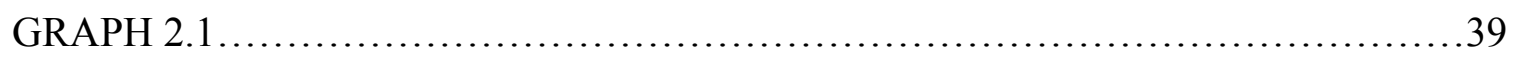

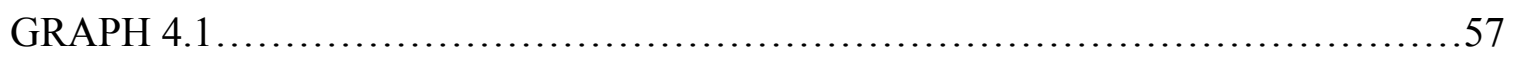

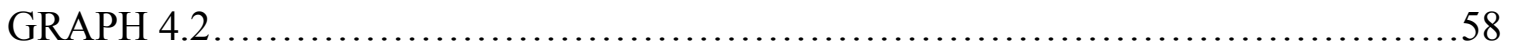

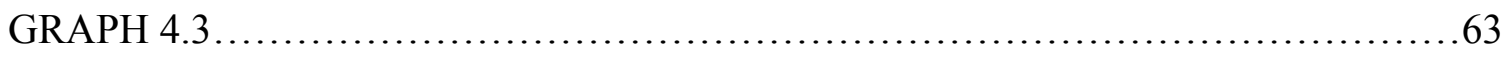

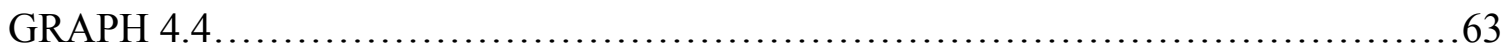

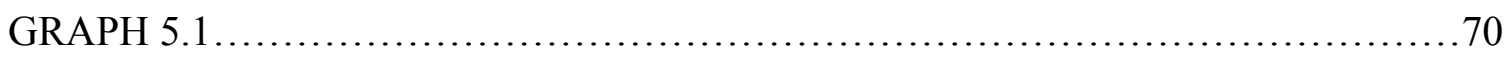

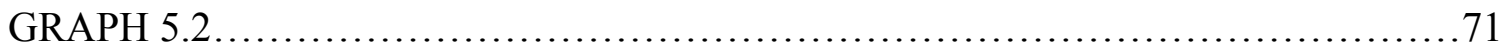

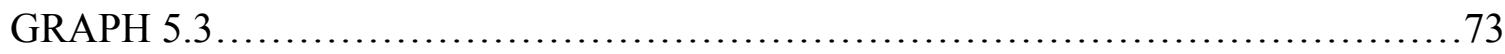

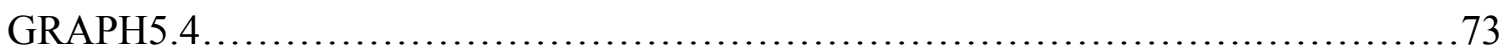

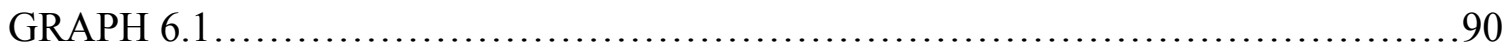

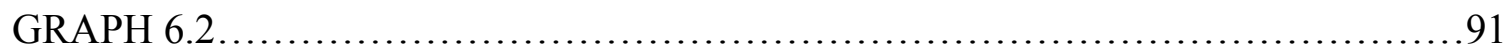

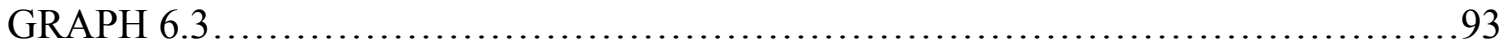

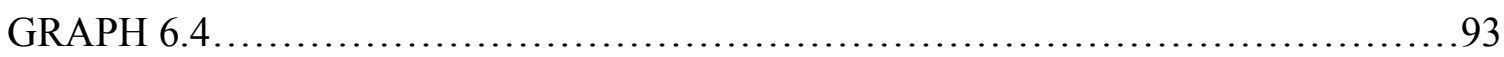

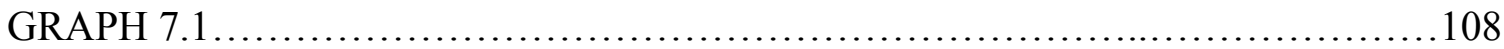

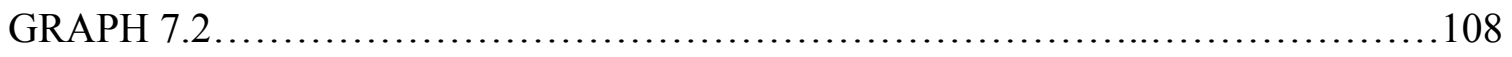

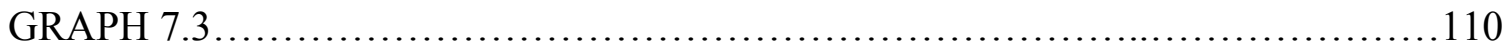

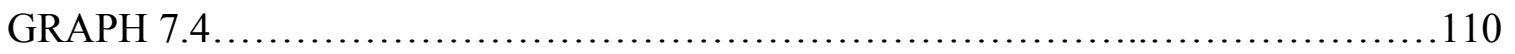




\section{INTRODUCTION:}

(The United States of America's) once unchallenged preeminence in commerce, industry, science, and technological innovation is being overtaken by competitors throughout the world... If only to keep and improve on the slim competitive edge we still retain in world markets, we must dedicate ourselves to the reform of our educational system for the benefit of all-old and young alike, affluent and poor, majority and minority. - A Nation at Risk, 1983

For two centuries, the United States has developed and maintained its economic superiority by relying on its vast natural resources and manufacturing power. As the twentieth century progressed, it became apparent that this reliance was unsustainable. In 1983, the Reagan administration released "A Nation at Risk" (National Commission on Excellence in Education 1983). The report found that if the United States wanted to retain its power, in the global economy, major educational reform had to take place. After the report was released, education reformers used the report, and its five recommendations, to draw attention to the national importance of higher education. "A Nation at Risk" cemented the language that connects education and economic competitiveness in the United States; this relationship and shift in the economy is not just a U.S. reality. Globalization has extended the ties between higher education and the neoliberal economy (Olssen and Peters 2007). As a result, globalization has led to the rise of knowledgebased capitalism and the knowledge society, which prioritize high human capital, and the suppliers of that capital in the global economy. Countries, states, and cities who can both

supply and nurture such capital are more economically viable and given a higher status in 
the global network (Olssen and Peters 2007). On the other hand, countries who can provide low cost and low human capital labor also benefit, by being places for global producers to create products at a lower cost creating a spatial division of labor.

The international spatial division of labor leaves the United States unable to compete with other nations in the 'less-skilled' labor market. Skills refer to abilities gained by individuals through formal and informal education and training programs. Due to the ability of companies to find lower-cost labor abroad, firms, the state, and cities in the United States have shifted policy strategies, to remain competitive, by focusing on 'high skilled' (high attainment/credentialed) occupations. This shift to focusing on high human capital, and the respective strategies which that pushed it forward, have tied together education and globalization (Olssen and Peters 2007; Spring 2008). While the way we frame and discuss globalization is relatively new, trade, capital, and ideas have moved across borders for centuries. What differs is that the twenty-first-century economy looks drastically different than it did just thirty years ago, causing a domino effect of changes for various institutions. A method of visualizing the said domino effect is under the guise of global flows.

Global flows refer to the spread of ideas, institutions, practices, and people, which have become the new language surrounding globalization and education (Appadurai 1996). Knowledge-based capitalism is a product of the global flows process, which happened through the rise in the influence and power of major global institutions, such as The World Bank, the World Trade Organization, and the United Nations; these influencers affect policy prioritization within education policy circles (Spring 2008). What these major institutions, multi-national companies, and the global financial markets 
have allowed for is a denser web of global structural connectedness. This connectedness is less between imperial powers and nation-states but rather between cities and firms. An indirect result is that globalization has played a substantial role in empowering cities to see themselves as part of a global marketplace. Creating an urban-centric economy where other social institutions are affecting cities and their policies. As cities have become the central nodes in the global economy, an increased competitive spirit between cities has also developed where they are fighting over not only business attraction and physical capital, but also human capital. Human capital refers to both the knowledge accumulated by individuals, firms, and cities along with the formalized skills gained by individuals.

Seeing the city as a competitive actor, fighting for resources, is key to understanding how cities affect the pathways for creating human capital (knowledge and skills). The environment wherein the city is interacting with and affecting other social institutions allows one to see how social institutions spillover, through global flows, and affect one another differently than they had before (Carlino 1995). Global flows are the process of creating and using a shared language between firms and institutions, while spillover refers to the effects of that process. Therefore, as firms and institutions use neoliberal principles, the spillover effect-taking place in the United States and abroad is the expansion of the culture of capitalism. Recognizing this expansion allows for the literature to study how the principles of neoliberalism influence institutions such as the city and higher education (Peck and Tickell 2002). The spillover effect of one societal institution on another is a structural and sociological process. Economic research also has examined the effect of spillover as it pertains to both the concentration and rise of human capital. 
Research on the impacts of spillover has shown that cities with high human capital had higher property cost and wages even when holding individual characteristics constant (Rauch 1993). Additionally, spillover creates markets and capital accumulation where it had not existed prior (Harvey 2005). A failure to study spillover can lead to a failure to recognize the interconnected nature of various societal institutions. Collectively, spillover literature shows that social institutions and mechanisms of growth do not exist in isolation. As growth or decline takes place, a series of domino effects also occur. It is through the process of global flows, and spillover - both positive and negative- that allows the language of competition to be a motivator for change. Cities use the language of competition and economic growth, to elevate characteristics like high skilled, high knowledge, high attainment individuals as key to remaining economically competitive (knowledge-based economy).

Over the last several decades, research regarding attainment has examined the economic benefits of having a more educated workforce. Scholars have shown that an educated workforce is a significant determinant of per capita income growth (Gottlieb and Fogarty 2003) and that educational attainment relates to employment growth (Simon 1998). Meaning, that while educational attainment has a positive lifelong benefit for the individual, (on average) it also has a communal spillover benefit especially in highly educated localities (Carlino 1995). It is due to this spillover that it is difficult to say that higher educational attainment directly leads to economic growth (Wolf 2003). There is research that does show a link between years of schooling and test scores to economic growth at a national level (Hanushek, Jamison, Jamison, and Woessmann 2008). We also know that there is an economic benefit to raising student achievement at the state level 
(Hanushek, Ruhose, and Woessmann 2016). The question remains if this holds true for cities; despite this, cities and funding organizations across the United States are using the language of competition, to push local education initiatives for both individual and communal benefit. The use of the idea of competition creates a shared language network that sees attainment and talent as central to urban growth. It is due to this belief in knowledge-based capitalism that research needs to understand how urban policymakers operationalize raising human capital.

This study examines how United States cities are currently working to raise their educational attainment as a form of human capital. Specifically, this research uses a regional approach by looking at three closely connected major U.S metropolitan cities. The three cities were selected from a larger base sample of U.S. cities. The explicit purpose of this research was to begin to bridge gaps in the literature by examining the connections between cities and higher education along with how competition between cities may influence (due to spillover and global flows) a variety of social institutions. The research will not explicitly answer the cause and effects of competition between cities and the changes to higher education. As a result, the following research questions create a platform for future research to understand how and why cities work to increase their human capital:

1. How are U.S. cities working to increase higher education attainment as a form of human capital?

1a. Why are cities working both formally and informally to increase educational attainment? 
1b. What connection do U.S. cities see between educational attainment and growth?

By raising these questions, further questions will arise for researchers regarding how shifts in the larger economy affect social institutions such as higher education. This research bridges the gap and helps to create a framework for further conceptualizing the direct and indirect effects of the globally competitive economy on the local level. This study starts by first applying a theoretical lens that sees growth, and desire to grow, as fuel for a city and regional initiatives such as those aimed at raising educational attainment. 


\section{CHAPTER I: THE GROWTH MACHINE}

Globally and domestically, cities compete with one another. They compete for all forms of capital. New Urban Politics (NUP) recognizes the changing realities of competition because of hypermobile capital (Cox, 1993). A result of hypermobile capital is that a city will unite to both maintain and attract business. This unification process brings city stakeholders together under a language of growth to meet the preconditions for competition. What growth means can have several conceptions but for this research, growth explicitly refers to economic growth. This definition can also incorporate simple population growth as well because as populations grow so does the local economy (Glaeser 1994). As a result, while growth refers to economic measures, the growth of a population and even the growth/adaptation of the built environment is also implied. Meaning that as local stakeholders unite around the goal of growth, they are also uniting around a multitude of means aimed at achieving the goal.

Whether it be through pro-business land use policy, labor, or access to raw materials, cities and nation-states compete for a piece of the global economy. Through the attraction of business, capital, and individuals, the city grows, which creates further opportunities for profit generation. We know that one means of growth is through the expansion of human capital (Glaeser 1994; Simon 1998; Gottlieb and Fogarty 2003; Hanushek, Ruhose, and Woessmann 2016). It is one thing though to be able to visualize growth and the preconditions that help to make it happen; scholars must question the 
benefits of various forms of growth. One benefit, of course, is that the simple growth of a population is the growth of the consumer base. It is also rational to hypothesize a multitude of social spillover effects from growth not connected to economic measures. For example, a citizen in a city can benefit from a new park by more than just having a place to form a community but also a place to exercise. Recognizing that both economic and non-economic benefits are the results of various forms of city growth, this research uses Molotch's theory of the growth machine as a theoretical framework.

The growth machine theory comes from Harvey Molotch (1976). It recognizes that cities, as places of economic activity and life, desire to grow. It is this very desire that underlies many local policy decisions. While local leaders, various regimes, and citizens may not agree on the means, there is often consensus around the desire to grow. Whether "local leaders" refer to the neighborhood organizer who is looking to add jobs and services or the local leader is the city's chamber of commerce, there exists a very basic desire to grow. A desire to grow is an important characteristic of the growth machine: the people at some level must believe that growth and the preconditions for growth are important for their well-being. With this in mind, it is important to conceive of the city as a collection of individual actors and organizations. Just conceiving of a growth machine as one autonomous body, would not recognize the variation between growth machines or how growth machines from within maintain themselves. What the theory does say is that the organizations and stakeholders who make up a growth machine come together to tackle any topic through formal and informal means.

To grow, Molotch asserts that the city relies on various preconditions. Examples of preconditions can be infrastructure, amenities, and access to add various forms of 
capital, especially human capital. These preconditions are what allow a locality to be able to compete with others. Preconditions receive various levels of allocation of public resources and then prioritized on the locality's agenda. One would expect to see higher prioritized goals/preconditions to receive support whether that be through government or a formal citywide collaboration organization. This research builds upon endogenous growth theories that see human capital and knowledge accumulation as two of the most central and important of any preconditions in the knowledge economy.

The theory of the growth machine extends beyond just saying that growth occurs and that there are certain preconditions for growth. A growth machine, to be able to maintain itself, must be a stable structure, doing so through what Molotch calls the mutual reinforcement of political, cultural, and economic dynamics (1993). Therefore one would expect to see growth, and the initiatives which tie to strengthening the preconditions of growth, involve a wide breadth of city stakeholders. It is mutual reinforcement that allows a variety of institutions within the city to lean on one another for sustained success. Growth machine theory also suggests that mutual enforcement can create a structure whereby the actors working to strengthen preconditions for growth may be unaware of how their role reinforces the larger growth coalition. One can argue the connectedness of the coalition works to weave the language of growth throughout the city.

Issues do exist with this theory. Molotch's original growth machine theory does very little to answer the how questions, such as: how do cities create these coalitions, how do cities prioritize growth, how do cities use the mutual desire for growth for both communal and individual benefit, and to what effect does globalization undercut the 
growth machine? Each of these questions highlights different limitations of the theory (Cox 1999). The theory is also limited because, for many, its use outside of the United States is ill-advised (Jonas and Wilson 1999). Molotch himself argues that the theory does not explain all aspects of growth or the rationale for growth (Molotch 1999); this is why much of the research that uses the growth machine as a framework focuses on who is involved in growth.

The question of "for whom does the benefit of growth accrue," helps in understanding individual city mutual reinforcement while also addressing many of the theory's critiques. Focusing on benefits and their reinforcing structures allows cities to share similar growth machine principles. For example, Clarence Stone's research showed what he called a "corporate regime" in Atlanta (1989). This collection of individuals, mostly downtown business elites and leaders in Atlanta, acted as a stable collection of relationships, which were both formal and informal; they were central in deciding how decisions happened and who was a part of the process. While tenants of this type of regime may be found in most large cities in the United States, studying urban regime theory and growth machine beyond a city case study level would not be as constructive. Additionally, when questioning to whom the benefit of growth accrues to researchers have questioned to what degree does growth trickle down (Clark, Green, and Grenell, 2001; Cain 2014). Other researchers have studied the level of power the everyday citizen has to push back against the growth machine (Been, Madar and McDonnell 2014). Therefore, while critiques of the theory exist, the research discussed above signals a need to adjust growth machine theory as cities become more central in the global economy. 
This research builds on Molotch's theory by looking at how cities are addressing the precondition of a highly educated workforce that has globally become a demand for business in the twenty-first century. Studying this phenomenon will contribute to the literature about the influence of globalization and regimes may have on the preconditions for growth for American cities. After investigation, if Molotch's theory plays out as stated, one would expect to find local elites, businesses, nonprofits, and government o be woven into the mutually reinforcing fabric of educational attainment initiatives as a way of greasing and reinforcing the growth machine. Molotch's theory also would suggest that these types of growth initiatives would somehow incorporate and require citizen buyin as a growth mechanism for the city. Also, by examining how cities work to maintain, grow, and even attract a highly educated citizenry, the literature can consider how this form of growth either supports or questions the growth machine. Before diving deeper, there is a need to address what the city means, the history of higher educational attainment in the United States, and how competition, mimicry, and labor help to tie the city and education together in the knowledge economy. 


\section{CHAPTER II: THE LITERATURE}

This study situates itself directly between two main areas of literature: first the urban literature and, second, the literature about higher education. One of the most elementary yet central concepts the literature provides is a framework for what defines "the city" and how it has shifted over time. The concept of time is very important because, as stated above, the shifting economy has placed the city rather than the state at the center of economic competition, unlike ever before. The literature on global cities emerges to address how cities compete with one another for position in the global network by competing and benchmarking. Most importantly, cities are competing by framing themselves as centers of knowledge. Again, the transformation to a knowledgebased economy goes back to the transformation of the American city from a place of industry to now being places of knowledge creation; this shift has caused cities to become centers for highly educated laborers. Through the concentration of high human capital, cities work o meet the requirements of being acknowledged as a knowledge city.

Today, higher education is a key form of human capital. The evolution of both the demand for and the supply of individuals with higher education credentials also brings forth the literature regarding the current function of higher education. While this does create, a chicken or the egg type scenario, wherein one can ask if higher education is driving cities or are cities driving the demand for higher education both questions tie together the urban and higher education literature. The proposed study does not see these 
areas of literature in parallel but as woven together by global flows; where the city and higher education connect through local initiatives aimed at ensuring the city meets a twenty-first-century precondition of growth, a highly educated labor force. By building on both of these areas of literature, this study helps answer questions about how local policy, programs, and initiatives may be driving urban growth and higher education at the same time.

\section{Urban Literature}

The transformation of the American urban metropolitan areas over the last several decades is complex. Cities are more than just central, dense localities but also include growing suburban sprawl. These various images of the city change the discussion around the spatial dynamics of a city but also the identity of a city. The shifting identity of cities influences how a city is defined and measured, causing a need for local policy to recognize regional impacts of local policy. Globalization causes cities to think beyond unilateral, single governmental entities for growth and economic development. Instead, cross-sector, multijurisdictional efforts are best for growth in the globalized economy (Felbinger and Robey 2001). As a result, multijurisdictional efforts are central to a city's ability to compete; one-way cities as regions work to ensure that their policies and business climate align with the demands of those businesses they are seeking to both attract and retain. One effect of such multijurisdictional, pro-business policies is that cities must balance both the economic market and their citizens. At the same time, cities must see those citizens as actors with autonomy. Problems can arise when these two come into conflict with one another. Initiatives designed to both empower the individual while also strengthening the city's competitiveness help to form mutual reinforcement. While this is not new or novel, cities have always had to juggle the demands of various 
stakeholder groups, the re-marketing of the city as a region of knowledge has shifted how cities compete with one another. Of importance in this section is how cities gauge where they currently stand regarding human capital to be a knowledge city. An additional point to gauge is how are practitioners and researchers attempting to measure the performance of cities to discover best practices.

Scholars have attempted to try to both quantify and qualify the characteristics of cities, especially cities that are models for growth. Research such as Florida's (2002) discussion about the so-called 'creative class' attempts to create hierarchy and distinct characteristics for what modernity looks like in the city. He argues that a city's ability to attract and maintain individuals in the creative class centers on both the built environment of the city and local policies. Florida asserts if the city can align these various efforts by attracting and maintaining a creative class, that growth for the city will result. He uses a rankings system for highlighting cities with high percentages of individuals within the creative class. Critiques have attacked his ranking of cities due to what many see as misinformed causality (Gibson and Kong, 2005). Others have found that simply adding members of the creative class to a city does not causally lead to stronger economic growth (Rausch and Negrey 2006). While Rausch and Negrey (2006) find elements of Florida's creativity index such as human capital and foreign-born population as important predictors for economic health and growth, holistically the creative class index does not alone predict economic growth.

Florida's work is just one example of how the complexity of cities is oversimplified when scholars, practitioners, and policymakers begin to attempt to place cities within categorical boxes. Florida's creative class index and the critiques mentioned 
above highlight the need to be cautious when prescribing and theorizing mechanisms of growth. The complexity of examining policy and mechanisms of growth is due to the varying interest of stakeholders, the diversity of citizens, and the relative uniqueness of every American city. These varying interests only intensify as economic development becomes multi-jurisdictional. The researcher and practitioners must examine not just individual institutions but how the city as a unit weaves various institutions together around a common language. A common language simplifies the discussion surrounding cities because it recognizes that various social institutions overlap and as a result can support one another.

To best summarize the complexity of the American city one must understand not only how the definition has shifted over time, but also how the built environment of cities interweaves into the varying social institutions that call the city home. It is the interwoven nature of social and economic insitutions that is the foundation for understanding how social institutions support and reproduce one another. Before addressing what, the literature says about the structure; it is essential to define what the literature means by 'the city.'

The city

The city as both a place and an institution has progressed and shifted through time. Calvino (1978) argues that what is meant by "the city" is particular to an individual and based on one's implicit visions. Such a subjective view of what the city allows for the possibility of contention around what the city should be regarding growth, economic development, and planning. Friction in the vision for the built and non-built environments of a city is common; this conflict exists between conceived and lived space (Brenner 
2000). In many ways, this differentiates the city and adds complexity. Through time, scholars have argued that indivudal behavior is influenced by the environment of the city (Simmel 1950; Krupat 1985; Kuo and Sullivan 2001). Although such an assumption rests on the premise that one's behavior is a product of one's environment, this is a foundational element in the study of urban sociology. If an individual is affected by the city, even if just slightly differently, then Calvino is right the city is as much perceived as conceived. This conception of the city allows for all actors and stakeholders to define the city beyond the economic means, which so often confines definitions of the city.

The economy is not the only means of examining the city (Weber 1921). Less concrete measurements can be argued as just as constructive, for example, the term community. The role of community and the meanings it imparts has created made the term contested in the literature and practice. Many sociological definitions of community - whether it be Tonnies', Weber's, or Durkheim's - center on a sense of connectedness. Patricia Hill Collin's states that traditional definitions frame community as apolitical and a natural concept; instead, she argues that communities emerge from spaces of political engagement that "catalyze dynamic social and political identities that actively engage contemporary realities" (2009). She also highlights the four dimensions of a more contemporary definition of community:

- community is about the interrelationships across power differences

- community is a functional principle of social organization,

- community is associated with symbolic boundary construction,

- community can serve as a means for aspirational political projects (Collins 2009). 
In urban policymaking, city leaders often use the word community interchangeably for 'the city.' One can argue that this is done to create a shared identity by those who call a city home. Not to be lost, and what Patricia Hill Collin's highlights, is that both the formation and maintenance of community at a city level would have to involve some degree of relationship building across power differences.

The concept of growth is central to the rings of the city thesis, even as the built environment changes because of cultural myths surrounding the equity of growth. As the city expands outward from some core, there remains an economic undercurrent to continue economic and physical growth causing adaptations in the built environment, which help with said growth. While the inner core of the city (the central business district) is the layer through which all of the outer rings of the city have traditionally extended from, suburbia and sprawl are shifting this discussion. Traditionally, as the city grows those on the periphery are pushed out to the next layer through succession (Burgess 1984). Each of these rings, or layer of the city, is context-specific for each city but universally share a variety of characteristics (Hanlon 2009). The process of succession stratifies the city by race, socio-economic status, and education (Adelman 2004; Domina 2006; Timberlake and Iceland 2007). While Burgess' concentric zones model may seem old-fashioned, Lang argues that it does inform the literature regarding the foundation for how historically cities have been imagined, in regards to land-use, form, and design (2002).

One area of literature, which pushes at the more traditional definitions of a city, is the research on edge cities. Garreau brought the concept of edge cities to the forefront in the mid-1990's (1994). Since then edge cities have referred to dense localities located on 
the periphery of major urban centers that differ in demographics than the nearby major city, examples include Long Beach, Oakland, Boca Raton and the Meadowlands (Garreau 1994). On the other hand, another form of the city is the edgeless city (Lang 2002). Edgeless cities are not dense, sprawling localities. Lang (2002) defines edgeless cities as "cities in function, in that they contain office employment, but not in form, because they are scattered." While Lang does not describe edgeless cities as new, (he cites evidence they have existed for a long period), his and Garreau's research reimagine the city, by helping the literature to question centrist and traditional definitions of what constitutes a city.

The definitions around edgeless cities, edge cities, and the concept of succession conform much more to a global westernized idea. Even within the westernized world, there exists no uniform law for what constitutes a city, and the definition of a city is regularly debated (centrist vs. de-centrist perspective on the New Metropolis). The debate shows that every city has unique variations in sprawl, suburbanization, culture, and community. The only thing universal is that the institutions that comprise the city are interconnected.

Building off the rings of the city literature, in which the city is some form of interconnected rings, the literature uses measurements that move away from density and instead focus on defining the city based on policy and economics. Due to the growth of the American suburbs, facilitated by the construction of the interstate highway system and public transit, the city is less dependent on density. The U.S Office of Management and Budget accounts for this in their definition of metropolitan and micropolitan statistical areas by measuring the city's parameters through the social and economic 
integration of the outer rings with the urban core (2013). Measuring "the city" using this methodology is not perfect, it is an economic centric measure for defining the city, but the definition does allow seeing the city as multijurisdictional regions.

Over the past twenty years, cities cores have begun to recognize the ties between the economic success of urban spaces to their suburbs and surrounding localities (Savitch et al. 1993). One strategy cities have used to address this is the consolidation of city and county government. A comprehensive merger allows cities regions to address urban sprawl, intraregional economic development competition, and concentrated poverty (Dreie, Mollenkorf, and Swanstrom 2001; Basolo 2003). This area of literature sees regionalism as an organizational structure for local governance and policy setting.

The benefit of defining the city as a metropolitan region is that it allows for the addition of local elites from the outer rings, beyond the urban core. Defining the city in this way allows a city to change over time. Envision the city as a living, breathing, evolving thing as it grows. Personifying a city as adapting and evolving makes the reality of a city being just one node in a network of localities even more complex.

\section{Global cities}

While trade and migration have, connected cities for thousands of years, never have cities been as interconnected as they are today. Modern globalization is changing how we view every aspect of the social and economic world. This shift in viewpoint requires the recognition that globalization is urbanization and urbanization constitute globalization (Spencer 2015). Cities are becoming the focus of the globalized structure rather than the nation-states that these cities call home (Sassen 1994). By seeing cities as networked, especially when one considers the previous discussion regarding cities being 
growth machines, one can begin to conceptualize the power that cities have as entities themselves and how cities compete as nodes in a network who are fighting to grow. At a more micro level, within each node/city, there is another network of mutually reinforcing institutions helping to make the collective unit of the city more central to the larger global network (Molotch 1993; Neal 2013). Collectively, the global network of cities is highly complex. The take away is that globalization of the twenty-first century is helping to shift how we discuss and view the city. Within this paradigm, there is a perceived hierarchy of the nodes of the network (cities), a hierarchy discussed in the academic literature using the language of global cities.

The literature surrounding global cities discusses a means of categorizing cities within this larger network. There is not a universal definition of what constitutes a global city; there are characteristics that help to constitute what is meant by the term. Therefore global cities are often referred to as existing on a continuum (Abrahamson 2004). The apex of global cities are localities, which are central nodes in the global economy, and because of their centrality, they also have a high notoriety around the world (Abrahamson 2004). A problem with global cities is that apex cities come from what World System Theory refers to as core nations. By grounding the definition of global cities in core nations, results in a definition of global cities, which influences the ability of cities to defined as central to the global city network. By gaining such power, a city increases their tangible and perceived importance in the global market. Due to the desire to be a global city, cities begin to mimic one another (Sassen 2005); this creates an environment that defines normative competitive behavior for cities using western ideals. Such a 
western-centric conceptualization of the hierarchical arrangement of cities is contested (Robinson 2006).

\section{Competitiveness}

Recognizing that a city's competitiveness centers on their adaption to modern western ideals is important for framing the discussion on how cities work to compete. Spatial competitiveness is the ability of an urban economy to both attract and maintain firms, causing stable or rising market shares, while maintaining or increasing the standards of living for those within the locale (Stroper 1997). Problems exist in using 'competitive' language when discussing cities. Unlike businesses, a city does not just go out of business (Krugman 1996). Cities adapt and learn like organizations out of a similar fear that an inability to compete will lead to extinction, but cities are centers of economic activity. They are not analogous to firms in how they compete. Instead, cities and their level of relative competitiveness require a separate language for measuring and discussing the language of competition.

Greene, Tracy, and Cowling (2007) created a simple model for understanding regional competitiveness (Figure 2.1). Although they admit, more sophisticated and extensive models do exist their model does help to summarize the three keys for regional competitiveness: inputs, outputs, and outcomes. The problem, they argue, with studies which look more or less at varying forms of competitiveness, is that the literature has failed to account for the connectedness of varying inputs and outputs. Their research also recognizes the gaps in the competitiveness literature regarding how places are working to be and remain competitive. They conclude that the current literature, surrounding competitiveness and the development of quantifiable metrics, is flawed by failing to 
account for the vast complexity of competition (Greene, Tracey and Cowling 2007, p. 16).

Figure 2.1:

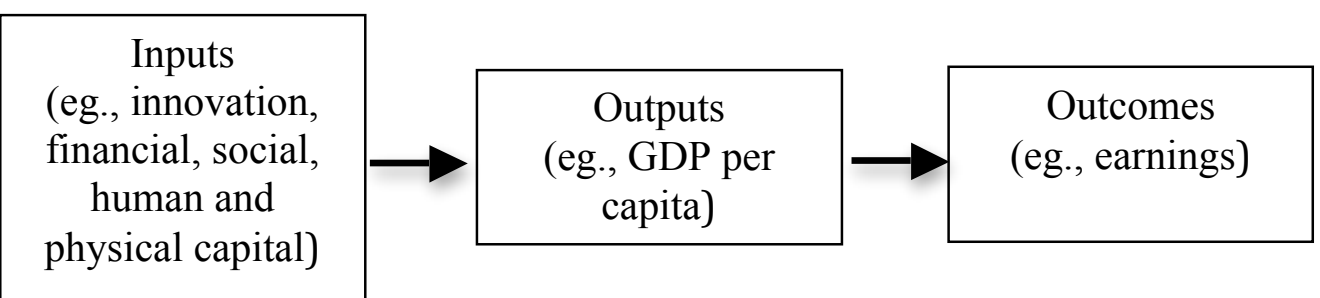

(Greene, Tracey and Cowling 2007)

One result of cities' competitive drive, is the desire to mimic traits of other cities perceived as competitive (the implications of this was discussed above). To mimic policymakers and research compare cities both domestically and internationally to understand the traits of a competitive city. One reason cities prioritize human capital is because the literature suggests that cities who can increase their human capital also experience a rise in employment and other economic growth indicators (outputs in the competitive model above Figure 2.1) (Simon 1998; Barro 2001; Tsai, Hung and Harriot 2010). Where the literature falls short, is in understanding how competition between cities impacts both the structural and relational embeddedness of organizations, individuals, and groups within a city that works to strengthen an input for regional competitiveness. Broadly, what cities do, like firms, is a search for best practices and then attempt to mimic these practices to maximize their inputs. One means of mimicry, and measuring performance is through the process of benchmarking.

\section{Benchmarking}

Competition between cities creates a need to be able to measure and compare cities both domestically and across the globe. Due to the vast number of differences 
between cities, especially when comparing cities across the globe, measuring and strategizing for growth and development is increasingly difficult. What is true universally is the method of benchmarking for monitoring economic development, understanding knowledge and practices of a locale and for promoting the attractiveness of a city/region (Huggins 2009). Benchmarking does not occur in one manner or by city/regional policymakers alone. Rather there exist three types of benchmarking and three types of bench-markers (Table 2.1). The table highlights the nine different ways that the process of benchmarking can take place (Huggins 2009).

Table 2.1:

Summary of Types of Regional (City) Benchmarking and Regional (City Benchmarks)

Types of Regional Benchmarking

\begin{tabular}{|c|c|c|c|c|}
\hline & \multicolumn{3}{|c|}{ Iypes of Regıonal Benchmarkıng } \\
\hline & & Independent benchmaking & Single Region Benchmarking & Multi-region Benchmarking \\
\hline \multirow{3}{*}{$\begin{array}{c}\text { Types of } \\
\text { Regional } \\
\text { Benchmarking }\end{array}$} & $\begin{array}{l}\text { Performance } \\
\text { Benchmarking }\end{array}$ & $\begin{array}{l}\text { Metrics-based comparison } \\
\text { of charactersitcs } \\
\text { undertaken by regionally } \\
\text { external organization }\end{array}$ & $\begin{array}{l}\text { Metrics-based comparison of } \\
\text { characteristics undertaken by } \\
\text { authorities/stakeholders } \\
\text { representing one region }\end{array}$ & $\begin{array}{l}\text { Metrics-based comparison of } \\
\text { characteristics undertaken by } \\
\text { authorities/stakeholders } \\
\text { representing more than one } \\
\text { region }\end{array}$ \\
\hline & $\begin{array}{c}\text { Process } \\
\text { Benchmarking }\end{array}$ & $\begin{array}{l}\text { Structures and systems } \\
\text { comparison of practices } \\
\text { undertaken by regionally } \\
\text { external organizations }\end{array}$ & $\begin{array}{l}\text { Structures and systems } \\
\text { comparison of practices } \\
\text { undertaken by } \\
\text { authorities/stakeholders } \\
\text { representing one region }\end{array}$ & $\begin{array}{l}\text { Structures and systems } \\
\text { comparison of practices } \\
\text { undertaken by } \\
\text { authorities/stakeholders } \\
\text { representing more than one } \\
\text { region }\end{array}$ \\
\hline & $\begin{array}{c}\text { Policy } \\
\text { Benchmarking }\end{array}$ & $\begin{array}{l}\text { Comparion of the public } \\
\text { policies influencing } \\
\text { processes and performance } \\
\text { undertaken by regionally } \\
\text { external organization }\end{array}$ & $\begin{array}{l}\text { Comparion of the public policies } \\
\text { influencing processes and } \\
\text { performance undertaken by } \\
\text { authority/stakeholders } \\
\text { representing one region }\end{array}$ & $\begin{array}{l}\text { Comparion of the public } \\
\text { policies influencing processes } \\
\text { and performance undertaken } \\
\text { by authority/stakeholders } \\
\text { representing more than one } \\
\text { region }\end{array}$ \\
\hline
\end{tabular}

(Huggins 2009)

Table 2.1 illustrates the ways cities and independent groups benchmark. First, there is performance benchmarking. These often are more quantifiable regional benchmarking approaches, which allow cities to understand where they sit amongst their peers. A very common means of doing this by practitioners, policymakers, and researchers is through ranking cities on a variety of different economic and social 
measures. Critiques of work like Florida's, discussed above, are correct in that rankings often mask the complexity of the city. There exists the need to look beyond just quantifiable numbers to see processes and policy differences between the cities one may be attempting to emulate. Therefore, rankings are only one means for static benchmarking.

On the other hand, process and policy benchmarking allow the city to understand more qualitatively, what they are doing in comparison to the cities they see themselves like or desire to be in the global cities hierarchy. Central to understanding benchmarking is examining how cities address process and policy benchmarking when they wish to emphasize human capital in their growth and development planning. One method for incorporating human capital into this discussion is using a process benchmarking technique called the City Intellectual Capital Model (CGICM) (Viedma 2004). CGICM is a model that allows one to measure, compare, and manage the intangible assets that a city possesses (Figure 2.2). One of the central pillars of this model is human capital. Human capital refers to the knowledge, experience, intuition, and skills individuals have to complete tasks and goals of the city; it is the property of individuals, not the city (Martinez 2006). 
Figure 2.2:

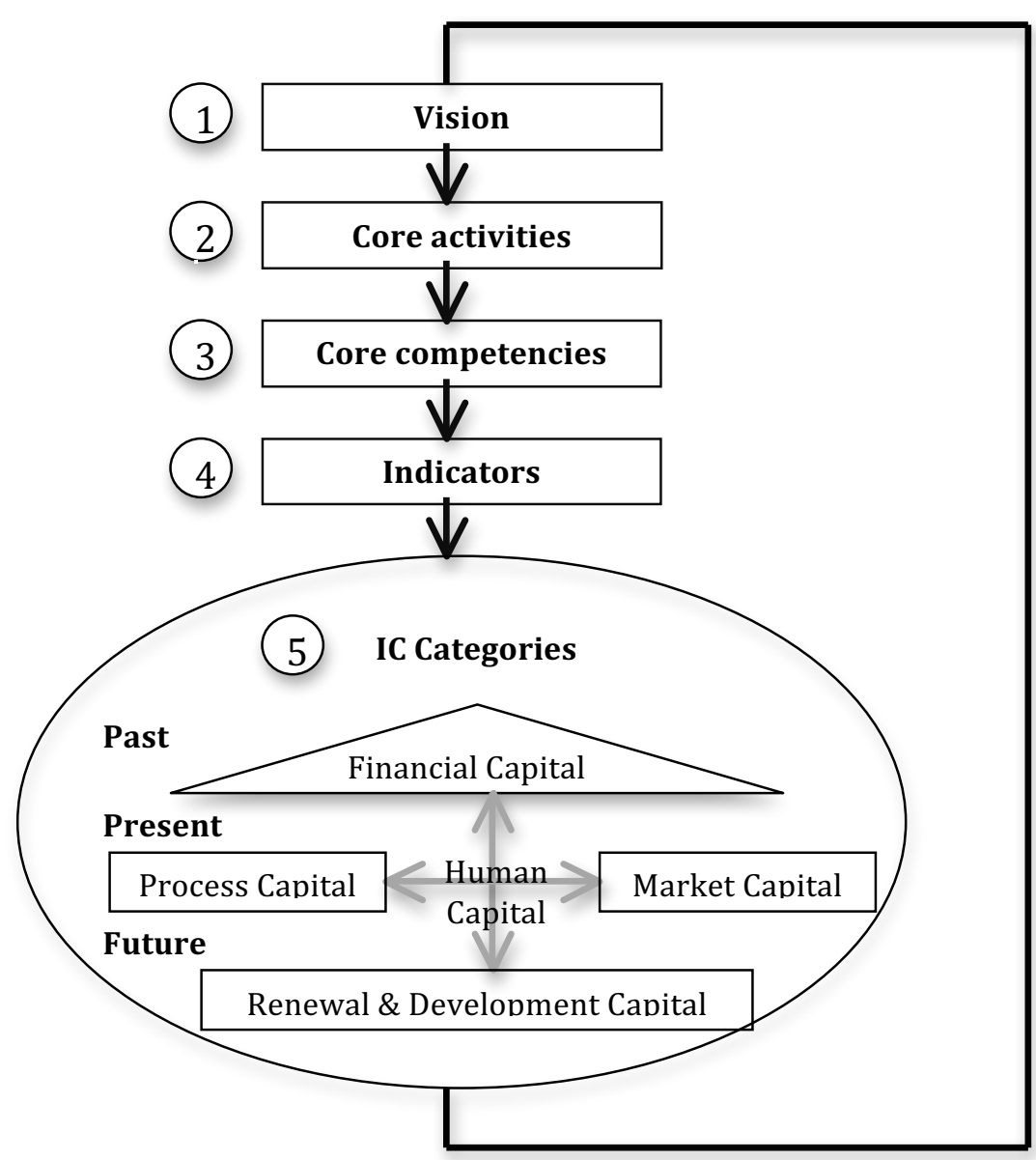

(Viedma 2004)

The CGICM shows the centrality that human capital plays in understanding differences between cities. This model allows cities to understand both the everyday processes that take place, both formally and informally, to increase regional capital. The CGICM allows cities to address policy and whether if larger scale policy shifts need to take place to shift processes and hopefully the performance benchmarking measures. Research tools like the CGICM see human capital as central to the benchmarking process where twenty-firstcentury cities are both looking to mimic cities which attract, retain, and develop their human capital but specifically cities who do this while growing economically. 


\section{Knowledge cities}

Through benchmarking, cities can place themselves on the spectrum of global cities; in turn, cities create visions/ goals to better mirror themselves with cities they see as equal while also comparing themselves to cities they aspire to be like (Sassen 2005). The focus on human capital is an ever-important economic development reality as cities transform from being centers of physical based production to places of knowledge creation and transfer (Carrillo 2004). This shift has placed a greater economic importance on higher education for economic viability; encouraging higher education to develop relationships with industry and business (Dale 2007). Human capital as a central economic component is not new or novel; it has been an essential element of growth for centuries (Becker 1975).

Human capital can be broken down further into the two roles it plays as a function of growth: a stock of skills (produced by education and training) and a stock of knowledge (a source of innovation) both of which are desirable assets for a city to possess. Endogenous growth literature then tells us that as knowledge accumulates, growth happens (Romer 1986; Romer 1990; Seiter 2003). It is the connection between knowledge and growth that makes both the accumulation of skills and the collection of knowledge, by a city, foundational pieces in the global neo-liberal economy (Glaesear, 1994; Olseen and Peters, 2007). Recognizing the ties between knowledge, growth, and economics the following paragraphs weave together the discussions of the "knowledge economy" and "knowledge development" to explore what knowledge is for cities and why these concepts are important if cities wish to be competitive in the global cities network. 
The concept of the knowledge economy places importance on companies' abilities to gather, create, and utilize knowledge. The process, which takes place within the knowledge economy, can be broken down into three steps: knowledge production, knowledge transmission, and knowledge transfer (Clarke 2001; OECD 2006). This process emphasizes education in the transmission stage. By extension, this recognition that education plays a role in the development and transmission of knowledge helps in solidifying the importance of ongoing transmission as key to the global knowledge economy. While the more formal institution of education is of primary focus, cities recognize that to sustain themselves, the city itself must not strengthen just the human capital of its citizens, but the city must be knowledgeable to grow.

Ergazakis et al. (2004) define knowledgeable cities as "a city that aims at knowledge-based development, by encouraging the continuous creation, sharing, evaluation, renewal, and update of knowledge." Case studies from around the world show the characteristics of the development of knowledge cities. To summarize this literature Ergazakis, Metaxiotis and Psarras $(2004 ; 2006)$ did a meta-analysis of several of these case studies to create a more comprehensive understanding of what it takes to develop a knowledge city. They found the following list to be the five key characteristics of a knowledge city (Ergazakis, Metaxiotis and Psarras 2004; Ergazakis, Metaxiotis and Psarras 2006):

Five Key Characteristics of the Development of a Knowledge City (in no order):

1. Political and societal will is indispensable

2. Strategic vision and development plan is crucial

3. Financial support and strong investments are necessary 
4. Setting up of agencies to promote the development of knowledge-based region

5. International, multi-ethnic character of the city is necessary.

Beyond these characteristics, Huggins and Izushi (2009) have also produced their model, which they have discussed alongside the WKCI, which is a global index that ranks cities based on a variety of knowledge city indicators, to show the process for how cities and regions produce and strengthen knowledge. Their model for knowledge-based production is shown in Figure 2.3.

The model consists of two sections. The first (the top of the figure) represents the production of goods and services. A standard set of production factors - physical capital, labor, and human capital — is combined with technology. The second section (the bottom half) represents the production of new knowledge, which in Huggins and Izushi (2009) say give rise to productivity growth. Their model shares characteristics with others aimed at connecting the environment of the city to the importance of knowledge for growth (Clarke 2001; OECD 2006). Where these models fail, is in showing how cities are working to increase knowledge for the sake of being spaces that are more competitive.

\section{Figure 2.3:}

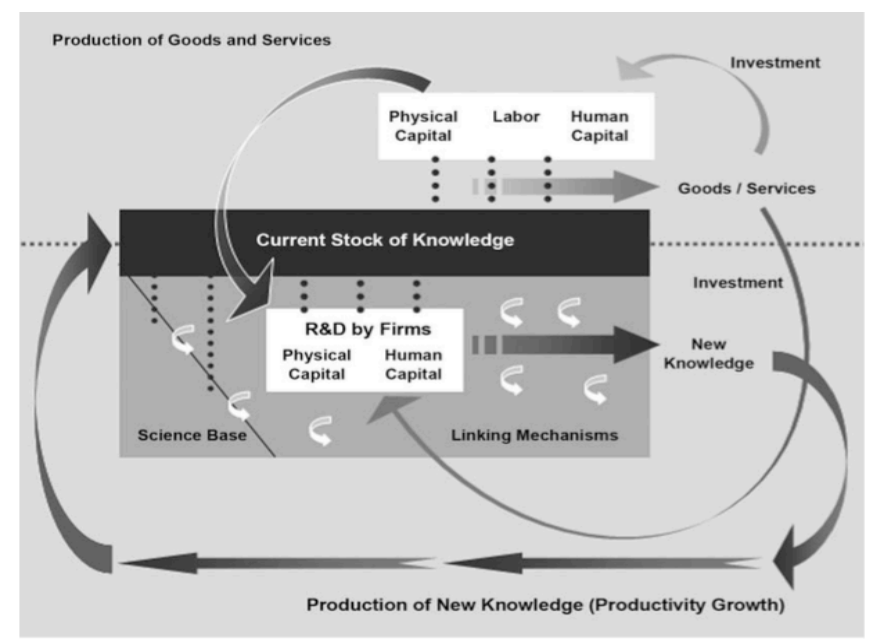

(Huggins and Izushi 2009) 
Cities focus on their pursuit of being knowledge hubs by attracting high knowledge individuals and growing knowledge from within. This drive for knowledge and talent (that collectively mean high human capital) creates a competitive atmosphere both within cities and between cities. As a result, cities develop processes and development strategies that see talent attraction as central to either creating or maintaining a competitive advantage amongst other cities.

There remains no one clear measure or method for attracting talent. There are hosts of different factors, which contribute to a city's ability to attract talented individuals (Florida 2005; Frenkel, Bendit and Kaplan 2013). What is conclusive about talent attraction is that if a city wishes to succeed at it, there exists a believed requirement that the built environment must reflect the demands of individuals who possess the knowledge, talent, and skills the city wishes to attract and retain. When a city changes the built environment for attraction, individuals already within the city are susceptible to displacement; this creates a metaphorical tug of war when cities work to raise human capital, in that cities must find ways to balance growth of the established citizenry and attraction of new talent.

Educational attainment is not the sole way of measuring human capital, but it is an important investment for cities wishing to raise their human capital (Becker 1993), because, from a pure cost-benefit perspective, higher educational attainment means a higher average wage for the individual (Baum, Ma and Payea 2010). Firms are willing to pay more for higher educated workers because as knowledge is acquired, individuals become better workers, meaning higher output (Carlino 1995). By extension, for cities, this means higher tax revenues. Increased productivity is one economic measure 
positively connected to high concentrations of human capital (Rauch, 1993). Beyond tangible economic benefits, there are additional knowledge spillover effects (Audretsch and Lehmann 2005; Florida 2005; Trippl and Maier 2010). The literature lacks evidence to suggest that spillover effects produce permanent long-term economic growth (Carlino 1995). Therefore, while higher education is an individual good, because it grants autonomy and power to people, higher education attainment has positive communal benefits. It is the dual function of higher education that provides the foundation for scholars from a variety of disciplines to argue that human capital investment and the call for growing educational attainment is more than an individual benefit but is a form of economic development for cities (Wagner, Joder and Mumphrey 2003).

For the past one-hundred and forty years, U.S. cities with higher human capital have experienced higher growth rates (Glaeser, Scheinkman and Shleifer 1995; Simon 1998; Simon and Nardinelli 2002). There are those that argue that cities can do no better than to focus on their region's education level- its stock of human capital (Gotlieb and Fogarty 2003). The evidence is truly unclear on whether high attainment is the trait causing higher growth rates. Additional literature also shows that the human capital of a city correlates with current economic health but not the strongest predictor of economic growth (Rausch and Negrey 2006). What is important for this research is not the degree that human capital impacts growth, but the perception by growth machines that human capital (both knowledge and skills) accumulation results growth.

The urban literature tells us in the knowledge-based, globally connected economy that cities are becoming competitive with one another like never before. Cities work 
regularly to create visions, goals, and master plans, which aim to centralize the energy of the locale around some aspirational dream. However, what the CGICM shows us is that human capital is at the center of these endeavors. While human capital can be measured using employment statistics and economic activity, we also know one of the biggest indicators of employment in the U.S. is educational attainment. The tie between employment and attainment is a result of the increased skill requirements of industry which see post-secondary attainment as a measure of both skill and knowledge. Skill requirements are referred to as talent, and educational attainment is a screener of that talent skill base. As society continues to push educational attainment as a means for screening laborers, more and more cities are competing for these "talented" individuals. One can then see how a city's educational attainment ties to economic health.

With all of this in mind, it is not difficult to see how the competition between cities to knowledge and skill bases, may be speaking with and interacting with the ongoing higher education debate in the United States- even if indirectly. Therefore, before elaborating on how this research will examine the connection between global cities and higher education, a connection must be made between the city as a driver of labor and formal education as a sorting mechanism of said labor. To establish the connection between those two points the following section focuses on higher education and workforce literature with a focus on the intended function of higher education in the United States. Also, the following sections also highlight the growth of higher education. Higher Education in the United States of America

Education has long served as a form of mobility and as a central pillar of the American dream (Putnam 2015). The belief has been and still exists that a higher 
education credential bestows - almost automatically - various social and economic benefits upon individuals. While the return on investment for the average college degree remains, high, there is growing discussion surrounding whether all higher education degrees are equal especially due to the rise of for-profit colleges and universities and the de-bundling of degrees (Craig 2015). While the college degree for all model and the belief that everyone needs formalized credentials makes sense regarding presorting the labor market, it creates an unsustainable model for K-16 education in the United States due to credential inflation. The current system of education relies on a portion of the population failing, thereby supporting the very stratified system education is supposed to break apart (Labaree 2010). To examine the stratified system, along with the role the growth machine may or may not be playing, we must examine the literature on the current state of higher education in the United States.

\section{Higher education and workforce policy in the united states}

The history of higher education in the United States is older than the country itself; examining such a broad period of time the history of higher education is broken into ten generations (Geiger 2011). Each of these eras of history speaks to shifts in the spirit and function of higher education for the country. Early higher education was concentrated in only a few institutions. Private education and, more specifically, denominational education was king. It took the passing of the Morrill Act of 1862 and 1890 , and the land grants received by states. As a result, to spur a new age of growth in addition to the concept of the 'American university.' The Morrill Acts was a turning point in policy where higher education moved to meet the demands of the community. By 1908 , there was a defined standard for universities. It was at this time that the collegiate 
ideal emerged, denominational doctrines were deemphasized, and a growing emphasis on the social skills brought on by extracurricular activities emerged (Geiger 2011). As higher education grew, differentiation and hierarchy began to define the system which resulted in both an elite arm and mass education arm of higher education. At the end of the Second World War, while higher education existed for racial minorities and women, the hierarchy of institutions still placed white, male institutions on top. The G.I. Bill of 1944 spurred further growth in education, sending over 2.2 million soldiers to colleges and universities after returning from war (Olson 1973; Thelin 2011). Within higher education, the increases in attendance by returning soldiers resulted in the doubling of enrollments in many colleges and universities from 1943 to 1946 (Thelin 2011).

In the 1950's, as the space age gained momentum, the federal government stepped up and began to focus on both the function and goals for the future of American higher education. Many of the articulated goals by both the federal government and the National Education Association (NEA) focused on access while also stating that the focus of higher education should be on individual advancement and public interest (United States Government 1947; National Education Association 1957). While a lot has changed since these reports -especially regarding those allowed in higher education and the make-up of higher ed. - the individual and societal benefits have become defining functions of the higher education system.

The individual and collective functions of higher education create an area of inquiry regarding both how and for whom the educational system works. Due to those questions, much of the higher education literature focuses on the inequities addressed by higher education as well as how higher education remains unavailable to many despite 
countless numbers of reforms throughout the education policy timeline. One of the core historical points is that education in the United States, specifically the delivery of education, has and remains a local responsibility. While the federal government's role has shifted throughout time, especially with the creation of the Department of Education in the 1980's, a large amount of autonomy remains with states and individual institutions regarding the creation and governance of higher education. This system of state power differs greatly from many other nations (Bok 2013). The various types of higher education providers add a layer of complexity; community colleges, research universities, for-profit universities all play different roles in the institution of American higher education. With this in mind, the way we conceptualize and experience higher education is a product of individual states rather than federal governance.

With each state has their unique funding models and visions, there exist a diverse number of philosophies regarding higher education. What overarches and connects the states to one another, are philanthropic foundations, political parties, and the federal government. Philanthropic foundations use the power of the purse to pursue a national agenda regarding the operation of higher education (Barnhardt 2017). They fund initiatives both inside higher education and outside that impact the ongoing direction of higher education in the United States. From a governmental perspective, both of the main political parties have macro-level platforms regarding education that guide education policy at every level (Payne 2013). It is here, where political and the funding elites of the local growth machine could push and pull higher education policy to serve the desired function that they wish to espouse. 
Defining the function/role of higher education is increasingly complex, as an increasing number of institutions, such as the non-profit sector, politics, and the economy become more involved (Bowles and Gintis 2011). As a result, while local governments have varying levels of control over K-12 education (based on whether education sits formally inside or outside of the control of city government) what is uniform across the United States is that city governments have little authority in education policy for higher education. Despite not being formally "in-charge," cities do play a role on the demand side of the equation. The understudied demand relationship by cities is beyond the effects human capital has on economic growth. Since the 2008 recession, 8.4 million jobs have been created for those with a four-year college degree, while jobs requiring high school degree only grew by 80,000 (Carnevale, Jayasundera and Gulish 2016). These shifts in job requirements show growth on the demand side of the labor market for high human capital.

As the economy has shifted so too has the language around societies various institutions including education. Carl D. Perkins Career and Technical Education Act of 2006 replaced the phrase "vocational education" with "career and technical education" (United States Department of Education 2007). While this may seem like a simple terminology change, the phrase "career and technical education" signifies the changing demands of the economy, and how those demands are reshaping higher education policy. Additionally, each reauthorization of the Elementary and Secondary Education Act since 1965 (No Child Left Behind of 2001, and Every Student Succeeds Act of 2015 were both reauthorizations of this legislation) have further emphasized the need for all students to 
gain college and career ready skills. It is those very skills, especially the language surrounding career readiness that has formally aligned education to industry demands.

In 2014, President Obama signed a bi-partisan piece of legislation known as "The Workforce Innovation and Opportunity Act" (WIOA), which replaced the Workforce Investment Act (WIA). This act marked the first time in fifteen years where the federal legislature sought to reform the public workforce system (Employment and Training Administration 2014a). WIOA brought together in partnership the U.S. Departments of Education, Health and Human Services, and Labor, along with several other federal government entities. The purpose of the legislation was to align the work taking place across the federal government directed at helping individuals obtain jobs and "a pathway to the middle class" (Employment and Training Administration 2014a). Highlights of the legislation include aligning federal investments to support job seekers and employers, strengthening the governing bodies that establish state, regional and local workforce investment priorities, and helping employers find workers with necessary skills (Employment and Training Administration 2014a). The language used by WIOA highlights the handing of power from the federal government to regions and cities. By streamlining support from the federal government:

WIOA empowers State and Local elected officials and private sector-led workforce boards with the responsibility of developing a strategic, integrated plan that supports economic growth and labor force needs intended to grow the capacity and performance of the workforce system. (Employment and Training Administration 2014b)

Workforce development boards under WIOA empower American cities by giving control into the hands of localities and states. WIOA brings together education and economic development. The legislation requires workforce boards to contract out, and 
oversee regional career centers while also requiring boards to be engaged with industry. WIOA furthers the call for expanding the country's pool of high-educated citizens by focusing on skills training and non-traditional students throughout the educational pipeline. A takeaway regarding WIOA is that the legislation empowers cities to connect industry to those seeking employment. Here is where we see cities taking in one hand the supply side of the labor market and the demand side (businesses) and working to ensure they align for the success of the individual citizens, business, and importantly the communities they serve. One part of this alignment, especially in the 21 st century economy, is the desire by cities to create a large percentage pool of highly educated individuals in hopes of being an economically competitive high skilled, knowledge city.

WIOA, No Child Left Behind, and Race to the Top have all impacted state and local policy. Each of these federal policies placed additional responsibilities on localities. Pauline Lipman argues that federal education policy is a story of nurturing an atmosphere of small federal government, where competition at the state and local level will spur educational reform (2011). She further argues that policy has been formally used to adapt education in the United States to conform to neo-liberal urbanism. While not to imply causality, the shifts recent federal education policy and the growing centrality of cities have taken place as higher education has boomed in the United States.

\section{Rise in higher education}

As of 2016, college graduates make up a larger share of the workforce than those with a high school degree for the first time in American history (Carnevale, Jayasundera and Gulish 2016). One reason is the steady boom in those enrolling in higher education. Between 1992 and 2002 enrollment at degree-granting institutions rose 15 percent and 
from 2002 to 2012 enrollment rose 24 percent (United States Department of Education 2015). Over the past forty years, there has been a steady rise in the number of individuals who are obtaining a post-secondary degree in the United States. Women outpace men in enrollment, completion and recently in the share of the overall population with a bachelor's degree (Sax 2008); additional evidence suggests that gaps between racial/ethnic groups are closing (Kalmijn and Kraaykamp 1996; Everett, Rogers, Hummer and Krueger 2011). Table 2.2 shows the educational attainment of the U.S. population over the age of twenty-five for the study's base year of 2015. Increases in enrollment and completion across the board, over the last several decades, signals buy-in by individuals that higher education is not just a mobility pathway but also a labor market requirement.

Table 2.2:

\begin{tabular}{|c|c|c|c|c|c|c|}
\hline \multicolumn{7}{|c|}{$\begin{array}{l}\text { Educational Attainment of the Population Aged } 25 \text { and Older by Age, Sex, Race and Hispanic Origin, and Other } \\
\text { Selected Characteristics (numbers in thousands) for } 2015\end{array}$} \\
\hline Characteristic & Total & \begin{tabular}{|l|} 
High School \\
graduate or \\
more \\
(Percent) \\
\end{tabular} & \begin{tabular}{|l|} 
Some college \\
of more \\
(Percent)
\end{tabular} & $\begin{array}{l}\text { Associate's } \\
\text { degree or } \\
\text { more } \\
\text { (Percent) }\end{array}$ & $\begin{array}{l}\text { Bachelor's } \\
\text { degree or } \\
\text { more } \\
\text { (Percent) }\end{array}$ & $\begin{array}{l}\text { Advanced } \\
\text { degree } \\
\text { (Percent) }\end{array}$ \\
\hline Population 25 and Older & 212,132 & $88.40 \%$ & $58.90 \%$ & $42.30 \%$ & $32.50 \%$ & $12.00 \%$ \\
\hline \multicolumn{7}{|l|}{ Age } \\
\hline 25 to 34 & 43,006 & $90.50 \%$ & $65.00 \%$ & $46.50 \%$ & $36.10 \%$ & $10.90 \%$ \\
\hline 35 to 44 & 39,919 & $88.70 \%$ & $62.80 \%$ & $46.70 \%$ & $36.30 \%$ & $13.80 \%$ \\
\hline 45 to 64 & 83,213 & $89.40^{\circ} \%$ & $59.00^{\circ} \%$ & $42.60 \%$ & $32.00 \%$ & $12.10^{\circ}$ \\
\hline 65 and older & 45,994 & $84.30 \%$ & $49.70 \%$ & $34.10 \%$ & $26.70 \%$ & $11.30 \%$ \\
\hline \multicolumn{7}{|l|}{ Sex } \\
\hline Male & 101,888 & $88.00^{\circ} \%$ & $57.60 \%$ & $41.20^{\circ} \%$ & $32.30 \%$ & $12.00 \%$ \\
\hline Female & 110,245 & $88.80 \%$ & $60.10 \%$ & $43.40^{\circ} \%$ & $32.70 \%$ & $12.00^{\circ}$ \\
\hline \multicolumn{7}{|l|}{ Race and Hispanic Origin } \\
\hline White Alone & 168,420 & $88.80 \%$ & $59.20 \%$ & $42.80 \%$ & $32.80 \%$ & $12.10 \%$ \\
\hline Non-Hispanic White alone & 140,638 & $93.30 \%$ & $63.80 \%$ & $46.90^{\circ} \%$ & $36.20 \%$ & $13.50 \%$ \\
\hline Black Alone & 25,420 & $87.00 \%$ & $52.90 \%$ & $32.40 \%$ & $22.50 \%$ & $8.20 \%$ \\
\hline Asian Alone & 12,331 & $89.10 \%$ & $70.00 \%$ & $60.40 \%$ & $53.90 \%$ & $21.40^{\circ} \%$ \\
\hline Hispanic (any race) & 31,020 & $66.70 \%$ & $36.80 \%$ & $22.70 \%$ & $15.50 \%$ & $4.70 \%$ \\
\hline \multicolumn{7}{|l|}{ Nativity Status } \\
\hline Native Born & 175,519 & $91.80 \%$ & $61.30 \%$ & $43.30 \%$ & $32.70 \%$ & $11.90^{\circ}$ \\
\hline Foreign Born & 36,613 & $72.00 \%$ & $47.60 \%$ & $37.60 \%$ & $31.40 \%$ & $12.50^{\circ}$ \\
\hline \multicolumn{7}{|l|}{ Disability Status } \\
\hline With a disability & 28,052 & $78.60 \%$ & $41.60 \%$ & $24.90 \%$ & $16.70 \%$ & $5.70 \%$ \\
\hline Without a disability & 183,351 & $89.90^{\circ} \%$ & $61.50 \%$ & $45.00 \%$ & $34.90 \%$ & $12.90^{\circ}$ \\
\hline
\end{tabular}

(Ryan and Bauman 2016) 
The shifts in higher education and education more broadly, cause domino effects in other social institutions. For example, there are more households and marriages where both partners hold a college degree (McClendon, Kuo and Raley 2014). This new norm has many social and economic benefits for the family unit, as well as larger society, with one of the most prevalent being the earnings potential higher education attainment creates. The evidence is clear, those who hold a higher education credential earn more throughout their lifetime (on average) than those who do not, a statistic even more significant for women (Marcotte 2010). In 2015, the Bureau of Labor Statistic released Graph 2.1. The graph shows how at a national level, higher attainment means both higher average earnings and the less likelihood of being unemployed.

\section{Graph 2.1:}

\section{Earnings and Unemployment Rates by Educational Attainment for 2015*}

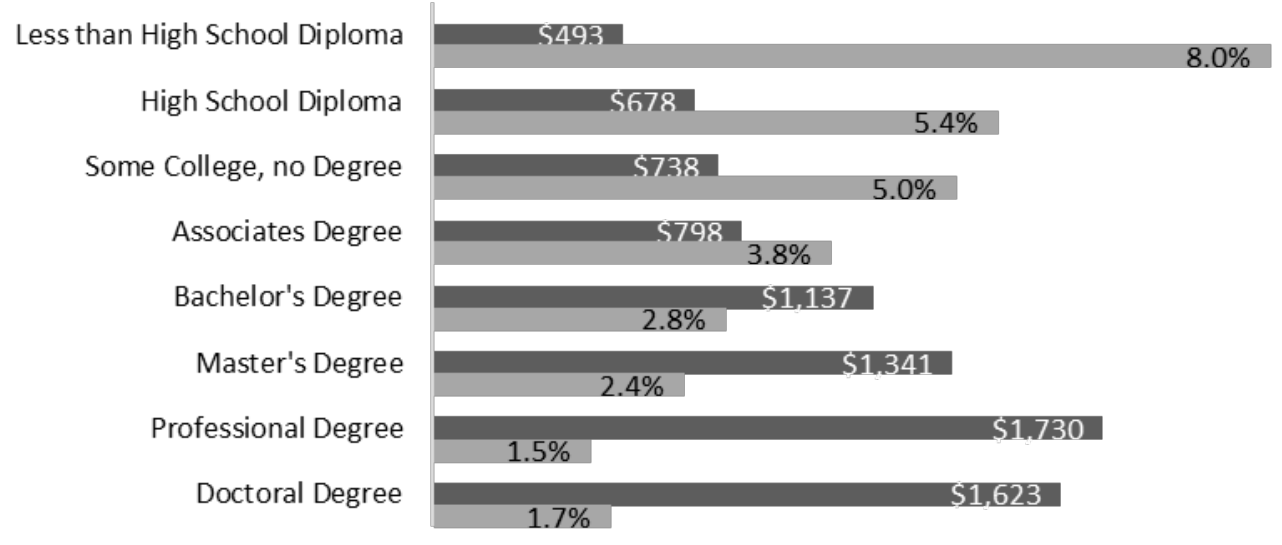

*Earnings represents median usual weekly earnings. All data is for those 25 years of age and over. (United States Bureau of Labor Statistics 2016)

Admittedly, graphs such as this mask the economic and labor realities faced by workers. For example, while there is an increasing demand for high attainment individuals and an increasing number of people obtaining a higher education credential, 
workers still experience underemployment (Livingstone 1999; Jensen and Tim 2003). People are underemployed if they meet one of the following criteria: involuntary parttime work, involuntary temporary work, over-qualification, and underpayment (Maynard and Feldman 2011; Glyde 2016). While over the past century more jobs have required higher education credentials (Livingstone 2009a), there is a growing number of higher educated individuals who are underemployed (Livingstone 1999). Supporting the reality, that while higher education provides an individual with the knowledge and skills that make them more employable, a credential vs. jobs gap exists (Livingstone 2009b). The credential vs. jobs gap presents a question of access, and return to a post-secondary degree, along with whether education itself is perpetuating a stratified society.

\section{Education as a form of individual and structural reproduction}

Over the past century, the United States has seen a spatial shift in educational attainment. During the last half of the twentieth century, the most educated portions of the populous have moved out of the central cities and into the suburbs, the outer rings of the city (Saatcioglu and Rury 2012). The spatial shift has become especially true for families with school-age children, which are less likely to live in many large central cities within the U.S. (Sander and Testa 2015). A cumulative result of these spatial shifts is the existence of segregation within cities and their suburbs based on educational attainment (Domina 2006). As a result of this segregation, one can see how education affects the city, and the city affects education through the demand for a higher educated labor pool. To be a part of the highly educated labor pool one must be able to access it.

Much of the above discussion surrounding the demand for higher education credentials assumes that higher education, and access to it, is fairly consistent and 
equitable across the United States population. A reality we know not to be true. The American Dream sits upon the foundation of economic mobility, with education historically being one of the main mobility pathways (Goldin and Katz 2008; Putnam 2015). The growth in enrollment amongst minority groups does not show this. The reality exists that obtaining a higher education degree (whether it is a certificate, associates, bachelors or graduate degree) is not an equal process; first-generation college students and minorities experience unique challenges in climbing up the educational ladder (Reid and Moore 2008). Even if a person is to gain access to higher education system one will enter a stratified environment. Degree-granting institutions in the United States have varying levels of stigma, most often created by university ranking processes. A result is that a bachelor's degree does not always equal a bachelor's degree, effectively creating a hierarchy across higher education institutions. This stratified system is further complicated when realizing how higher education stratifies students within the same schools.

Evidence suggests that once students arrive at college, they segregate by experiences and background further reproducing sections of the populous (Armstrong and Hamilton 2013). The literature often addresses solutions to this inequity by focusing on school reform. While correct, this strategy may not be addressing broader policy problems (Ladd 2012). Specifically, how higher education in the United States often codifies and reinforces inequality. Even if an individual can access higher education, research shows unequal financial returns for a college degree but that on average higher education as a net positive investment (Strohush and Wanner 2015). Additional evidence 
suggests that for some students, they are worse off by going to college (Sawhill and Owen 2013).

Going forward, as the supply of laborers with higher education credentials increases, the value of such a credential will go down. Educational inflation or credential inflation refers to the relationship between increased attainment, and the devaluation of degrees. Compounding this is the gradation of value earned from receiving a college degree, not all degrees are equal. Researchers must account the long-term effects of credential inflation in the college for all era; also, how credential inflation affects the individual and larger society.

\section{Summary of Literature}

The literature, specifically the research on global cities, points to a connected world through which neoliberal economic principles have created an environment of competition between cities. By recognizing the connection between educational attainment/human capital and the built environment of the city, the literature brings these two areas of research together. This research builds upon the foundation of competition, human capital, and that the city as playing a more central role in the twenty-first-century economy.

Being a knowledge city is important due to research that shows that the investment in the educational pipeline by cities, regions, and states has long-term positive economic development impacts (Bartik 2011). What findings such as those by Bartik supply the literature is the ability to further substantiate the ties between the urban and higher education (Gottlieb and Fogarty 2003). The ties between the urban and education are global in scale (Barro 2001; Tsai, Hung and Harriott 2010). What is lacking is how 
and to what degree cities influence the demand side of higher education in the United States even though they have no formal oversight of the higher education process. This dissertation will help bridge gaps in the literature by examining how cities are working to become centers for knowledge to compete in domestic and global economies.

Before going into the proposed methodology of this research project (now that the literature has been discussed), I want to address the central research questions again.

1. How are U.S. cities working to increase higher education attainment as a form of human capital?

1a. Why are cities working both formally and informally to increase educational attainment?

1b. What connection do U.S. cities see between educational attainment and growth? 


\section{CHAPTER III: METHODS}

The research for this dissertation examined three U.S. cities and used a comparative approach for understanding both the similarities and differences among the sample of cities. Due to lack of empirical research on how cities work to advance educational attainment, this study leans on the larger urban and human capital literature for methods of examining multiple cities. A central pillar of this research is growth; one must ensure the methodological process account for questions and methods that draw on this very theme. Much of the methodological framework comes from a model found in Benner and Pastor's book Just Growth; their model used a two-part comparative analysis (2012). The author derived their sample of three cities from a preexisting collection of cities known as the Talent Dividend Network because of how the program tied together education and competition.

\section{The Talent Dividend Network}

In 2011, CEO's for Cities, the Kresge Foundation, and the Lumina Foundation for Education created a joint competition in which one of 57 participating cities won a $\$ 1$ million prize (TDN 2010; Living Cities 2014). The winning city had to show the greatest increase in the number of people awarded a post-secondary degree (per one thousand population) over a four-year academic period. The collection of participating cities was known as the Talent Dividend Network (TDN). Upon completion of the four-year period at the end of the 2012-2013 academic year, the official winner was Akron, Ohio; the city 
raised the number of individuals awarded a college degree by $20.2 \%$ during the four-year time. The final rankings of this competition are listed in Appendix II.

The competition's theory of change is rooted in the importance of high educational attainment for citywide growth. In the competition's final report, the TDN explicitly states this program theory as the reason for having such a competition. Additionally, TDN hoped that the work done during the time of the competition would continue (Living Cities 2014). It is the TDN's desire for the initiatives to sustain that has created a lasting impact of the competition; because many of the programs and initiatives started by cities are still in existence and are used to help the cities increase attainment. Recognizing that the 57 TDN cities have a desire to grow their human capital makes this sample of cities even more interesting for discussing the competitive U.S. labor market. The program theory of growth aligns with previously discussed growth theory. Furthermore, the emphasis on the connection between high human capital and growth makes this sample of cities a sound population for examining both how and why cities emphasize higher educational attainment. Non-competitive networks also exist, such as "The Graduate! Network" which is a collection of cities working to raise the percentage of adults completing college (Graduate Network 2015). This study chose the TDN because, while shorter term, the competition was broader in its vision for higher educational attainment.

\section{The Big Picture}

The first step was to design a process that took the overall base sample and lowers it down to an observable size. Every city in the TDN was examined at the metropolitan statistical area (MSA) level (except for the Sarasota MSA, which was excluded from the 
sample due to the lack of availability of data, and Honolulu for which data was collected at the county level). Two additional cities were added, San Francisco and New York City, as reference cities due to often being perceived and referenced as cities with high human capital which makes the overall sample a collection of 58 cities.

Data were collected at the MSA level based on the urban literature, which pushes researchers and practitioners to conceptualize the city beyond an urban core and see the city regionally. During the TDN competition, a majority of cities were measured and awarded based on their core-statistical areas; as a result, this research expands the geographic spaces from the original TDN geographies. MSAs are defined by the United States Office of Management and Budget and are calculated by the connectivity of the labor market to the principal city (United States Office of Management and Budget 2013). All thirteen-principle federal statistical agencies gather data at the MSA level providing both a breadth and depth of data.

Demographical data were populated for all 58 cities using the American Community Survey five-year estimates (United States Census 2016a). This data includes median household income, poverty percentages, percentage foreign-born, occupation, and educational attainment statistics. Historical data were used, regarding educational attainment, to act as a reference for longitudinal performance (Minnesota Population Center 2016). Economic data was collected from the U.S Department of Commerce to measure MSA exports and per capita real GDP from the U.S. Bureau of Economic Analysis. The data were used to discuss the characteristics of cities across the country that are working to raise their human capital (TDN participants) while also placing them 
in the context of cities like New York and San Francisco who are often used aspirational benchmarks for both attracting and retaining high human capital talent.

All 58 cities were ranked using bachelor's degree attainment and above. The word "above" is included to signify that some of these individuals also hold even higher forms of human capital such as graduate and professional degrees. Since cities focus more on bachelor's degree attainment, even people with higher forms of human capital must be included in the bachelor's attainment calculation because, while not their highest degree, they still count as possessing a bachelor's degree. The cities were not re-ranked when discussing associate degrees because the status of a knowledge city, within the current paradigm, is gained through higher levels of attainment, which requires the analysis to be focused on those who possess at least a bachelor's degree.

Several longitudinal graphs were created to show differences over the past twenty-five years between high and low attainment cities regarding some college/associate degrees, bachelor's degrees and above, and median household income. Data for these graphs comes from the Minnesota Population Center (2016) and the United States Census Bureau (2016a; 2016b).

\section{Case Studies}

Once the city demographic data were collected, a multiple-case study procedure was created for examining three cities. This case study procedure was based on the work of Yin (2014) and the COSMOS Corporation (1983). The initial framework in Figure 3.1; this framework served as a methodological roadmap for the study. 
Figure 3.1: Multiple-Case Study Procedure

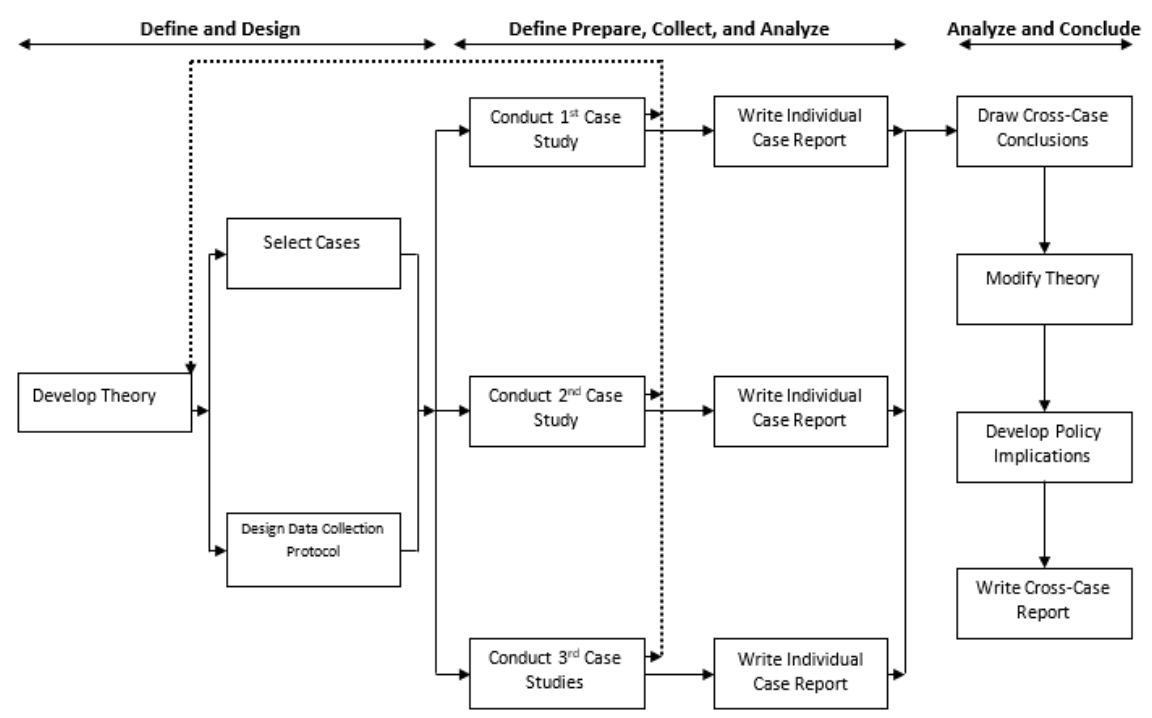

(COSMOS Corporation 1983; Yani 2014)

Growth Machine Theory, the urban literature, and education literature provide the theoretical framework for conducting these case studies. From there the TDN has supplied a pool of cities with a common desire to raise higher educational attainment, leaving the selection of cases (cities) and the protocol for examination.

The research recognized the complexity and variations between cities, which led to focus on a region of the country in the selection of cases. While comparing cities from sea to shining sea may give a more macro level view, it would not be the most helpful. Instead, when discussing regional urban economies, proximity to one another is best for comparison due to the interconnected nature of economies and regional competitiveness. Of particular interest to this study was how cities which once depended heavily on manufacturing power are fighting to remain central in the knowledge economy. Agtmael and Bakker (2016) have examined how cities in the U.S. rustbelt are adapting. Lacking is 
an understanding of how the central United States is working to remain a competitive economic space. With this in mind, the understudied Midwestern and Southern region of the United States, specifically the I-65 Corridor between Nashville and Indianapolis was selected as a geographic area for analysis. This corridor has three cities, Indianapolis, Louisville, and Nashville, which sit near the middle and bottom of the bachelor's degree attainment rankings. Placing these cities in positions to aspire to move higher in the performance rankings, to meet the precondition of high human capital.

The I-65 corridor between Nashville and Indianapolis is one of the busiest interstate systems in the United States. Over 8,500 trucks move through the Nashville and Indianapolis corridor daily, and it is predicted to remain one of the highest trucking corridors until at least 2040 (United States Department of Transportation 2015a). Louisville, which sits as the central point in this corridor is also a top twenty-five foreign trade gateways (United States Department of Transportation 2015b). Collectively, this information allows the research to see this geographic space as not only a region of interconnected cities but as a region with weight in the national and international economies. The concept of weight is important because unlike cities such as Houston, Chicago, and Boston, who are in the TDN, Indianapolis, Louisville and Nashville receive less notoriety for being global cities. In some ways, their respective status gives even further motivation for these three cities to work to increase various preconditions for growth including human capital. Additionally, Nashville, Louisville, and Indianapolis are all consolidated cities. Meaning that they each have consolidated their city and county governments and as a result share common local policy-making structures. From the formal institutional perspective, a similar government structure allows the cases to be 
more comparable when discussing local policy/ initiatives aimed at addressing raising human capital.

States and the federal government use corridor studies for understanding the demand for various forms of infrastructure (roads, water, railways, broadband internet, etc.). What the literature shows is that infrastructure is also important because of the relationship it has with economic growth (Haughwout 1999; Duggal, Saltzman and Klein 2007). Updates to infrastructure can even lower barriers to entry for entrepreneurship (Audretsch, Heger, and Veith 2015). Most importantly, like human capital, infrastructure is a precondition for growth. While this research in no way addresses infrastructure needs, demands, or the capacity needs of these cities, Interstate I-65 does serve as a common economic connector. By using a corridor of an interstate highway as a geographic space, the research also illustrates how infrastructure ties cities together as nodes in the national economy.

\section{Figure 3.2: Detailed Multiple-Case Study Procedure}

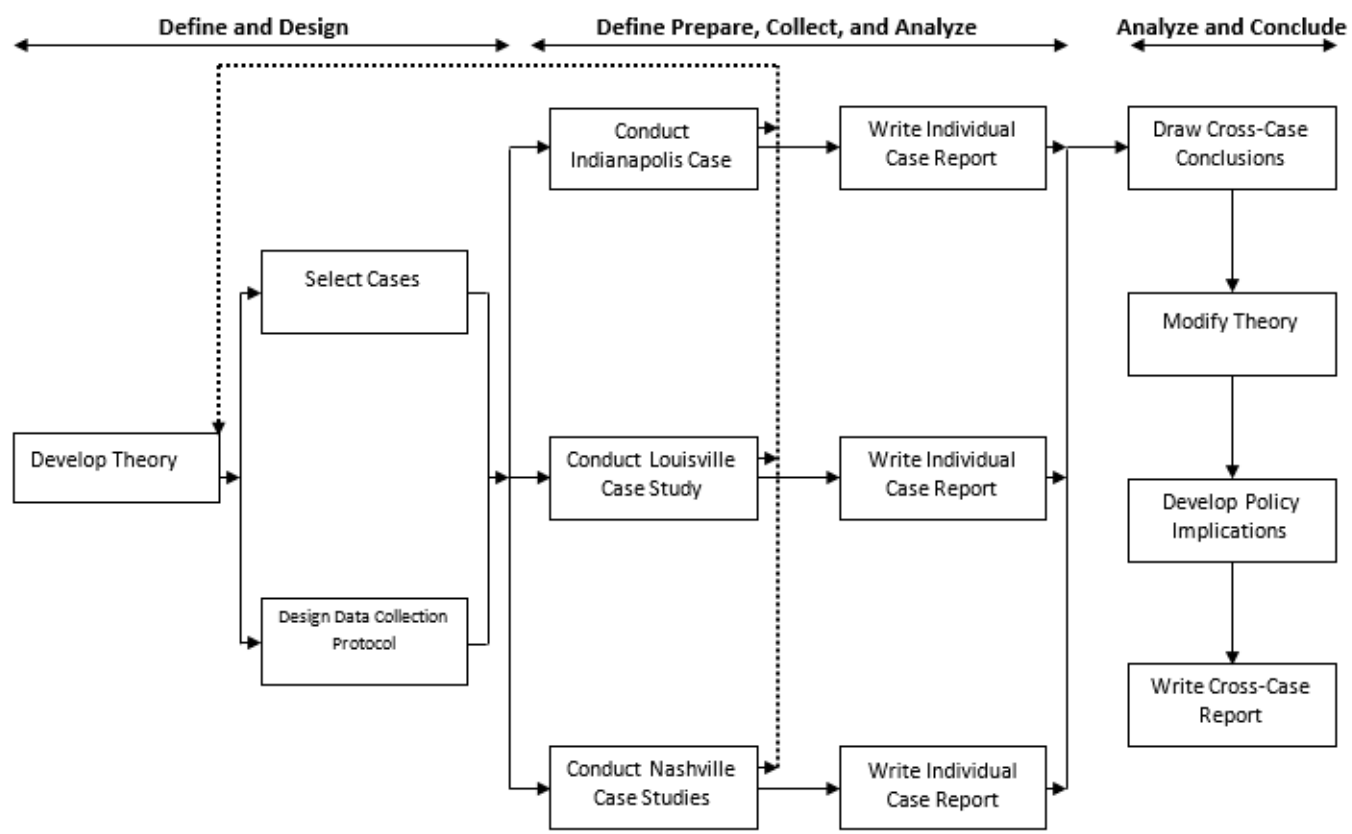

(COSMOS Corporation 1983; Yani 2014) Revised 
For the data collection protocol, loosely structured individual interviews were conducted. Interviews were the best investigative tool due to the lack of literature on the topic. The interviews were with those who currently work for organizations that focus on citywide attainment, skills, and attraction. A copy of the interview guide is in Appendix I. The first interview was with the researcher's former employer (discussed in-depth in a positionality section below). From here, snowball sampling was used.

\section{Researcher Positionality}

To provide full disclosure, it as important to note that several years before conducting this dissertation the author worked for two of the organizations studied, one is a regional chamber of commerce and the other a city-wide educational initiative. Only one of the staff interviewed across both organizations was there at the same time as the researcher, due to organizational staff turnover. The researcher's experience provided the dissertation with background knowledge about these two organizations, which led to the development of the dissertation research project. It also is important to note this background because those professional experiences provided a unique view of how cities and their organizations are working to raise attainment at the city-level. The experience at each of these organizations influenced questions asked by the author and the initial interview question guide (Appendix I). Specifically, questions about the perceived level of collaboration taking place were influenced by the author's prior experience. Those experiences created a unique perspective for studying this area. The author's experience, along with the steps taken for adding depth to the study (e.g., examining multiple organizations) are not limitations but rather add value to the research. 


\section{Case Study Analysis Protocol}

Twenty-four interviews were conducted across the three case studies; this totaled 18 organizations (7 in Nashville, 6 in Louisville, and 5 in Indianapolis). At six organizations, multiple people were interviewed, often due to the inability to gain entrée with executive leadership until meeting with someone first. Almost all interviews were conducted with individuals serving in executive leadership positions in their respective organization. Interviewing this type of individuals were able to speak on an organization in its totality and also regarding the prioritization of their work. Each interview took place in person at the organization's office, (two interviews took place over the phone due to the unavailability to meet in person) and lasted around an hour. Each interview was audio recorded, transcribed, and coded using a line-by-line method. First, from those codes, case level themes emerged. After completion of each of the case studies, collective themes across all three cases were pulled from the case level themes. The themes focused on answering the two primary research questions: why are cities working to raise higher educational attainment, and how are cities working to raise attainment?

In this dissertation, the findings are presented in isolation of one another, following the individual case report model as shown in Figure 3.2. In addition to the recorded interview data, many interviewees provided materials regarding their work. Materials included internal organization documentation about strategies, publicly available documentation, and studies conducted to understand educational and workforce demands. These materials were examined for themes alongside the recorded interview transcriptions. Documentation also provided a way to validate interview data. 
After writing individual case reports, all of the data was reexamined to examine collective findings. Interviews were re-read along with documentation, and the case reports to discover what collective themes emerged from the data. The collective themes are reported as cross-case conclusions (Chapter 8). The dissertation in its entirety serves as the cross-case study, shown in Figure 3.2.

Before discussing the case study findings, the next chapter presents the descriptive findings from the base sample of cities, the Talent Dividend Network. 


\section{CHAPTER IV: THE GREAT DIVERGENCE}

Cities across the country are competing with one another to be central in the global cities network. As stated in Chapter 2, the literature discusses competition through global flows, the knowledge economy, global cities, and benchmarking. To gauge where one sits within the global network of knowledge cities, a locality needs to measure performance. This chapter examines each of the cities in the base sample (made up of the Talent Dividend Network cities, minus Sarasota, with the addition of New York City and San Francisco) with the goal to understand the characteristics of these aspiring knowledge cities. This sample of cities made up $44.3 \%$ of the entire 2015 U.S. population. Highlighted below are the educational attainment, general economic demographics, and the occupational breakdowns for each of the 58 metropolitan statistical areas.

\section{Educational Attainment}

There is a growing demand for individuals with higher educational attainment in the knowledge economy. This demand requires cities, who seek to be attractive for economic development, to strengthen and attract such a talent supply. Essentially, this places cities with higher percentages of individuals with associates, bachelors and graduate degrees at a competitive advantage in the neoliberal domestic and global economies (Olssen and Peters 2007; Moretti 2013). The base sample of cities was ranked 
by their percentage of the MSA population, over the age of 25 , with a bachelor's degree

or above ${ }^{1}$

Table 4.1:

\begin{tabular}{|c|c|c|c|c|}
\hline \multicolumn{5}{|c|}{2015 Educational Attainment of Cities: By Percentage of Population with Bachelors Degree and Above } \\
\hline City & TDN & \begin{tabular}{|c|} 
Percentage of \\
Population High \\
School \\
Graduate or \\
Equivalency \\
\end{tabular} & \begin{tabular}{|c|} 
Percentage of \\
Population with \\
Some College \\
or Associates
\end{tabular} & $\begin{array}{c}\text { Percentage of } \\
\text { Population } \\
\text { Bachelor } \\
\text { Degree and } \\
\text { Above }\end{array}$ \\
\hline Washington-Arlington-Alexandria, DC-VA-MD-WV Metro Area & Yes & $18.80 \%$ & $22.60 \%$ & $48.90 \%$ \\
\hline St. Louis, MO-IL Metro Area & Yes & $16.60 \%$ & $25.80 \%$ & $45.60 \%$ \\
\hline Boston-Cambridge-Newton, MA-NH Metro Area & Yes & $23.70 \%$ & $22.60 \%$ & $44.60 \%$ \\
\hline Raleigh, NC Metro Area & Yes & $19.50 \%$ & $27.50 \%$ & $43.20 \%$ \\
\hline Madison, WI Metro Area & Yes & $22.50 \%$ & $29.20 \%$ & $42.80 \%$ \\
\hline Denver-Aurora-Lakewood, CO Metro Area & Yes & $20.40 \%$ & $29.10 \%$ & $40.60 \%$ \\
\hline Minneapolis-St. Paul-Bloomington, MN-WI Metro Area & Yes & $22.40 \%$ & $31.10 \%$ & $39.40 \%$ \\
\hline New York-Newark-Jersey City, NY-NJ-PA Metro Area & No & $25.60 \%$ & $22.20 \%$ & $37.50 \%$ \\
\hline Baltimore-Columbia-Towson, MD Metro Area & Yes & $26.30 \%$ & $26.30 \%$ & $37.30 \%$ \\
\hline Hartford-West Hartford-East Hartford, CT Metro Area & Yes & $27.10 \%$ & $25.90 \%$ & $37.20 \%$ \\
\hline Manchester-Nashua, NH Metro Area & Yes & $27.20 \%$ & $28.20 \%$ & $35.80 \%$ \\
\hline Portland-Vancouver-Hillsboro, OR-WA Metro Area & Yes & $21.50 \%$ & $33.60 \%$ & $35.80 \%$ \\
\hline San Francisco-Oakland-Hayward, CA Metro Area & No & $19.00 \%$ & $31.30 \%$ & $35.70 \%$ \\
\hline Chicago-Naperville-Elgin, IL-IN-WI Metro Area & Yes & $24.70 \%$ & $27.10 \%$ & $35.50 \%$ \\
\hline Fargo, ND-MN Metro Area & Yes & $22.40 \%$ & $36.80 \%$ & $35.40 \%$ \\
\hline Albany-Schenectady-Troy, NY Metro Area & Yes & $27.80 \%$ & $29.60 \%$ & $34.80 \%$ \\
\hline Philadelphia-Camden-Wilmington, PA-NJ-DE-MD Metro Area & Yes & $30.30 \%$ & $24.30 \%$ & $34.80 \%$ \\
\hline Columbus, OH Metro Area & Yes & $28.70 \%$ & $27.60 \%$ & $34.00 \%$ \\
\hline Omaha-Council Bluffs, NE-IA Metro Area & Yes & $24.70 \%$ & $32.50 \%$ & $33.80 \%$ \\
\hline Richmond, VA Metro Area & Yes & $26.40 \%$ & $27.90 \%$ & $33.70 \%$ \\
\hline Milwaukee-Waukesha-West Allis, WI Metro Area & Yes & $26.90 \%$ & $29.90 \%$ & $33.30 \%$ \\
\hline Honolulu County, Hawaii & Yes & $26.40 \%$ & $31.80 \%$ & $32.70 \%$ \\
\hline Rochester, NY Metro Area & Yes & $27.70 \%$ & $29.70 \%$ & $32.50 \%$ \\
\hline Charleston-North Charleston, SC Metro Area & Yes & $25.60 \%$ & $31.10 \%$ & $32.50 \%$ \\
\hline Nashville-Davidson--Murfreesboro--Franklin, TN Metro Area & Yes & $28.50 \%$ & $27.40 \%$ & $32.30 \%$ \\
\hline Charlotte-Concord-Gastonia, NC-SC Metro Area & Yes & $24.90 \%$ & $30.30 \%$ & $32.20 \%$ \\
\hline Los Angeles-Long Beach-Anaheim, CA Metro Area & Yes & $20.00 \%$ & $26.90 \%$ & $32.10 \%$ \\
\hline San Diego-Carlsbad, CA Metro Area & Yes & $27.00 \%$ & $31.70 \%$ & $31.90 \%$ \\
\hline Indianapolis-Carmel-Anderson, IN Metro Area & Yes & $29.10 \%$ & $28.40 \%$ & $31.50 \%$ \\
\hline Pittsburgh, PA Metro Area & Yes & $34.90 \%$ & $26.10 \%$ & $31.50 \%$ \\
\hline Columbia, SC Metro Area & Yes & $26.80 \%$ & $30.80 \%$ & $30.70 \%$ \\
\hline Houston-The Woodlands-Sugar Land, TX Metro Area & Yes & $23.30 \%$ & $27.90 \%$ & $30.60 \%$ \\
\hline Grand Rapids-Wyoming, MI Metro Area & Yes & $27.90 \%$ & $31.50 \%$ & $30.50 \%$ \\
\hline Syracuse, NY Metro Area & Yes & $29.50 \%$ & $29.80 \%$ & $30.30 \%$ \\
\hline Buffalo-Cheektowaga-Niagara Falls, NY Metro Area & Yes & $29.60 \%$ & $30.80 \%$ & $30.00 \%$ \\
\hline Providence-Warwick, RI-MA Metro Area & Yes & $28.30 \%$ & $26.80 \%$ & $29.80 \%$ \\
\hline Akron, OH Metro Area & Yes & $33.50 \%$ & $28.10 \%$ & $29.40 \%$ \\
\hline Cleveland-Elyria, OH Metro Area & Yes & $30.00 \%$ & $30.00 \%$ & $29.30 \%$ \\
\hline Harrisburg-Carlisle, PA Metro Area & Yes & $35.80 \%$ & $24.90 \%$ & $29.30 \%$ \\
\hline Jackson, MS Metro Area & Yes & $25.40 \%$ & $31.90 \%$ & $29.20 \%$ \\
\hline Detroit-Warren-Dearborn, MI Metro Area & Yes & $27.50 \%$ & $32.30 \%$ & $29.00 \%$ \\
\hline Oklahoma City, OK Metro Area & Yes & $27.40 \%$ & $31.70 \%$ & $28.80 \%$ \\
\hline Orlando-Kissimmee-Sanford, FL Metro Area & Yes & $27.90 \%$ & $31.60 \%$ & $28.80 \%$ \\
\hline Wichita, KS Metro Area & Yes & $27.40 \%$ & $33.50 \%$ & $28.60 \%$ \\
\hline Little Rock-North Little Rock-Conway, AR Metro Area & Yes & $30.00 \%$ & $30.80 \%$ & $28.50 \%$ \\
\hline Tampa-St. Petersburg-Clearwater, FL Metro Area & Yes & $29.80 \%$ & $31.10 \%$ & $27.50 \%$ \\
\hline Dayton, OH Metro Area & Yes & $29.20 \%$ & $33.10 \%$ & $27.30 \%$ \\
\hline Louisville/Jefferson County, KY-IN Metro Area & Yes & $30.70 \%$ & $30.20 \%$ & $27.30 \%$ \\
\hline Baton Rouge, LA Metro Area & Yes & $32.20 \%$ & $27.40 \%$ & $27.20 \%$ \\
\hline Knoxville, TN Metro Area & Yes & $31.90 \%$ & $28.00 \%$ & $27.10 \%$ \\
\hline Memphis, TN-MS-AR Metro Area & Yes & $29.10 \%$ & $30.40 \%$ & $26.80 \%$ \\
\hline Tulsa, OK Metro Area & Yes & $29.90 \%$ & $32.50 \%$ & $26.20 \%$ \\
\hline Chattanooga, TN-GA Metro Area & Yes & $30.20 \%$ & $31.00 \%$ & $24.10 \%$ \\
\hline El Paso, TX Metro Area & Yes & $24.50 \%$ & $29.90 \%$ & $21.30 \%$ \\
\hline Youngstown-Warren-Boardman, OH-PA Metro Area & Yes & $42.00 \%$ & $26.70 \%$ & $20.30 \%$ \\
\hline Lakeland-Winter Haven, FL Metro Area & Yes & $36.20 \%$ & $28.50 \%$ & $18.80 \%$ \\
\hline Stockton-Lodi, CA Metro Area & Yes & $26.40 \%$ & $33.20 \%$ & $18.40 \%$ \\
\hline McAllen-Edinburg-Mission, TX Metro Area & Yes & $23.20 \%$ & $22.10 \%$ & $16.70 \%$ \\
\hline
\end{tabular}

(United States Census, 2016a)

${ }^{1}$ The rationale for including "above" is discussed in Chapter 3. 
For the whole sample, the mean for some college/associate degrees is $29.1 \%$ compared to all metropolitans in the U.S., which have an average attainment level of $30.6 \%$. For bachelor's degrees above, the mean of the sample is $31.74 \%$ compared to all metropolitans in the U.S., which have an average attainment of $27.9 \%$. The top ten cities in this sample have an average of $41.7 \%$ of their population, over the age of twenty-five, with at least a bachelor's degree compared to $22.7 \%$ for the bottom ten cities. There is a 32.2\%-point difference between the top city, Washington D.C., and the bottom ranked city McAllen, TX for bachelor degree attainment and above. The polarization between the top and bottom cities, although derived from a limited sample of cities, highlights the haves and the have-nots of high human capital in the United States. There is room for optimism. All of these cities, minus two, (by being part of the TDN) have actively stated that they wish to grow their human capital pool even further. Meaning that while cities like Raleigh and Minneapolis can cite this performance metric as a competitive victory, both are not giving up when it comes to further human capital growth. If the bottom ten wishes to compete with top ten, their attainment growth would have to outpace those ahead of them. To see if the outpacing is occurring a historical analysis looks at educational attainment of the top and bottom cities for the base year of 2015 over the past twenty-five years (top and bottom refer to the cities with the highest and lowest bachelor's degree and above attainment in the base year 2015).

Graph 4.1 shows how the top and bottom ten ranked cities have grown their bachelor degree and above over the past twenty-five years. Graph 4.1 shows that the bottom ten cities are doing enough to stay in the race. While this does not mean to suggest that zero of the 58 cities in the sample are outpacing those ahead of them, this 
graph does show that overall bachelor degree attainment has increased at an equal pace for high and low attainment cities.

\section{Graph 4.1:}

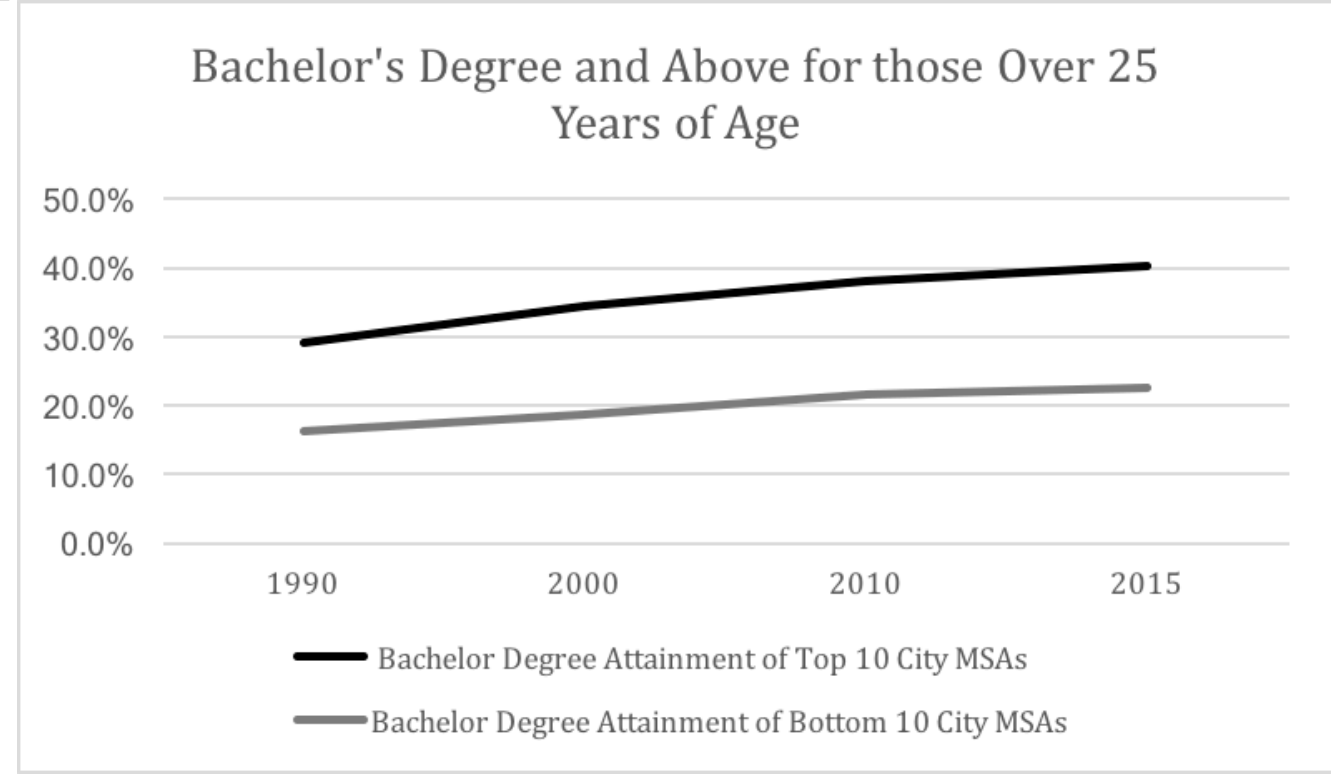

\footnotetext{
*This graph uses data from the 2015 American Community Survey 5-Year Estimates. (United States Census, 2016a) and historical data from the Minnesota Population Center (2011).
}

The bottom ten cities have made progress is in the average percentage of those twenty-five and over with some college or an associate's degree (Graph 4.2). (For Graph 4.2, the top ten and bottom ten are still referring to their ranking from Table 4.1, the cities were not re-ranked by some college/associates degrees.) Cities that have historically been low attainment cities regarding bachelor degrees have seen an increase those with an associate's degree; creating a unique opportunity for low bachelor attainment cities to competitively situate themselves for career paths requiring solely associate degree holders. 


\section{Graph 4.2:}

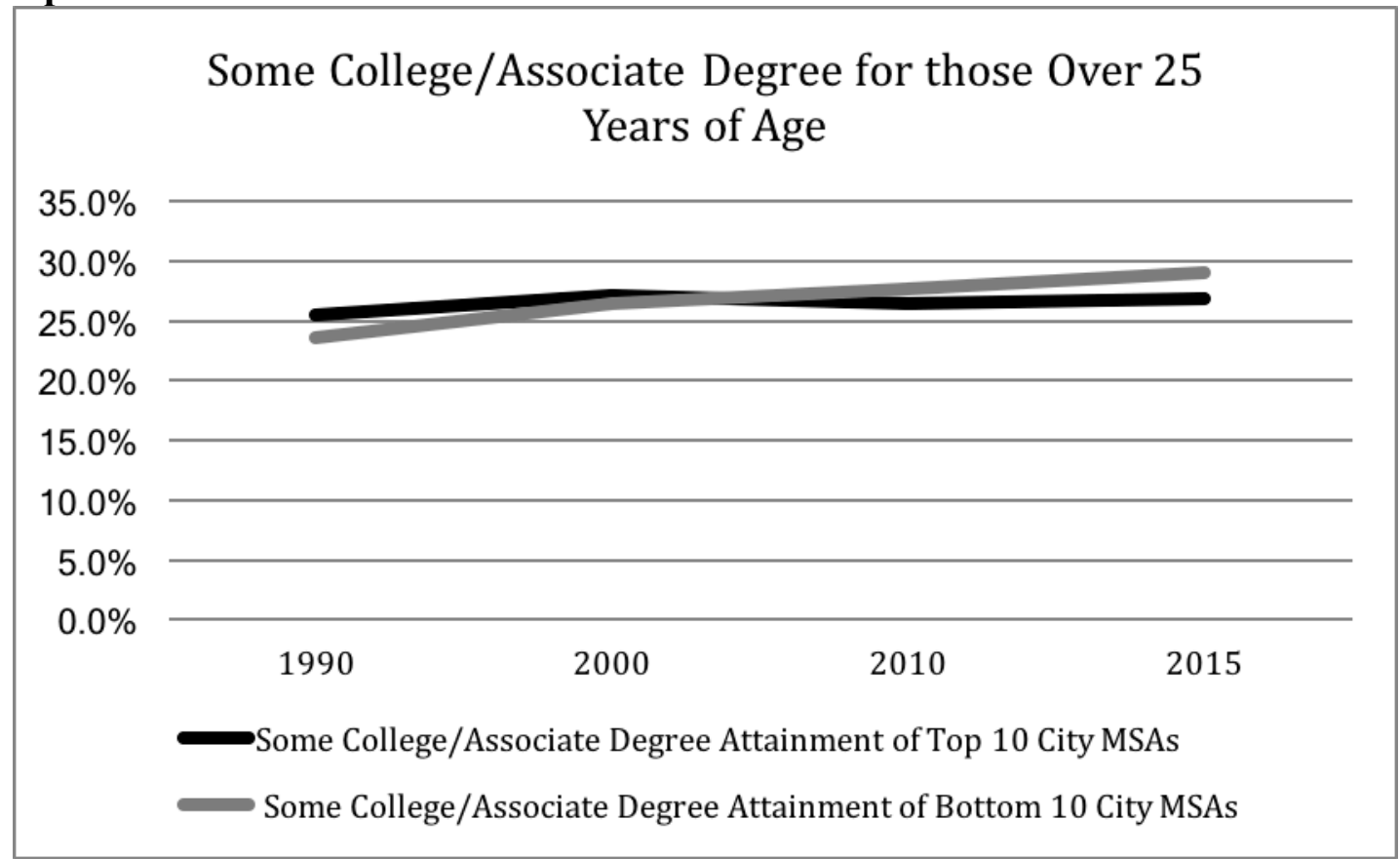

*This graph uses data from the 2015 American Community Survey 5-Year Estimates. (United States Census, 2016a) and historical data from the Minnesota Population Center (2011).

There is evidence to substantiate the above findings. Since 1970, the difference between the most and least educated cities in America has doubled (Tavernise 2012). Research has shown that the distance between historically high and low educated metropolitans is a national, generalizable, trend (Moretti 2013). Moretti, using a full sample of all U.S. metropolitan areas, found that cities with high educational attainment, going back into the 1980's, are outpacing cities with historically lower college attainment (2013). He goes on to argue with additional evidence, that the distance between high and low attainment cities is part of a "great divergence," where high-educated cities are separating themselves from lower educated cities.

While the evidence presented above is only a subsample of American cities, these findings do fit with Moretti's findings by showing that while higher educational 
attainment is rising nationally, cities with historically high attainment levels show little sign of giving up their competitive advantage. While having high attainment is one advantage, it would be wrong to see attainment as isolated from other social institutions and preconditions for growth. In order to paint a fuller picture of why historically high attainment cities remain in the lead, the focus has to shift to understanding the demographic and occupation characteristics of high attainment cities.

\section{Demographics}

This section examines the demographic traits of the sample cities. Table 4.2 shows all 58 cities, sorted by bachelor's degree attainment. Fourteen demographic categories were included. These demographic measures focus on economic and labor data; this is based on research that shows that educational attainment of a city is an indicator of current economic health. Data on the percent foreign born was added because it is seen as a predictor of future growth (Rausch and Negrey 2006). Also included in Table 4.2, is whether the city is a state capital and if the city is a consolidated city. While state capitals are often centers of high human capital jobs, there is evidence to suggest that if one controls for educational attainment, being a state capital is not a significant predictor of growth (Rausch and Negrey 2006). Finally, the dollar value for exports of each MSA is included as a measure of connectivity to the global economy. 
Table 4.2: TDN Cities, Ranked by Bachelor's Degree and above

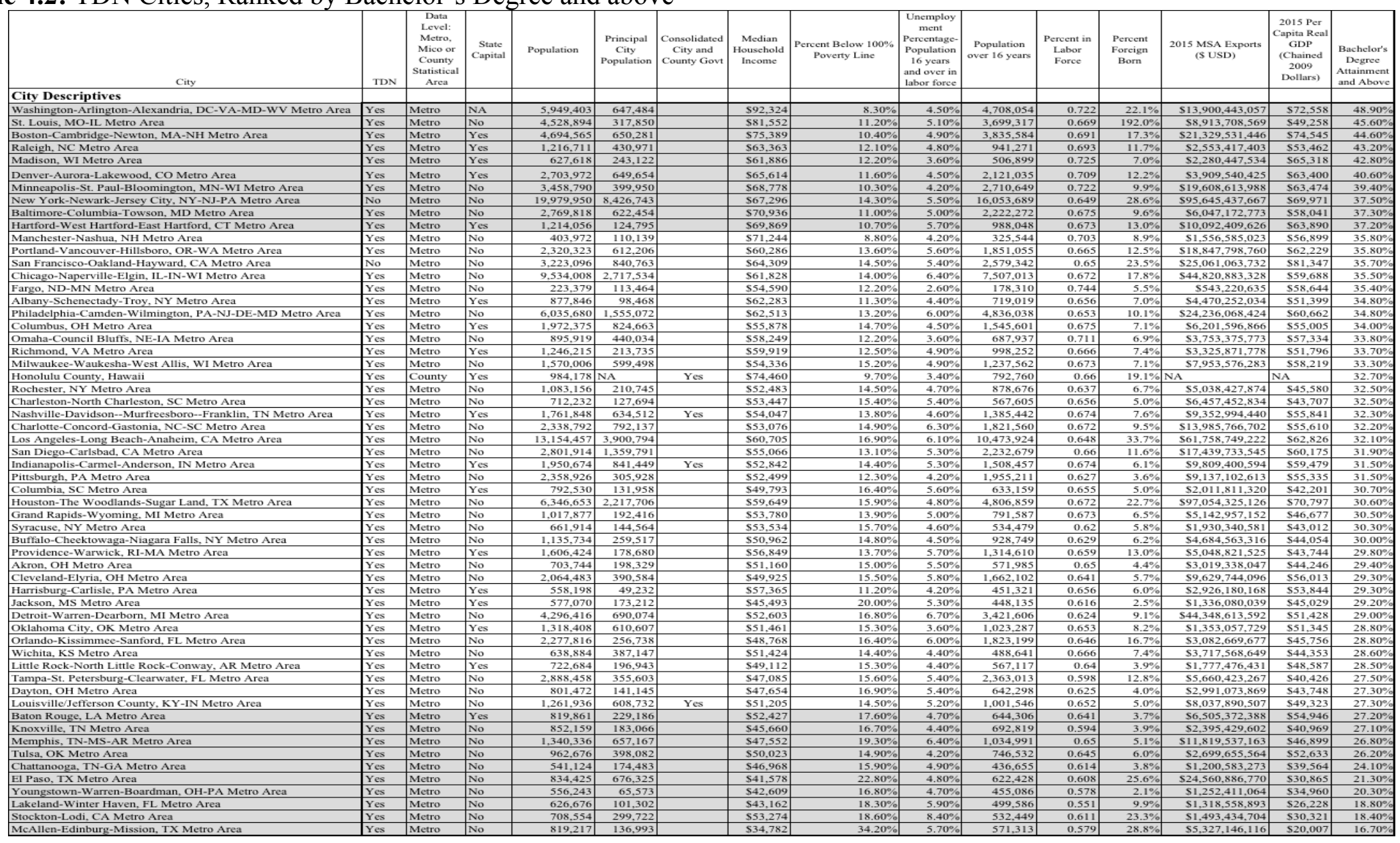

*This chart uses data from the 2015 American Community Survey 5-Year Estimates. (United States Census, 2016a; International Trade Administration, 2017;

United States Bureau of Economic Analysis 2017a) 
The overall sample has an average population of 2,399,057 people with an average annual median household income of $\$ 56,074$ compared to all U.S. metropolitans that have an average median household income of $\$ 52,175$. The sample is less impoverished than all metropolitans (the average for the sample is $14.8 \%$ percent living below $100 \%$ of the poverty line while the average for all metropolitans is $16.3 \%$ ). In terms of unemployment, the sample mean percentage of $5.6 \%$ is the same as the average for all metropolitans. The average foreign-born population of the cities in the sample is $10.9 \%$, which is slightly higher than average for all metropolitans of $10 \%$. Collectively, while this sample is in no way generalizable, the sample does closely reflect all U.S. metropolitans. For purposes of understanding differences between the more highly educated cities and the lower ranked cities, comparing the economic, demographic categories between the top and bottom ten-attainment cities is most helpful.

From an economics perspective, the literature has shown that high human capital plays a role in both sustaining and growing a city's economy (Romer 1986; Romer 1990; Carilino 1995; Seiter 2003; Florida 2005; Rausch and Negrey 2006). One would, therefore, expect cities with higher attainment also to have stronger and larger economies. For the sample, Table 4.3 indicates just that. Median household incomes are higher; unemployment is lower and fewer people are living below the poverty line in higher attainment cities. 


\section{Table 4.3:}

\begin{tabular}{|c|r|r|}
\hline \multicolumn{3}{|c|}{ Average Demographics of Top 10 vs Bottom 10 } \\
\hline & \multicolumn{1}{|c|}{ Top 10 Cities } & Bottom 10 Cities \\
\hline Population & $4,714,378$ & 806,127 \\
\hline Principal City Population & $1,251,330$ & 292,190 \\
\hline Median Household Income & $\$ 71,701$ & $\$ 45,804$ \\
\hline $\begin{array}{c}\text { Percent Below 100\% Poverty } \\
\text { Line }\end{array}$ & $11.2 \%$ & $19.5 \%$ \\
\hline $\begin{array}{c}\text { Unemployment Percentage- } \\
\text { Population 16 years and over in } \\
\text { labor force }\end{array}$ & & \\
\hline $\begin{array}{c}\text { Population over 16 years } \\
\text { Percent in Labor Force }\end{array}$ & $3,778,682$ & $5.4 \%$ \\
\hline Percent Foreign Born & $69.3 \%$ & 623,617 \\
\hline MSA Exports (\$ USD) & $\$ 18,428,072,249$ & $\$ 5,857,301,554$ \\
\hline $\begin{array}{c}\text { 2015 Per Capita Real GDP } \\
\text { (Chained 2009 Dollars) }\end{array}$ & $\$ 63,392$ & $11.2 \%$ \\
\hline Income Per Capita & $\$ 52,247$ & $\$ 37,739$ \\
\hline
\end{tabular}

*This chart uses data from (United States Census, 2016a; United States Bureau of Economic Analysis. 2017a; United States Bureau of Economic Analysis. 2017b; International Trade Administration; 2017)

Historically, the median household income gap has remained consistent over the past twenty-five years (Graph 4.3). Previous literature examining the impacts of high human capital on growth used income per capita rather than median household income (Glaeser, Scheinkman and Shleifer 1995; Simon 1998; Mathur 1999; Simon and Nardinelli 2002; Gotlieb and Fogarty 2003). Graph 4.4 shows the top and bottom comparison for average income per capita income for Top vs. Bottom attainment cities. Median household income takes all incomes in the region and reports the middle number in the sample. Income per capita takes all the income and divides it by the population; like any average, this allows high incomes to pull the calculation up. 


\section{Graph 4.3:}

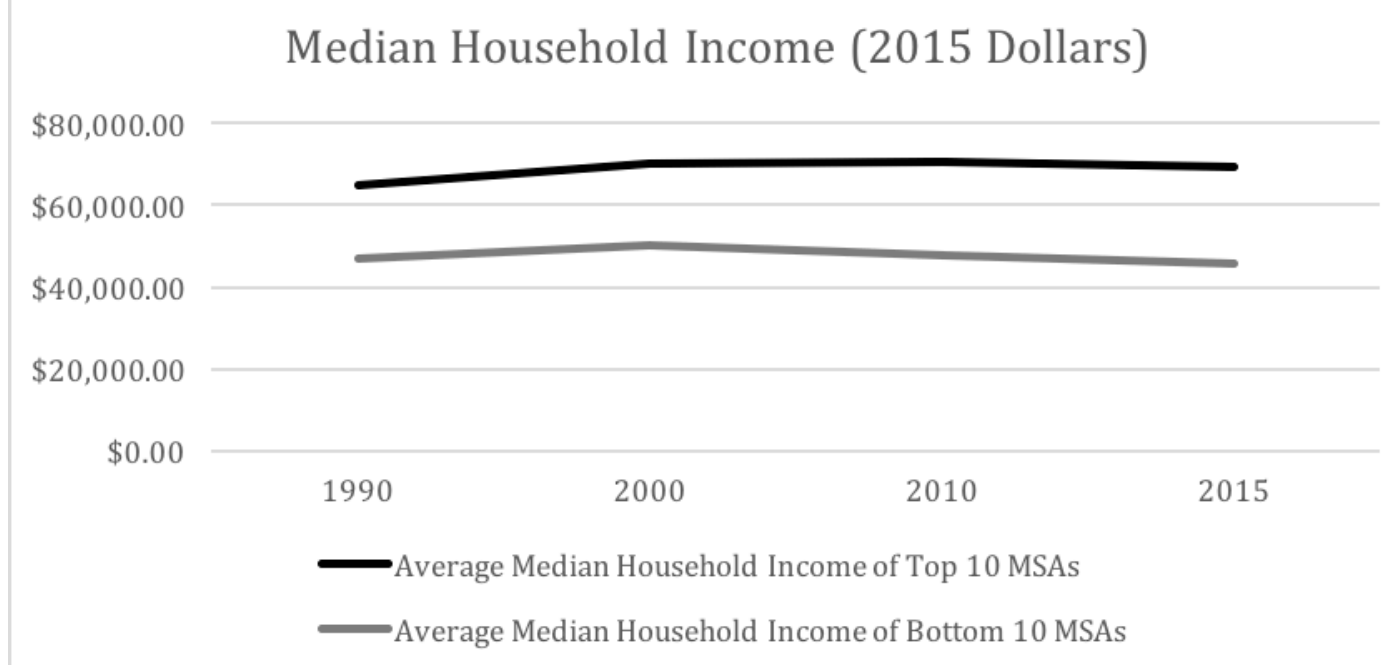

*This graph uses data from the 2015 American Community Survey 5-Year Estimates. (United States Census, 2016b) and historical data from the Minnesota Population Center (2016). Income numbers adjusted for inflation into 2015 dollars.

\section{Graph 4.4:}

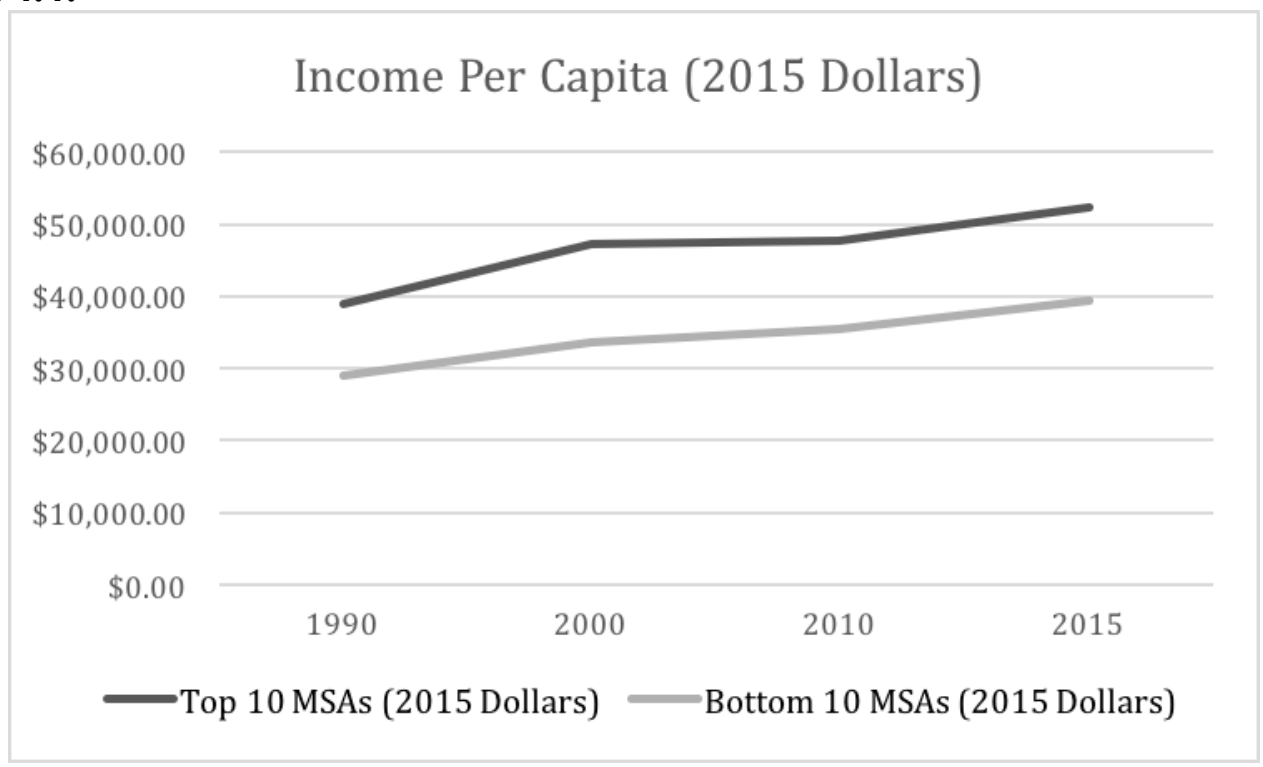

*This graph uses data from the 2015 American Community Survey 5-Year Estimates. (United States Census, 2016b) and historical data from the Minnesota Population Center (2016). Income numbers adjusted for inflation into 2015 dollars. 
While these demographics do not provide further answers regarding the best indicators of future growth, this comparison showed the large contrast between high and low attainment cities for the included measures (Table 4.3). The problem that low attainment cities have is that as they work to strengthen attainment and other measures, so too do cities at the top. Meaning that like bachelor degree attainment and above, if lower attainment cities are to change their numbers, they must do so at a faster growth rate than high attainment cities, assuming they desire to change their position in this on-going competitive performance race.

Another means often used for performance benchmark cities, regarding their ability to retain and attract high human capital, is to look at the occupational characteristics of a city. Occupational characteristics reflect a cities' capacity to increase high human capital ultimately. Occupational statistics also help in describing the current culture and climate of a city.

\section{Occupational Statistics}

Over the last half-century, the United States has experienced a shift in the occupational makeup of its population. Gone are the days of a large blue-collar class. Due to outsourcing, technology, and a host of various realities, other occupational categories have grown. Most of the growth has occurred in service, business, managerial, science, and technology sectors (Reisinger 2003; Florida 2005). As occupational shifts take place, historically men and women have not fared equally (Bagachi-Sen 1995).

For cities, the occupational shifts mean that if they are to grow, not only do they need to attract individuals who meet the criteria for these sectors, but cities must also develop processes to foster growth in both the supply and demand side of these 
occupations. In the overall sample, the average percentages for each occupational category are $37.7 \%$ for Management, business, science, and arts occupations $(35 \%$ for all U.S. metropolitans), $17.5 \%$ for service occupations (18.7\% for all U.S. metropolitans), $24.9 \%$ for sales and office occupations (24.4\% for all U.S. metropolitans), $8.2 \%$ for Natural resources, construction, and maintenance occupations $(9.6 \%$ for all U.S. metropolitans), and $11.6 \%$ for production, transportation, and material moving occupations (12.2\% for all U.S. metropolitans). Occupational make up of a city informs the impact attainment has on workforce and occupations. As with prior sections in this chapter, these findings also compared the averages of each occupational sector for the top and bottom, degree attainment cities (Table 4.4).

\section{Table 4.4:}

\begin{tabular}{|l|r|r|r|r|r|}
\hline \multicolumn{3}{|c|}{ Top Attainment Cities vs Bottom Attainment Cities: Occupational Breakdown for 2015 } \\
\hline & $\begin{array}{c}\text { Percent } \\
\text { Occupation: } \\
\text { Management, } \\
\text { business, } \\
\text { science, and } \\
\text { arts occupations }\end{array}$ & $\begin{array}{c}\text { Percent } \\
\text { Occupation: } \\
\text { Service } \\
\text { occupations }\end{array}$ & $\begin{array}{c}\text { Percent } \\
\text { Occupation: } \\
\text { Sales and } \\
\text { office } \\
\text { occupation: } \\
\text { Natural } \\
\text { resources, } \\
\text { construction, } \\
\text { and } \\
\text { maintenance } \\
\text { occupations }\end{array}$ & $\begin{array}{c}\text { Percent } \\
\text { Occupation: } \\
\text { Production, } \\
\text { transportation, } \\
\text { and material } \\
\text { moving } \\
\text { occupations }\end{array}$ \\
\hline Top 10 Cities & $45.2 \%$ & $16.4 \%$ & $23.0 \%$ & $6.9 \%$ & $8.6 \%$ \\
\hline Bottom 10 Cities & $31.6 \%$ & $18.9 \%$ & $25.3 \%$ & $10.2 \%$ & $14.0 \%$ \\
\hline
\end{tabular}

(United States Census, 2016a)

For this sample, $45 \%$ of the occupations, on average, in top ten cities are in the management, business, science and arts occupations compared to $31 \%$, on average, for the bottom ten cities. Bottom attainment cities on average have higher levels of individuals in production, transportation, and material moving occupations. Taken together, Table 4 and Table 5 both show the occupational characteristics of this sample of cities. They highlight the reality that high attainment cities, on average, have higher 
percentages of individuals in management, business, science, and arts occupations. Table 4.4 is not making a causal claim between occupational characteristics and attainment status of the city. What the differences between high attainment cities and low attainment cities do point to is the desire to be a high attainment city may connect to the desire to shift the occupational characteristics of a city.

\section{Summary}

The findings in this chapter show that high and low attainment cities differ on a variety of characteristics. Additionally, these findings have shown that while low attainment cities are making gains in the areas of bachelor's degree attainment and above, on average, these cities are slowly losing ground to those with historically higher bachelors attainment. The ongoing gap epitomizes the adage "that the rich get richer." The findings hinder the argument that by raising attainment cities are in automatically more competitive; instead, the findings point to a reality that raising attainment most often keeps cities from falling further behind in the race. Making the attainment race, not a race to the top, but rather a race to maintain one's competitiveness while possibly passing one or two cities on the way. The solution to this competitiveness race is not easy. No magic formulas currently exist for raising attainment at an accelerated pace. Cities, especially low attainment cities, are working daily to ensure they have all of the ingredients of being a competitive marketplace.

The next three chapters look specifically at how Indianapolis, Indiana, Louisville, Kentucky, and Nashville, Tennessee are working to raise their educational attainment. Each of the cities sat near the middle and bottom of the previously mentioned sample. These cities currently lack the competitive economic advantage of having relatively high 
educational attainment (when looking nationwide). By examining the processes, policies, and goals related to raising higher education attainment, the following chapters explore how cities prioritize and gauge various methods for raising attainment. The focus of each of these case studies is not longitudinal; the research focused solely on how these cities have been working for the past several years and today to raise their human capital. The data presented in the case study chapters came from interviews with select organizations in each city that focus on increasing high human capital. More research needs to take place to examine the expansive organizational networks seeking to increase human capital that exist in U.S. metropolitans. Findings do not answer what the impact of raising attainment may be on cities, but rather describes the strategies utilized by these cities (whom all participated in the Talent Dividend Network) to, in theory, raise postsecondary attainment.

The case studies are a snapshot of the multitude of organizations and initiatives, which focus on attainment both directly and indirectly. The reader will find similar themes like access, workforce development, and attraction in more than one of the cities. Chapter 8 examines the common approaches collectively and ties them to the literature; it also serves to answer the additional research questions of why is this work done and how do cities see attainment increases tied to growth. These case studies are the first step in answering the overall research question: how are U.S. cities working to increase higher education attainment as a form of human capital? 


\section{CHAPTER V: INDIANAPOLIS}

Among the 58 Talent Dividend Cities, Indianapolis ranks $29^{\text {th }}$ in bachelor's degree attainment (second highest of the three cases study cities) with $32 \%$ of its MSA holding a bachelor's or above degree ( $28 \%$ have at least some college or an associate's degree). As of 2015, the Indianapolis MSA had a population of 1.9 million people; of this, only 841,449 live in the central city (United States Census, 2016a). Like cities across the United States, Indianapolis is reinvesting in the urban core. Driving this investment is the increased demand by younger generations to live in more dense communities. The effect is apparent just driving through downtown Indianapolis. Found throughout the city's core are new condominiums, apartments, restaurants, and bars. These changes to the physical environment highlight one of the strategic focuses of Indianapolis, attraction. This chapter uses interview data to show how Indianapolis is working to break down access barriers to higher education, attract high attainment individuals, and strategically align the workforce with industry.

Indianapolis, like most Midwestern cities, is looking for an identity that will lead to a competitive advantage in the twenty-first-century economy. Before understanding Indianapolis today, and how they are working to raise their human capital, a brief history of the city is provided. 


\section{History}

In the year 1825, the state of Indiana formed the city of Indianapolis to be the new state capital (Leary 1971). Chosen because of its centrality in the state and a supposedly navigable waterway called the White River, the city also sat on a new national road, which would connect the state capitals of Ohio, Indiana, and Illinois (giving Indianapolis the saying it still holds today as the city at the crossroads of America). It took until the last decade of the nineteenth century for Indianapolis to become an industrial hub. From 1880 to 1900 , the number of industrial manufactures almost doubled to 1,190 (Geib 1981). By the early 1900's the city was a major gas, food manufacturing, banking, and automobile hub with a population of 169,000 . As the twentieth century moved forward, Indianapolis remained at the crossroads of America. Historians attribute much of its growth to this very fact. In 1970, as Indianapolis became a thriving metropolitan and modern city, a new governing structure titled "Unigov" merged city and county governments bringing together the booming suburbs and city services. In Indianapolis' nearly two hundred years of existence, the city has seen itself grow from a small prairie farm to a metropolitan of nearly two million people in 2015.

\section{The Numbers}

For decades, like a majority of American cities, manufacturing has been central in Indianapolis and the source of many of the city's big booms. Graphs 5.1 and 5.2 show Indianapolis' increases in both the "some college/associates degrees" category and "bachelor's degrees and above." Like in previous chapters, the time span only looks post1990 just before a shift in national bachelor's attainment, which began in the early 1990's. Since 1990, Indianapolis has grown the share of their population with a higher education credential. From a simple trends perspective, Indianapolis has gained in their 
percentage with at least some college or an associate's degree (Graph 1). Theoretically, one might credit these gains in keeping Indianapolis competitive with other American cities regarding the attainment pool that they can supply employers.

\section{Graph 5.1:}

\section{Indianapolis: Some College/Associate Degrees}

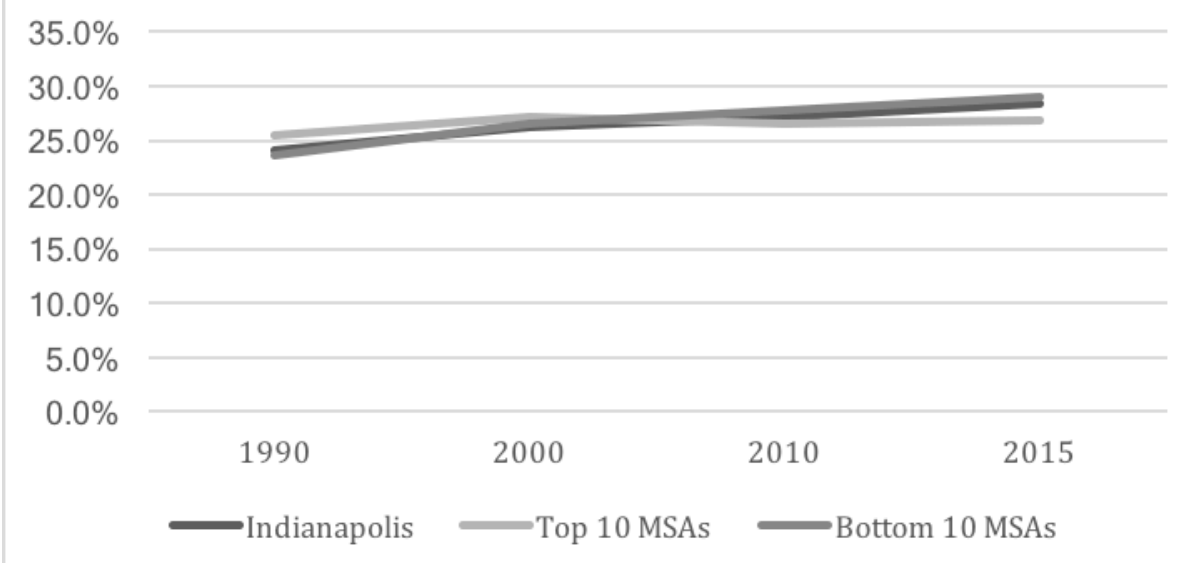

(United States Census 2016a; Minnesota Population Center 2016)

While Indianapolis has kept up with the growth of the share of their population with some college/ associates degree, they have failed to do so at the same rate for bachelor's degrees. Since 1990, Indianapolis has cut into the lead of the historically educated cities in this sample. Much of this gain took place in the early 90's. Since 2010, Indianapolis has merely maintained their position in the race for higher bachelor's degrees (Graph 5.2). From a purely human capital market perspective, these findings indicate that Indianapolis has gained little to no competitive advantage over the past twenty-five years.

It is hard for a city to raise attainment or sustain attainment growth if there is a lack of industry demand, creating a supply and demand relationship between attainment and industry. The occupational make-up of a city offers several insights into both where 
a city has come regarding its economic climate, and the city of labor demands the city most likely currently has. Since 1990, Indianapolis has seen large growth in the management business, science, and occupational art category. This category includes those in the engineering, legal, and healthcare fields (Table 5.1).

\section{Graph 5.2:}

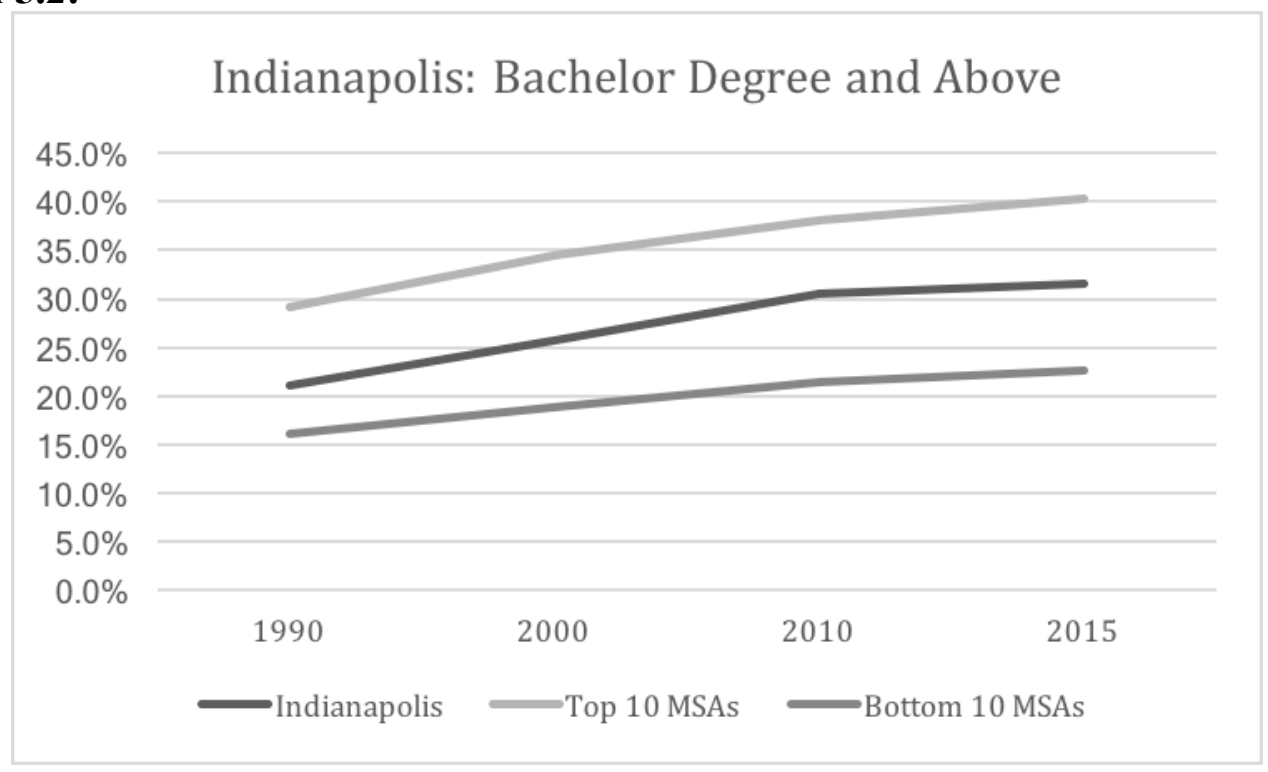

(United States Census 2016a; Minnesota Population Center 2016)

This percentage increase has meant a decline in the share of those in the office, natural resources, construction and maintenance occupations. This decline took place at the national level at the same time due to the shifts in automation and global trade, especially in production occupations. These occupational shifts are more likely to impact males, due to their high majorities in these labor categories, highlighting the intersection of attainment, occupation, and gender. 
Table 5.1:

\begin{tabular}{|c|c|c|c|c|c|}
\hline \multicolumn{6}{|c|}{ Indianapolis Occupational Make-Up } \\
\hline Occupations & $\begin{array}{c}\text { Management, } \\
\text { business, } \\
\text { science, and } \\
\text { arts occupations }\end{array}$ & $\begin{array}{c}\text { Service } \\
\text { Occupations }\end{array}$ & $\begin{array}{l}\text { Sales and } \\
\text { office } \\
\text { occupations }\end{array}$ & $\begin{array}{c}\text { Natural } \\
\text { resources, } \\
\text { construction, } \\
\text { and } \\
\text { mainenance } \\
\text { occupations }\end{array}$ & $\begin{array}{c}\text { Production, } \\
\text { transportation, } \\
\text { and material } \\
\text { moving } \\
\text { occupations }\end{array}$ \\
\hline 1990 & $26.6 \%$ & $12.5 \%$ & $34.3 \%$ & $12.4 \%$ & $14.2 \%$ \\
\hline 2015 & $37.2 \%$ & $16.3 \%$ & $25.3 \%$ & $7.8 \%$ & $13.4 \%$ \\
\hline
\end{tabular}

(United States Census 2016a; Minnesota Population Center 2016)

Occupation and attainment alone fail to tell the full story of ongoing economic and labor shifts. One main assumption that existed is that since educational attainment rose and a higher percentage of people moved into the management occupation category, the spending power of Indianapolis' citizen also probably grew. This assumption is because, on average, people with higher attainment earn more over their lifetime. The problem is that as attainment grew in Indianapolis, median household income declined (Graph 5.3). Median household income does not tell the full story of how wealth is distributed in a growing economy. Unlike median household income, the income per capita (Graph 5.4) for Indianapolis increased. The simple takeaway is that, when adjusted for inflation, incomes in Indianapolis have decreased for most citizens. There is more wealth in Indianapolis today than twenty-five years ago; it is the distribution of wealth that helps create the contrasting images in Graph 5.3 and 5.4. 


\section{Graph 5.3:}

\section{Indianapolis Median Household Income (2015 Dollars)}

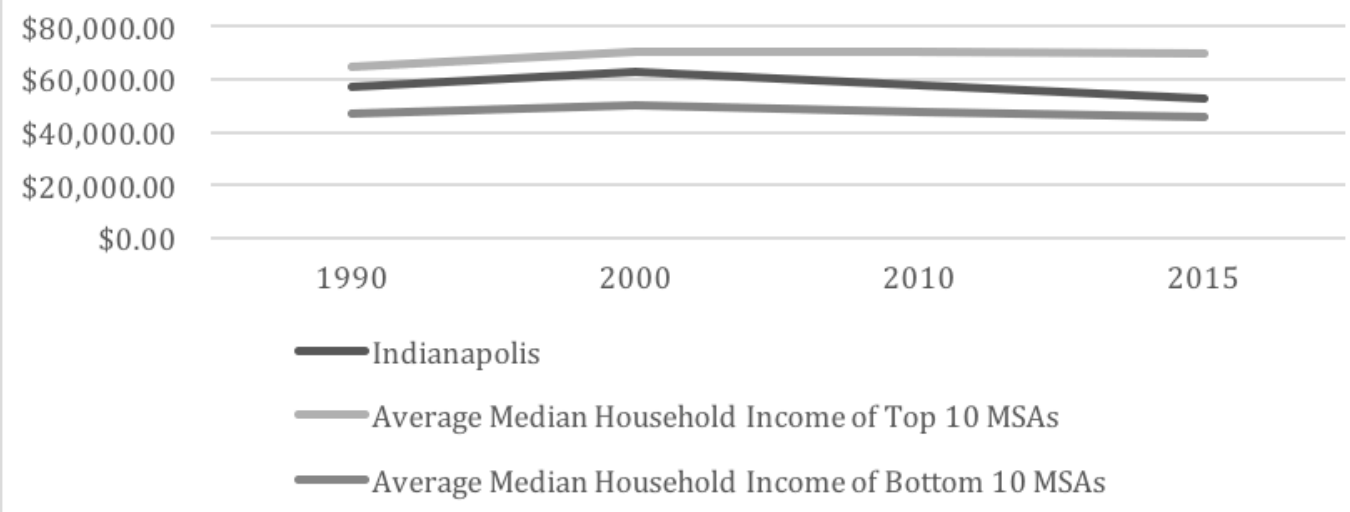

(United States Census 2016a; Minnesota Population Center 2016)

Graph 5.4:

\section{Income Per Capita: Indianapolis MSA (2015 Dollars)}

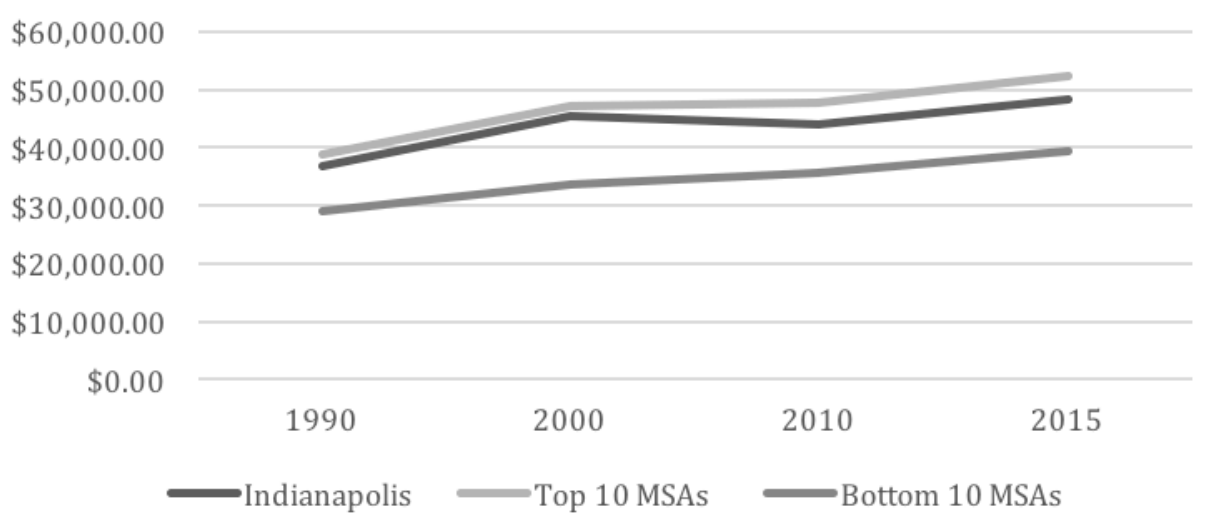

(United States Bureau of Economic Analysis 2017a)

Taken together, the rise of educational attainment, the shift in occupational makeup, and declining household incomes suggest that Indianapolis experienced attainment growth on par with a majority of other American cities but this growth has not 
necessarily lead to economic growth for the average citizen. Despite this, Indianapolis has increased its effort to raise itself in the performance rankings for bachelor's degrees and above. In just the past decade, Indianapolis has been strategic in their attempt to become a more competitive city. To operationalize attainment growth, multiple organizations in Indianapolis are working increase the city's pace of knowledge attainment.

The Goal

The state of Indiana set a goal to increase the percentage of residents $25-65$ years of age with at least an associate's degree to $60 \%$ by 2025 (Indiana Commission on Higher Education 2012). States across the country have set similar percentage goals for increasing educational attainment. What differs from state to state is how they measure attainment. Some states only count associate degrees and above while others also include certificates (Strategy Labs 2016). National organizations like the Lumina Foundation (based in Indianapolis) have advocated for states and municipalities to set higher education attainment goals. Lumina itself has set their own goal, where they are working to raise the national higher education attainment level, including certificates, up to $60 \%$ by 2025 .

As a foundation, Lumina developed the "Community Partnership for Attainment" grant for cities seeking to raise their human capital (Louisville and Nashville both received this grant from Lumina). Lumina Foundation, being local, has invested heavily in the Indianapolis region, with millions of dollars gifted toward attainment and talent. By creating a goal, stakeholders at the state and city levels have a measurable rallying point. These goals can also have a competitive peer pressure effect. As other states and 
cities begin to create goals and policy, the localities who compete with them feel pressured to do the same (or take similar actions). It is this competitive reality that pushes attainment, talent, and skill goals to be a means for both empowering citizens and a more macro-economic good. As a city, Indianapolis has not set its own attainment goal, and as a result, organizations across the city have looked to the state and Lumina's goal as the mark to meet. After conducting interviews with stakeholder organizations across Indianapolis, access, workforce alignment, and attraction emerged as three of the city's largest priorities for meeting their goal. The following sections present how Indianapolis operationalizes each of the three-strategic program focuses.

\section{Strategic Program Focuses}

\section{College access}

The phrase college access encompasses a wide variety of topics around a student's ability to be prepared for college, admitted, and then successful. More and more cities around the country are joining the college access conversation by introducing initiatives and policies aimed at breaking down access barriers. Cities have done this by adding and increasing the number of college counselors in schools, by creating collegegoing community events, and bringing multiple sectors together to help lower the economic cost of higher education.

Statewide, the Indiana Commission for Higher Education has created the $21^{\text {st }}$ Century Scholarship. According to the Commission, the scholarship:

Provides students up to four years of undergraduate tuition at any participating public college or university in Indiana. If you attend a private college, the state will award an amount comparable to that of a four-year public college. If you attend a participating proprietary (for-profit) school, the state will award a tuition scholarship equal to that of Ivy Tech Community College of Indiana (Indiana Commission on Higher Education 2017). 
To be eligible, students must meet some requirements including family income. In the Indianapolis region, the Central Indiana Community Foundation (CICF) has led the effort to increase both the enrollment and retention of students into the scholarship program. "We raised the percentage of students, eligible students that are enrolling in seventh and eighth grade but also raising the level of awareness in their community that this is an important scholarship" (CICF Interview). By raising the percentage of students taking part in the scholarship program, CICF has been able to leverage their own scholarships better. By combining $21^{\text {st }}$ Century Scholarship dollars and CICF's various scholarships, students can receive financial support beyond tuition to the full cost of attendance. The collaboration between the $21^{\text {st }}$ Century Scholars Program and CICF has allowed for a mutually benefiting arrangement "...We sit on their scholarship advisory council. We work closely and try to mirror each other's efforts and leverage each other's efforts whenever we can" (CICF Interview). Here, CICF and the $21^{\text {st }}$ Century Scholarship program lean on one another to address the cost burden faced by students. Beyond their scholarship work, and their work to support the $21^{\text {st }}$ Century Scholarship, CICF has also been involved in support of Marion County Promise.

Marion County is the economic hub of the Indianapolis MSA and is the location of downtown Indianapolis. The Marion County Promise is an affiliate of a larger statewide organization, Promise Indiana. While one serves a larger geography, their purposes are the same. Marion County Promise works "to ensure every child has the assets, champions, and community support to pursue their dreams" (Marion County Promise, 2017). The initiative is new, "we (CICF) support it financially, support operations, so that they can get off the ground and going" (CICF Interview). The program 
targets students entering kindergarten. Participating families create a College Choice 529 account; essentially, these accounts allow individuals to invest money for their child's future post-secondary expenses. Promise Indiana and Marion County Promise believe that students who have saved dedicated funds for college, take part in college-focused programming, and experience hope through the community will be more likely to go onto higher education (Promise Indiana 2017). By looking more holistically at the student along with their family, CICF sees this work as reaching across their three strategic areas: inspiring places, family success, and college readiness and success.

CICF's recognition of the unequal barriers students face permeates through their work and creates a policy environment that recognizes the intersectional realities experienced by students on their educational journey. Looking to the future, Mayor Joe Hogsett of Indianapolis has announced the creation of Indianapolis Promise. A task force is set to meet throughout 2017 and develop a report about the scope and steps going forward. While growing in popularity, cities who have created their promise programs often guarantee tuition to a select group of partner institutions for all (or a near all) students in their municipality. Depending on how it is structured, stakeholders in Indianapolis see the newest promise to be a game changer for students and the city. Just breaking down access barriers is not enough for Indianapolis. The city recognizes that the supply of talent, attainment, and skills supplied by the educational system need to align with workforce demands.

\section{Workforce development}

When cities discuss "the workforce," often it is a binary policy problem where two forces, supply and demand, fail to fit together. Federal legislation such as WIOA, 
discussed in previous chapters, is one example of how the federal government, in cooperation with states, has worked to tackle the issues surrounding America's workforce. Cities receive less and less funding every year from WIOA, at the same time that U.S. cities face increased competition both domestically and internationally for all forms of capital. What this has meant is that cities must use what little resources they get from the federal government, and their states, along with private investment, to both understand and develop supply strategies for meeting the demand of the twenty-firstcentury economy, which is highly skilled, high attainment individuals.

Three organizations in Indianapolis have come together and created the Indianapolis Regional Workforce Partnership to help ensure the supply of labor in Indianapolis aligns with the workforce needs of industry. These organizations are EmployIndy, the Region 5 Works Council, and the Central Indiana Corporate Partnership (CICP). EmployIndy is the Workforce Investment Board for Marion County under WIOA. The Region 5 Works Council covers nine counties in central Indiana (eight of which are in the Indianapolis MSA, including Marion County). In total, the state of Indiana is broken into eleven work councils; these councils have statutory authority help develop a career, technical and vocational education curriculum within their region. The third organization, CICP, "brings together chief executives, foundations, and universities into a strategic and collaborative effort dedicated to the region's continued prosperity and growth" (Central Indiana Corporate Partnership 2017).

Within the partnership, each organization has their own designated "lane"; this relationship allows the organizations to work collaboratively and within a defined role. Figure 5.1 illustrates each of these lanes. The bottom portion of the figure shows the 
addition of two more stakeholders, city government and the Indianapolis Chamber; their role is to serve as policy advocates and to help attract individuals usually with high human capital.

The function of the partnership can be broken down even further. EmployIndy and Region 5 overlap, they do a lot of the same low to middle-skill development; the organizations even share several board members. Alternatively, the Central Indiana Workforce Development Initiative (a CICP program), which recently became its own organization called Ascend Indiana, focuses on high attainment individuals. What this simply means is that Indianapolis, through the regional workforce partnership, is working to raise the city's pool of human capital through implementing EmployIndy's Workforce Ecosystem and through the creation of Ascend Indiana by CICP.

Figure 5.1: Indianapolis Workforce Partnership
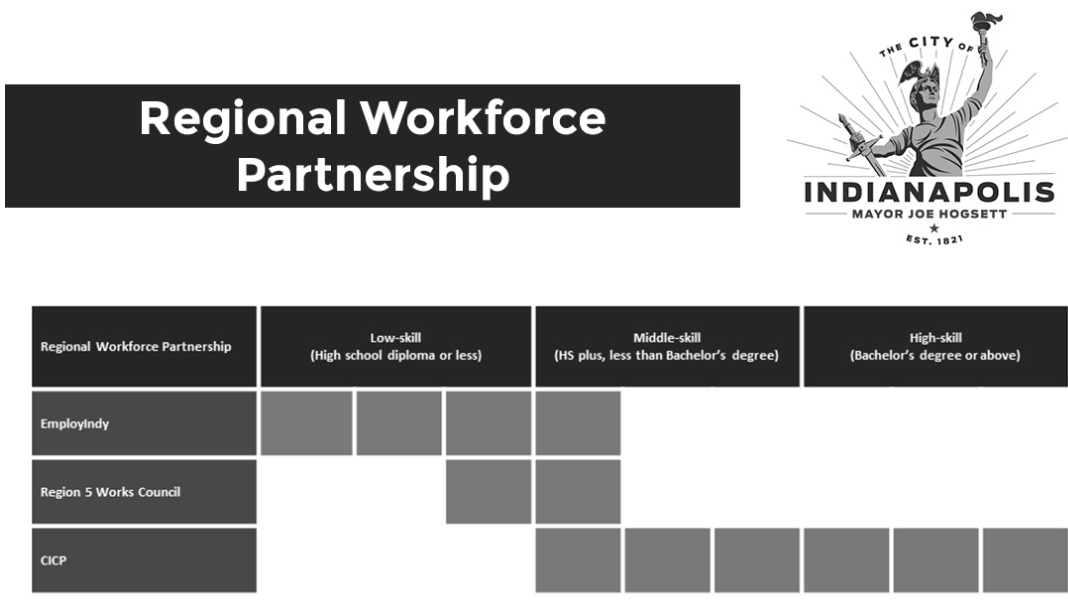

EmployIndy:

As the Workforce Investment Board for Marion County, EmployIndy has a variety of statutory requirements because of WIOA. Their primary mission is to engage 
those currently not working, seeking employment, and lacking the necessary skills to take a step toward an economically stable job path while also engaging with local businesses regarding labor shortages and demand. Under the leadership of a new Chief Executive Officer, starting in the summer of 2016, EmployIndy has examined each of their practices strategically and developed a strategic plan to align workforce and talent initiatives throughout Indianapolis. A result of this envisioning process is shown in Figure 5.2. The workforce ecosystem features a three-step process: helping people obtain a job, helping people obtain a better job, and then helping people find a career. From top to bottom, the various community stakeholders' roles are displayed:

Our vision of coordinating service delivery, not just as required by the federal law between those required partners, but also all the communitybased partners that we think really need to be part of our larger workforce ecosystem. - EmployIndy Interview

Building a highly interacted workforce system is seen by EmployIndy as strategically necessary. Their network thinking sees workforce as a citywide and region-wide policy problem. As EmployIndy looks forward, they are seeking to expand their collaboration to community-based organizations, high schools, and career technical education providers, which will allow their strategic plan (Figure 5.2) to be vertically integrated. As an organization, they recognize the complexity and volume of work this strategy will involve. To take this work to a more manageable size, they chose five underprivileged neighborhoods to prioritize. As an organization, they look at these neighborhoods from a multilevel perspective and attempt to recognize the various challenges faced by individuals in these neighborhoods. EmployIndy intends to meet the neighborhoods where they are, highlighting their assets and bringing citywide partnerships to address talent at the community level. It is important to note that EmployIndy is not the only 
workforce development board within the region; WorkOne Region 5 serves the counties that surround Marion County. Like all workforce boards, WorkOne Region 5 helps to connect businesses and individuals within their geographic space to opportunities for mutual advancement.

\section{Figure 5.2: Employ Workforce Ecosystem}

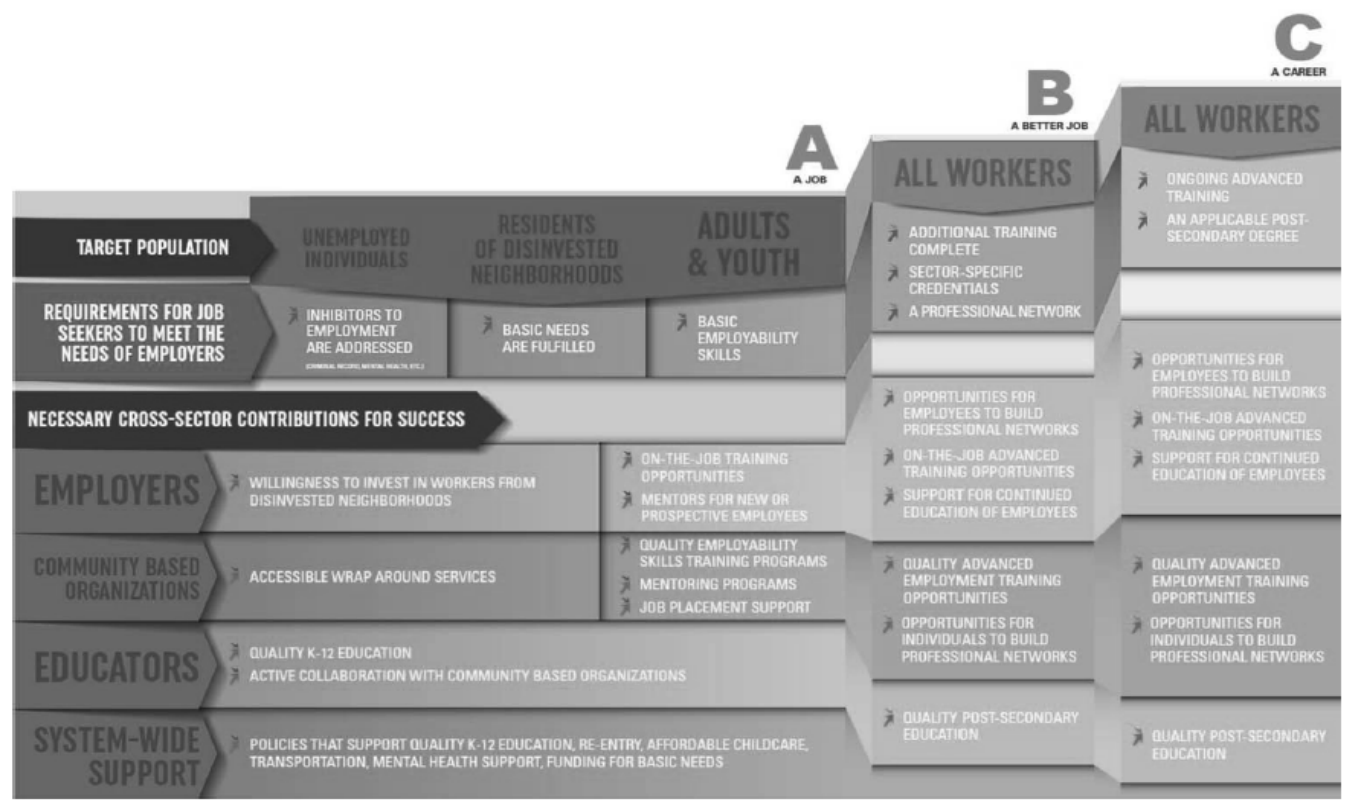

The integration and implementation of the Indianapolis workforce ecosystem are in its early stages. The goal is that by reconfiguring how EmployIndy both delivers their training and educational programs while strengthening collaboration across the city, Indianapolis can be a place of targeted and strategic workforce development. EmployIndy is not alone in attempting to create a smarter workforce ecosystem, of which human capital is at the core. As mentioned previously, Ascend Indiana focuses on the higher end of the skill continuum within the workforce partnership. While not structurally connected, EmployIndy and Ascend Indiana are relationally connected. The 
organizations speak to each other on a regular basis; seeing their work as tied together and mutually benefiting.

We are always talking. We text back and forth almost daily, on the work each of us is doing - EmployIndy Interview

The challenge is, the gap between open jobs and local talent continues to widen. By 2020, nearly a million jobs in Indiana are anticipated to go unfilled- Ascend Indiana

Stated simply, the labor market is complicated. Whether fresh out of postsecondary or finishing up a degree, individuals face a difficult time with aligning their interest to a job and companies often have a difficult time finding the "right" employees. For Indianapolis, Ascend Indiana launched in the fall of 2016 to fix this problem. They see the mismatch between an individual's and their alignment in the workforce as a result of an "asymmetry of information." Ascend's mission is to "bridge the gap between employers and talent in Central Indiana" (Ascend Indiana Interview). To do this, they use a "tech-enabled recruitment effort." Plainly, through a variety of means, the software provides both the job seeker and the employer with more information than the average job board. From there, the software along with Ascend's recruitment team prescreens candidates who are then sent to a company's hiring manager. In effect, the aim of this system makes the hiring and talent process more efficient. Another intended outcome, through their network building, is developing "a clear picture of demand and a very clear picture of supply" (Ascend Indiana Interview).

By having a clear picture, Ascend says that they have created talent pipelines between higher education and industry. Part of their work involves developing individualized plans for companies that connect them to educational 
providers to have a customized labor supply pipeline. The work done by Ascend exemplifies a growing integration between credential suppliers and the industries that are demanding high attainment credentials. This network and integration are beyond local geographies. Ascend is looking to expand its base of recruitment of talent for Indianapolis by taking this model to individuals around the region specifically, to those who are looking for a place to locate after college or a place to relocate after they have been in the workforce. As a result, Ascend's goal is both strengthening Indianapolis' ability to retain high human capital and also to attract talent to the region. By attracting and retaining this labor pool, Indianapolis can meet a precondition for growth in the knowledge economy. Ascend recognizes this and hopes to make the Indianapolis region a more attractive place for business through a larger and more efficient high human capital labor pool:

We want employers to not only think of Indianapolis and Indiana as a place that has a low cost of labor, low cost of office space, low taxes, we want it to be a place where we're also taking advantage of the incredible higher education infrastructure that we have in Indiana and throughout the Midwest and say, you're going to find the people that you need here, and you're going to save money in locating here, and by the way, the investments down town, meaning that this is going to be a more attractive place. - Ascend Indiana Interview

Here, attraction moves beyond being seen as a means for increasing the growth of high attainment individuals but also extends to creating a pathway for attracting businesses. Through the development of innovative and novel strategies that tackle the supply and demand of high capital, Indianapolis has the potential to increase their rate of attainment and move closer to the top attainment cities shown in Graph 5.1 and 5.2. Additionally, because of the Regional Workforce 
Partnership and the strong relationship with EmployIndy, Ascend can focus on a particular segment of the skills continuum. As a result, according to the language used by the organization, the EmployIndy partnership creates a workforce ecosystem that is designed to meet the needs of individuals, industry and the city's economic potential; to do this, the organizations recognize that they must attract high human capital. Ascend is part of this effort through their expanding network of higher education partners, but they are by no means alone in working to attract high human capital to Indianapolis to increase the city's attainment pool.

\section{Retain and attract}

The findings show that access and workforce development are two keys for Indianapolis as the city seeks to develop and retain high human capital. Attraction is the third piece of the pie. Ascend attracts talent from regional schools and attempt to do so through a workforce alignment focus. For Indianapolis, and more focused Marion County, the true driver of talent retention and attraction, is IndyHub, a local nonprofit organization. Established in 2005, their mission is "focused on both attraction and retention of talent to Indianapolis. We focus on the demographics of 20 and 30 somethings" (IndyHub Interview). When the organization was founded, "we focused intentionally on retention piece knowing that until we had a really strong community, and there was a strong community, but a strong recognized community that people who wanted to stay here and there was a really vibrant community, that attraction would be somewhat futile" (IndyHub Interview). 
As an organization, IndyHub has worked to operationalize their mission by filling a unifying void within the city. One interviewee stated that, "there needs to be a unifying voice" (IndyHub Interview). They have done this by bringing together organizations across the city in a de-siloing method in hopes of creating community through collaboration. As the quote cited above suggests, IndyHub sees that by creating a sense of connectedness and strengthening ties across organizations and groups that retention and attraction will happen more organically. It was this community building that they chose to focus on exclusively over their first nine years in operation. The result is that through event programming, partnerships, and advocacy, IndyHub has in many ways made themselves a large asset in the creation of Indianapolis being a knowledge city. Their recently launched attraction campaign, called No Means City, partners with businesses, neighborhoods, and organizations across the city to share the opportunities offered in Indianapolis.

It is important to note that IndyHub's mission is not explicitly focused on high attainment individuals. Their connection to the attainment race is more abstract than organizations whose mission it is to educate and develop talent, but this does not make them less important to Indianapolis' mission to increase the share of its population with some form of a higher education credential. While K12 improvement is important to any city's talent pipeline the returns are longer term; Indianapolis knows that it must also attract talent to the region to truly raise themselves to be a knowledge city. 


\section{Summary}

Indianapolis is leading other metropolitans in Indiana; they are on track to surpass the statewide goal of $60 \%$ post-secondary attainment by 2025 . While citywide attainment growth is something to be celebrated, unless the city's growth outpaces historically high attainment cities, then in regard to performance rankings little movement has occurred. Interview findings show how organizations perceive their work. The chapter cannot make claims as to whether these efforts are causing changes in outcome. As a region, the Indianapolis MSA is tackling their attainment shortfalls from every angle. Going forward, the success of these various efforts will be measured by their collective pace. These findings also highlight that when it comes to attainment and the links between the supply of human capital and its demand, cities must engage a wide variety of community stakeholders. Chapter 8 will examine common perceptions and ideas of why cities work to raise their human capital; the chapter will also discuss whether there are commonalities across cities regarding who is engaged in human capital efforts. Three strategies emerged from the work going on in Indianapolis to increase their share of the population with post-secondary attainment: develop, retain, and attract. 


\section{CHAPTER VI: LOUISVILLE}

Nestled on the Ohio River between Indianapolis, Cincinnati, Nashville, and St. Louis is the largest city in the Commonwealth of Kentucky. The Louisville MSA has a population that straddles two states and has over 1.2 million people, half of which live in the principal city. $27.3 \%$ of the Louisville MSA holds a bachelor's degree or higher, while $30.2 \%$ have at least some college or an associate's degree (United States Census, 2016a). These percentages place Louisville near the bottom in the study's larger sample; yet, Louisville plays a vital role in the U.S. economic system. As one of the largest export hubs in the U.S., Louisville has a unique competitive advantage related to its connectivity to the global market. Around \$8 billion in exports left Louisville in 2015 (United States Census, 2016a).

Louisville faces multiple challenges in remaining competitive in the global market, including $14.5 \%$ of the population living below the poverty line, a labor participation rate of $65 \%$, an aging population, and just $5 \%$ of its population being foreign-born (United States Census, 2016a). Instead of seeing these challenges as an anchor holding the city back, those interviewed see these as opportunities for investment and, yes, growth. Organizations, government, and various entities have taken on these challenges through innovative ideas around creating and supporting a citywide collegegoing culture. 


\section{History}

The founding of what is known today as Louisville, Kentucky took place in 1778 at the Falls of the Ohio (Yater 1979). Historians have cited the location of Louisville as both accidental and planned. As time moved forward, Louisville grew from not just a stopping point on the Ohio River, but a thriving manufacturing town and meatpacking center (the country's second largest in 1850) (Yater 1979). By 1850, Louisville was the country's tenth largest city (Yater 1979), signaling the city's rise of importance to the nation at the time. Also in 1850, the Louisville and Nashville (L\&N) Railroad was chartered connecting Louisville for the first time to the growing railroad infrastructure. The end of the Civil War and the start of Reconstruction was a time of an economic and population boom for the city. Constructed in 1870, the Louisville railroad bridge, across the Ohio River, connected the North and South rail networks making Louisville more central to the growing industrial corridor. By 1900 , Louisville was the $18^{\text {th }}$ largest city in the United States (larger than Indianapolis, Nashville, and Atlanta) (United States Census Bureau 1998).

At the start of the twentieth century, Louisville remained a manufacturing city but lacked the continuing population and economic growth experienced by other American cities. As the century progressed, Louisville never lost its manufacturing identity. Even as the city fought through the Great Depression and both World Wars, Louisville began to sprawl causing the central city to be less of the hub it had been. In effect, this created two Louisville's (the city and the county). This realization of two Louisville's is key to understanding both the history of Louisville and plateau of growth it experienced in the twentieth century. It would not be until the city and county merged in 2003 that 
Louisville could once again be able to brand itself as one of the country's largest metropolitan hubs. The region is referred to as Greater Louisville by locals. The Ohio River creates a division within the region from both a policy and systems perspective. Unlike the other two case cities, Louisville's knowledge network splits between two states. While many organizations work with their counterparts across the river for mutual reinforcement and support, the two-state geography of the city presents its own set of challenges.

The Numbers

Louisville's history paints a picture of great growth but also decades of stagnation. Over the past decade, the city has seen a revitalization of its urban core. Like many American cities, including Indianapolis, the past two decades were identity shifting. As manufacturing jobs moved away, Louisville has held onto its manufacturing roots but has worked to transform itself into a competitive global city. To be a competitive global city, Louisville perceives that one of the city's greatest needs is to strengthen human capital.

Since 1990, Louisville has increased the share of its population with some college/ associate degrees above even the high attainment cities discussed in previous chapters (Graph 6.1). If Louisville were able to convert even a fraction of this population into bachelor's degrees or higher, this could have direct impacts on the city's competitiveness in attracting and retaining businesses which rely on workers with at least a bachelor's degree. Currently, the problem is that Louisville lags behind historically high human capital cities. Over the past twenty-five years, the Louisville MSA has not been able to close the gap between cities, which have historically been ahead of the city in the 
high human capital game (Graph 6.2). While this could impart a negative conclusion regarding Louisville's efforts, the reader should focus on how Louisville's growth compares relatively. The takeaway is that while Louisville has been unable to elevate the city's position in the national attainment race, like Indianapolis, the city has not fallen behind in the race. These results suggest that Louisville, as a region, has made gains but must look at alternative strategies if they wish to make up ground in the race for high human capital.

\section{Graph 6.1:}

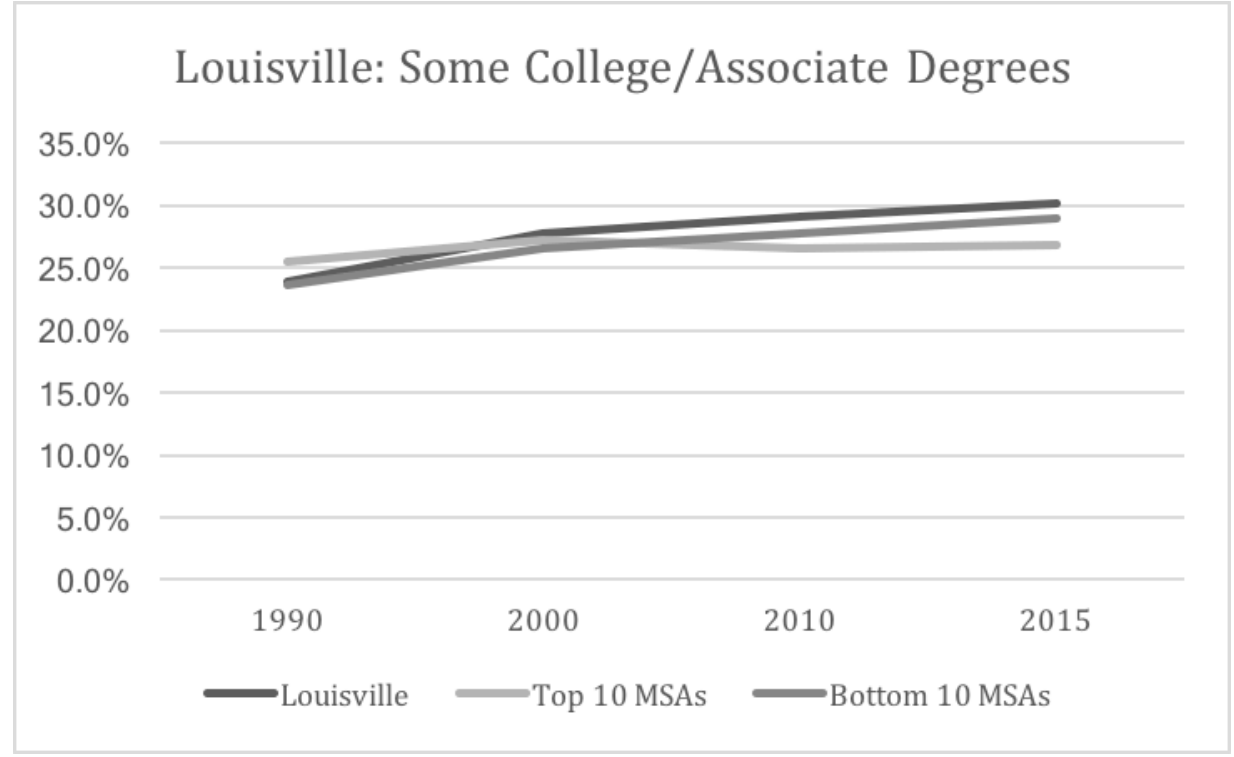

(United States Census 2016a; Minnesota Population Center 2016) 


\section{Graph 6.2:}

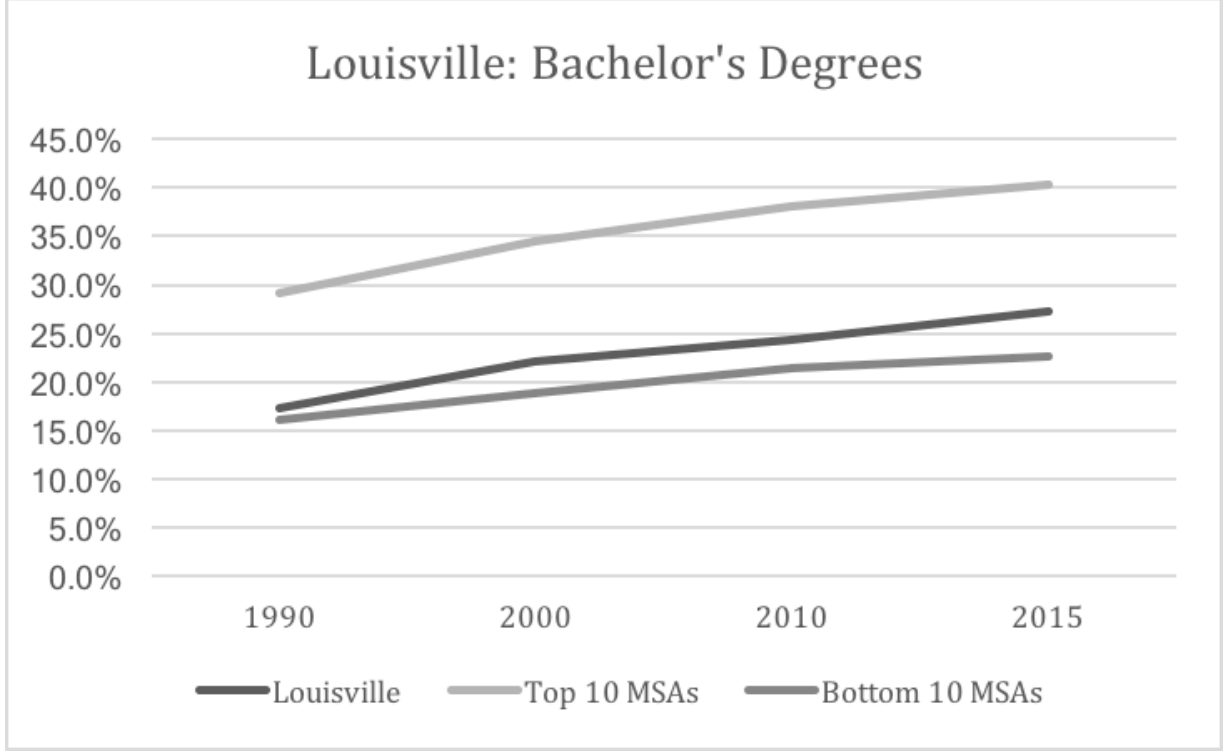

(United States Census 2016a; Minnesota Population Center 2016)

During the same period that Louisville experienced a rise in higher education attainment, the city also experienced shifts in its occupational make-up. One note of caution, the results in Graphs 6.1, Graph 6.2, and Table 6.1 should not be seen as causally related. With the rise of automation and the continued loss of blue collar jobs, more people have been pushed out of various labor sectors. Since 1990, Louisville has seen an increase of $10 \%$ in share of its population in the management, business, science, and arts occupations. Sales and Office occupations saw the larger decrease (eight percent). Natural resources, construction, and maintenance occupations saw the second largest decrease losing five percent of the share of the occupational make-up. The proportion of jobs in the overall labor market decreased. These occupational shifts look a lot like the shifts experienced by Indianapolis during the same period. 
Table 6.1:

\begin{tabular}{|r|r|r|r|r|c|}
\hline \multicolumn{2}{|c|}{ Louisville Occupational Make-Up } \\
\hline & $\begin{array}{c}\text { Management, } \\
\text { business, science, } \\
\text { and arts } \\
\text { Occupations }\end{array}$ & $\begin{array}{c}\text { Service } \\
\text { occupations }\end{array}$ & $\begin{array}{c}\text { Sales and office } \\
\text { occupations }\end{array}$ & $\begin{array}{c}\text { Natural } \\
\text { resources, } \\
\text { construction, and } \\
\text { maintenance } \\
\text { occupations }\end{array}$ & $\begin{array}{c}\text { Production, } \\
\text { transportation, } \\
\text { and material } \\
\text { moving } \\
\text { occupations }\end{array}$ \\
\hline 1990 & $24.10 \%$ & $13.10 \%$ & $33.00 \%$ & $12.90 \%$ & $16.90 \%$ \\
\hline 2015 & $34.80 \%$ & $16.00 \%$ & $24.80 \%$ & $7.70 \%$ & $16.60 \%$ \\
\hline
\end{tabular}

(United States Census 2016a; Minnesota Population Center 2016)

One would think that since Louisville grew both its highly educated population and the percentage of its population working in "management, business, science and arts occupations," that Louisvillians would have also experienced income growth. However, Graph 6.3 (after controlling for inflation) shows that Louisville's median household income has decreased since 2000. Graph 6.3 also shows that the lack of median household income growth was experienced in Louisville for all educational attainment. Graph 6.4 shows the change of income per capita over the same time span. The diverting income per capita between the high and low educated MSA's is historically consistent with previous findings (Gotlieb and Fogarty 2003). Louisville's growth pattern, in particular, conforms more closely to low attainment cities. 


\section{Graph 6.3}

\section{Louisville Median Household Income (2015 Dollars)}

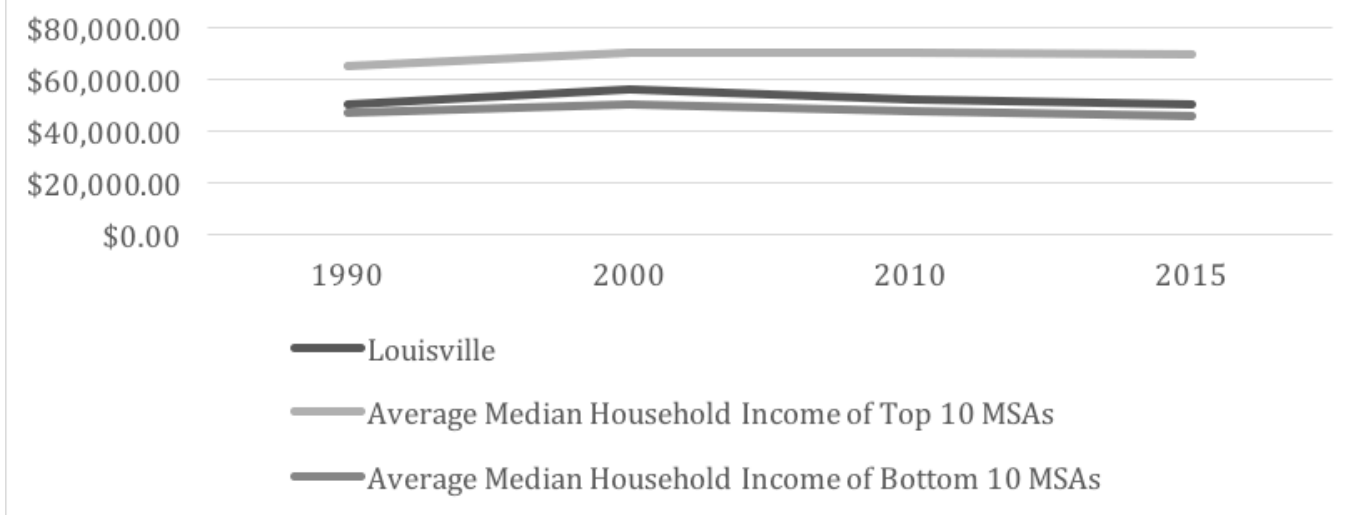

(United States Census 2016a; Minnesota Population Center 2016)

\section{Graph 6.4:}

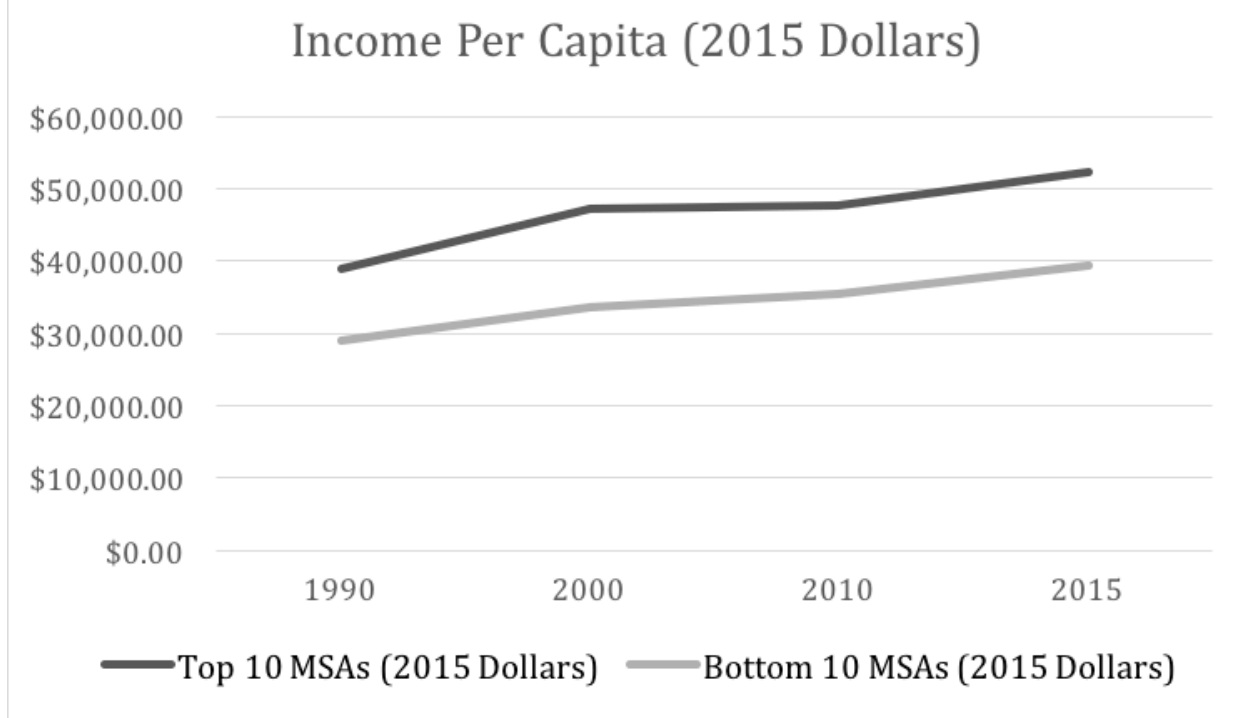

(United States Bureau of Economic Analysis 2017a)

Recognizing that rising educational attainment in Louisville and a shifting labor market has not helped to increase household inflation-adjusted incomes, how is Louisville rationalizing its drive for continued competitive advancement? To answer this 
question, how Louisville is actively working to raise attainment and how Louisville is fueling its educational attainment goals is discussed.

\section{A City Committed to Fostering Educational Attainment}

Leading up to the merger of city and county government in January 2003, the Brookings Institute helped Louisville conduct an assessment regarding the strengths and weaknesses of the city. The goal of this assessment was to capitalize on the forthcoming merger. One of the conclusions was that Louisville was behind benchmarked cities regarding being a "competitive environment." Education was one of the key measures against which Louisville was not stacking up to their benchmarked counterparts. Also, other reports from both public and private groups around the city began to highlight Louisville's need to strengthen its human capital. In 2008, the mayor created the "Mayor's Education Roundtable."

In the summer of 2009 , city leaders collectively decided to set a goal that would move Louisville into the top tier of peer cities. To do this meant that the city needed to add 55,000 Degrees. Questions remained on how to structure such an initiative. In May 2010, members of the Mayor's Educational Roundtable signed the Greater Louisville Education Commitment. The commitment outlined five key objectives and the 55,000 degrees goal (Mayor's Educational Roundtable 2010)

- Create and support a college-going culture;

- Use business community's unique points of leverage to accelerate attainment;

- Prepare students for success in college, career, citizenship, and life;

- Make post-secondary education accessible and affordable; and

- Increase educational persistence, performance, and progress. 
By October of 2010, the original signatories evolved into the initial board of what is the organization "55,000 Degrees" and the organization launched into action. At the time of the launch, the city raised over one million dollars to sustain the initiative for the first three years. While focused primarily only on Jefferson County (the core county in the Louisville MSA), across the river in Indiana, Education Matters has done similar work focused on raising attainment in five southern Indiana counties. Both 55,000 Degrees and Education Matters are tied to their Community Foundations.

Additionally, both sides of the river were recipients of the Lumina Foundation's Community Partnership for Attainment grants. The award sought to help regions and cities expand post-secondary attainment. Over the last decade, the city of Louisville and region have benefited greatly from grants, support, and recognition from large national organizations. By plugging into a national network, Louisville has been able to both share and learn best practices. Within the Louisville MSA, the city of Louisville has led the way in fostering inter-city collaboration.

The city's Cradle-to-Career framework has provided a blueprint, which sees attainment as multi-leveled and long-term (Figure 6.1). Most importantly, the Cradle-toCareer model recognizes that each step of the attainment process builds on the one before it. A failure at one-step can lead to a systematic failure throughout the Cradle-to-Career pipeline. 55,000 Degrees sees this systematic method of working as stronger suited for supporting equity within the city, "Students of color, immigrants, those with disabilities, low-income students face many barriers, and that is absolutely what has led us to this more cradle-to-career focus" (55,000 Degrees Interview). This systematic way of thinking attempts to link together the various institutions and organizations seeking to 
break down such barriers. Often, organizations fix what amount to symptoms of the failures earlier in the pipeline. For Louisville, as with the other two case study cities, the strategic findings focus on the end of the Cradle-to-Career pipeline because of the immediate demands placed on a supply of high human capital labor.

\section{Figure 6.1:}

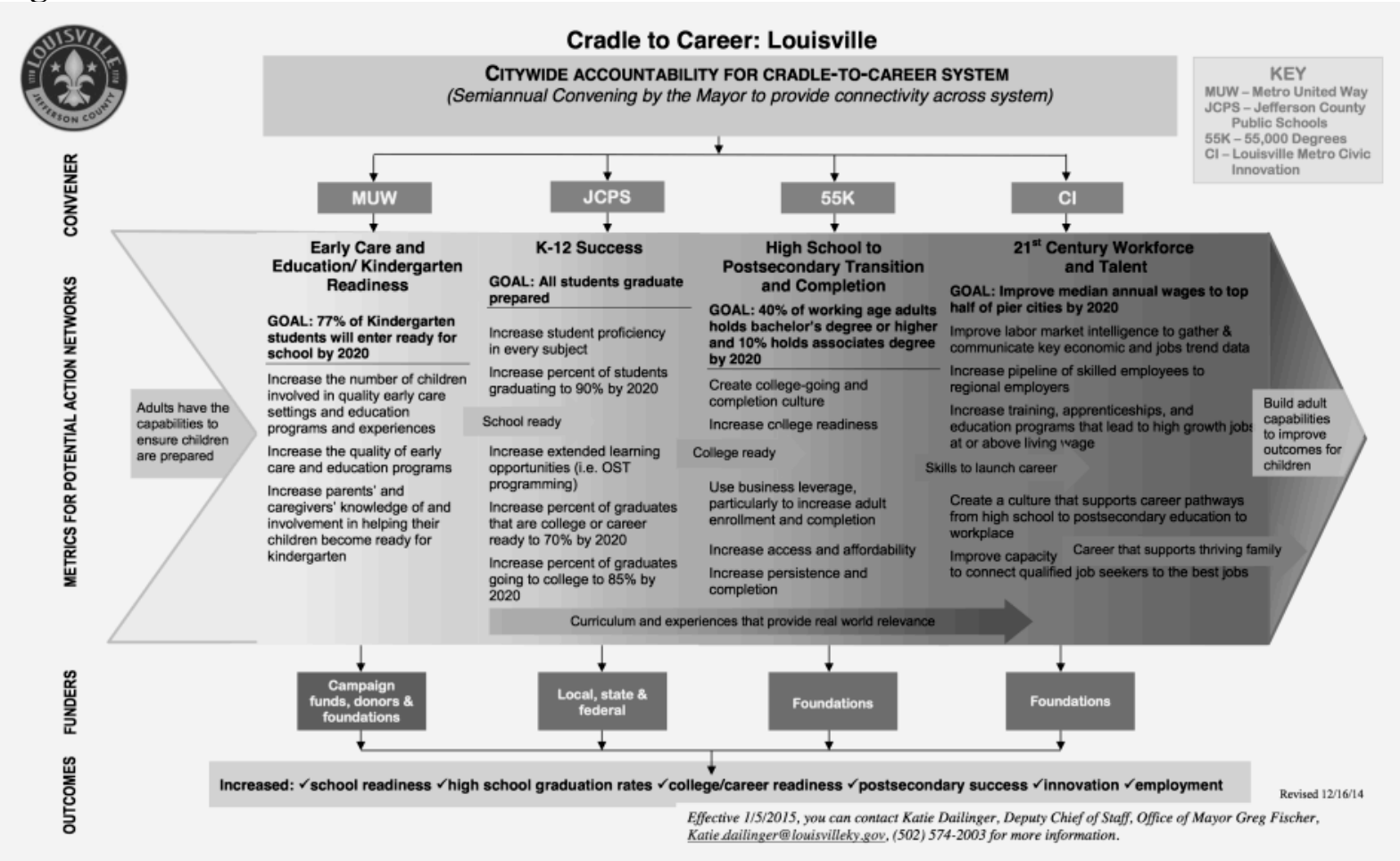

(Louisville Metro Government 2014)

\section{Strategic Program Focuses}

\section{Establishing a college-going culture}

For both the city of Louisville and the regional MSA, 55,000 Degrees has been a central convener, a backbone organization, creating a collective impact mindset behind attainment in Louisville and specifically in Jefferson County (known as Metro Louisville this is where the consolidated city resides). Of focus in this chapter is the operationalizing of attainment and talent development within Louisville. To understand Louisville and the value added to the region by 55,000 Degrees requires recognizing them as a backbone 
organization and how their work impacts the city. 55,000 Degrees subscribes to a framework known as collective impact theory. Collective impact initiatives are:

A long-term commitment by a group of important actors from different sectors to a common agenda for solving a specific social problem. Their actions are supported by a shared measurement system, mutually reinforcing activities, and ongoing communication, and are staffed by an independent backbone organization (Kania and Kramer 2011).

For Louisville, 55,000 Degrees is the backbone attainment organization. Collective impact differs from isolated impact which is a more traditional model used by organizations to tackle social problems. In isolated impact, the solution is "embodied within a single organization, and is combined with the hope that the most effective organizations will grow or replicate to extend their impact more widely" (Kania and Kramer 2011). Isolated impact often leads silo thinking leading to solutions that can work at odds and hurt systematic efficiency. Proponents of collective impact argue that this model de-isolates the non-profit sector by allowing for cross-sector coalitions (Kania and Kramer 2011).

Within Louisville, these cross-sector coalitions exist both organically and structurally as part of the mission to reach the city's attainment goal. Within this context, the term organically means that the coalitions take place due to the personal relationships of employees who are part of Louisville's workforce system organizations. While 55,000 Degrees is the official goal-oriented organization, a sense of shared ownership exists across organizations. Structurally, and more formally, due to the Mayor's Cradle to Career framework, and co-branded initiatives such as the city's Degrees Work program, organizations across the city share cross-sector ideas, tasks, and solutions. While creating a city-wide college-going culture seems abstract, the culture itself has helped in creating 
concrete collaborative initiatives and programs. Looking at what the city has done regarding college access provides examples of such work.

\section{College access}

Action Networks have been one means of working to bring various stakeholders together. These networks organize around a community problem about attainment; one of these networks is the College Transition Action Network (CTAN). The network addresses summer melt or the number of students who in the spring of their senior year of high school say they are going to college but do not make it to campus in the fall. The purpose of this effort is to decrease melt and thereby increase the number of students going to college, to accomplish this the network has made strategic efforts:

[The Network] developed a summer coaching program that we have run for three summers now. The partnership has run, when I say, "We," not just 55,000 Degrees although we end up being kind of the staff that make it happen in many cases. That has served, over 1,000 kids over the last two years, three years and it's just about pairing them with a near peer mentor to help them with that transition so when they get that thousandth piece of paper in the mail or over email they've got somebody to talk to that's like them and less intimidating. - 55,000 Degrees Interview

While this work does not have an immediate impact on attainment, this type of collaborative action has the potential to break down access barriers by helping students overcome the various hurdles of higher education. Work like CTAN is doing, and the support received by this network from 55,000 Degrees, is an example of how a city can raise attainment, break down access barriers, and create citywide ownership around attainment. The city recognizes that to fulfill its desired attainment goals, and to do so in a relatively short amount of time, requires looking beyond the traditional educational pathway. 
Adult education has been and continues to be at the center of Louisville's human capital efforts. In Mach 2017, Louisville Metro Government acknowledged, "more than 91,000 people in the Louisville area have some college credit but still lack a degree. Many of them work at companies that offer tuition-reimbursement programs and other educational benefits, but often struggle to utilize these benefits" (Louisville Metro Government 2017), To address this problem the city formalized the creation of Degrees Work. While the program has existed for several years under various iterations, in early 2017 the city of Louisville sponsored the start-up of Degrees Work. Day to day, the program is operated by KentuckianaWorks, which is the Workforce Development Board for Louisville. Currently, there are three participating companies/organizations; the benefit to the organizations is that the program brings college coaches to their workplace for their employees. The program helps the organizations create a college-going culture. Through this program, Degrees Work is supporting the mission of 55,000 Degrees by creating partnerships between higher education institutions and industry and helping to meet the human capital goals of the city.

Across the river in Southern Indiana, to help achieve Indiana's statewide goal of $60 \%$ higher education attainment by 2025 , Education Matters is doing similar work with adult education. The organization acts as a resource for adults in their five-county area, by providing support to individuals for choosing the right higher education institution and understanding the various avenues that are available financially to be able to obtain a degree. Education Matters acts as both a support networker and connector between adults desiring to go to college and higher education institutions. For the Indiana portion of the 
Louisville MSA, Education Matters serves as an attainment resource that helps to break down the barriers faced by adults who are seeking to complete a college degree.

Much of the work that occurs in regarding college access focuses on breaking down bureaucratic processes and helping people gain knowledge about the college process. The city sees a need going forward to take college access further by helping prospective students with the financial piece of the puzzle. 55,000 Degrees, going forward and beyond its 2020 mission, is strategically looking at how the city can break down the cost barriers associated with college. At the time of writing this dissertation, 55,000 Degrees has spent nearly a year investigating the best steps forward for the city of Louisville. They have looked at national organizations and studied cities who have "Promise" programs. These programs (like the one discussed in the previous chapter that the city of Indianapolis sought to explore) either fully guarantee the cost of attendance or at least the cost of tuition for students within a geographic space and/or meeting certain qualification criteria. This "begins to say a message: college is for everybody. Even though we say that people who come from low-income backgrounds just don't believe it" (55,000 Degrees Interview).

The intentions behind these promises are to tell and show the next generation of students that their city and community want to help in ensuring equal access and opportunity. Although this research does not provide evidence of any outcome regarding whether this is happening, the city perceives that work like this will create community around a shared college-going culture. While initiatives and programs such as these have a long-term return on investments, more cities (including Indianapolis) are exploring the 
tuition promise structure for both creating equity and showing to the market that the city is serious about growing its identity as a knowledge city.

\section{Workforce development}

There is a dialogue taking place between education providers, government, and private industry. This dialogue helps to facilitate and prioritize the demand and supply of the labor market. Because of WIOA, this dialogue is taking place in cities across the country. For Louisville, there are two workforce development boards, KentuckianaWorks serves the Kentucky portion of the Louisville MSA and WorkOne Southern Indiana serves the Indiana portion. Both development boards have traditional WIOA career centers. KentuckianaWorks has created two specialized career centers, one focused on health, and the other focused on manufacturing. The goal of this approach was "to work with groups of employers in the same sector and work backward from that" (KentuckianaWorks Interview). By bringing stakeholders within each sector to the table, face to face, KentuckianaWorks can adapt the strategy of the sector career centers and better support individuals seeking to increase their knowledge base. By bridging this gap, KentuckianaWorks is capable of seeing holes in the talent pipeline and be a facilitator between those working to help individuals increase their knowledge and those who are seeking to hire that labor.

Apart from the more traditional job placement and training, KentuckianaWorks is actively involved in supporting the mission of 55,000 Degrees by helping people obtain a higher educational degree. The KentuckianaWorks College Access Center (KCAC) supports individuals on both sides of the river, supplying resources and support to both traditional college-aged students and adults seeking to go back to school. KCAC helps 
them navigate the college-going process by providing in person and online support from the admissions process, to financial aid and selecting a major. While this work also fits in the college access section discussed above, it is included here to highlight the investment by KentuckianaWorks to bridge gaps between workforce development and higher education. Collectively, through their various career centers, KCAC, and Degrees Work (discussed above) KentuckianaWorks serves the Louisville region by being the means for industry to communicate needs and the voice that shares workforce demands and broad attainment opportunities with individuals. The efforts described above will not be enough to meet the goal of 55,000 Degrees. "(Attraction) has to be a part of the equation" (55,000 Degrees Interview). Louisville knows that to increase attainment they also must start to invest beyond just developing this talent pool; they also must work to retain individuals who graduate from their post-secondary institutions and attract individuals from outside the city.

\section{Retain and attract}

Like Indianapolis, the third key driver to Louisville's ongoing human capital strategy is retention and attraction. Greater Louisville Inc. (the Metro Chamber of Commerce) recognizes that if the city is to become a knowledge city capable of meeting the economic demands of the twenty-first century, "nothing is more crucial than attracting and retaining talented, skilled people to grow our region's economy and change the trajectory of our community" (Greater Louisville Inc. Interview). Recognizing this is one thing, operationalizing it and implementing it is another. To do this, in 2017 Greater Louisville Inc. announced the launch of an initiative called "Live in Lou." Using video, online content, "Dip-Lou-Mats," and social media, the goal is to create ownership around 
both retaining and attracting highly talented individuals to Louisville. Specifically, the initiative is aimed at "targeting 25-54-year-olds with an associate's degree or higher" (Greater Louisville Inc. Interview).

Greater Louisville Inc. (GLI) and Live in Lou see attraction and retention as tied together. Creating a messaging and marketing plan for sharing what the Greater Louisville region offers both professionally and personally to individuals and companies is the driving force behind the Live in Lou brand. GLI recognizes that the long-term success of both attracting and retaining individuals with high human capital requires collaboration across the city. Groups and small organizations across the city have recognized the need to retain and attract talent for over a decade. Going forward Louisville's ability to utilize this belief into a quantifiable measure of attainment growth will require the further investment in these areas.

\section{Summary}

Over the past twenty-five years, Louisville has experienced a revitalization of its spirit and aspirations. Interview findings showed how organizations perceive their work. The chapter cannot make claims as to whether these efforts are causing changes in outcome. Like a majority of cities, Louisville has been unable to catapult itself up the attainment hierarchy. However, as the city moves forward into the twenty-first century, there is a shared recognition by stakeholders that attainment is an important tool for the city to develop, retain, and attract individuals with higher education credentials. Many of the investments made such as the Cradle to Career initiative require long-term returns on investment. Additionally, the interviews showed that beyond the structural and organizational framework, Louisville, which considers itself as one of America's most 
compassionate cities, knows that to be the knowledge city it aspires to, that the doors to attainment must be obtainable by all within the city. How equitable access will be accomplished is still a work in progress as the city explores the creation of a "tuition promise initiative". Maybe the greatest accomplishment for the city is not in a sole program, initiative, or organization but rather in the recognition that solutions to Louisville's attainment woes will be through broad and integrated coalitions. 55,000 Degrees has laid the groundwork for this to take place long after the 2020 goal. 


\section{CHAPTER VII: NASHVILLE}

Over the last half-decade, Nashville has developed a buzz as a highly desired place to live and work. As of 2015, the Nashville MSA had a population of 1.7 million people with 32\% having a bachelor's degree or above (United States Census, 2016a). In 2014, the Nashville Chamber of Commerce called the city "red hot" due to its accelerated economic growth (Nashville Chamber of Commerce 2014). As a result, Nashville had an unemployment percentage of $4.6 \%$, which was below the national average (United States Census, 2016a). Municipalities around the United States looked at Nashville as an aspirational benchmark, hoping to discover Nashville's formula for growth. Their success is multifaceted, but Nashville's collective and regional identity plays a large role. It is important not to see Nashville as an isolated entity. The city is part of many national networks beyond the Talent Dividend Network.

Nashville has the designation as a Lumina Foundation Community Partnership grantee. This designation and grant process has connected the city with other grant recipients and national organizations all focused on increasing higher educational attainment. Nashville is also a part of the Graduate! Network, a national organization that works to increase the number of adults completing college by engaging business, higher education, and other community stakeholders. These two national networks and designations are not the only ones Nashville is part of but do illustrate the role large national organizations play in creating a common language around attainment in the United States. 
This chapter examines the organizations and initiatives taking place in Nashville that focus on human capital broadly and then discusses the impacts of state policy on workforce development and human capital initiatives. Findings center on two focus areas for the city: access and workforce alignment. Before discussing findings from individual interviews, a brief history of Nashville is offered.

\section{History}

Nashville was settled in 1779 and was officially designated as a town in 1784 when it was still apart of North Carolina. Like many towns at the time, Nashville geographically sits on a waterway, the Cumberland River, which in its infancy allowed for access to a major waterway. In 1843, Nashville became the state capital of Tennessee; the city was chosen based on its centrality in the state even with a population just under 10,000 residents (Burt 1959). The Civil War had a direct impact on Nashville. Tennessee joined the Confederacy, just eight months after Nashville fell to the Union. Upon the conclusion of the war, Nashville was a different city than it had been before. By 1870, Nashville had become less of a city dependent on the river and became a central railroad hub connecting to Louisville, Chattanooga and St. Louis due to the expansion of the L\&N Railway. From 1885 to 1895 , greater Nashville doubled in population (Burt, 1959). The main industries of this period were cotton mills, sawmills, and the printing-publishing industry.

At the dawn of the twentieth century, Nashville remained a major manufacturing center in the South (Burt 1959); this did not change during either of the world wars or the Great Depression. During the early twentieth century, Nashville became the "Athens of the South" due to its ties to art, culture, and education. This nickname is also due in part 
to the building of the Parthenon for the Tennessee Centennial and Vanderbilt University. After World War II, the music industry emerged in Nashville starting with radio, which spawned the music publishing and musical tourist industry (Doyle 1985). Leading to the designation of being "The Music City." As the century progressed, more and more citizens began to move outside of the city's boundaries, leading to the consolidation of city and county government in 1963. As the twentieth century ended Nashville saw extended economic and population growth, cementing itself as a central hub in the American South. At the start of the twenty-first century, Nashville remains a vital city in the Southern United States.

\section{The Numbers}

The story of Nashville is quite different from Indianapolis and Louisville. As the Athens of the South, Nashville has a rich history and high concentration of higher education institutions. While these schools alone are not solely responsible for Nashville's higher than average citywide post-secondary attainment, this history has left a cultural, social, and economic impact on the city. Even as the city has boomed in population over the past ten years, and K-12 attainment stagnated, Nashville has been able to raise citywide higher educational attainment. Graph 7.1 shows increases in Some College/Associate Degree populations in the 1990s, but a slow leveling off as the 2000's progressed. On the other hand, over the past 25 years, Nashville has made gains compared to top attainment cities regarding Bachelor's Degrees and above (Graph 7.2). What this possibly may signal is that Nashville was able to both grow its population while also raising attainment and closing the gap between historically high attainment cities. This trifecta of growth, and especially the results illustrated in Graph 7.2, 
effectively places Nashville as a more central player in the fight to have the highest attainment labor pool.

\section{Graph 7.1:}

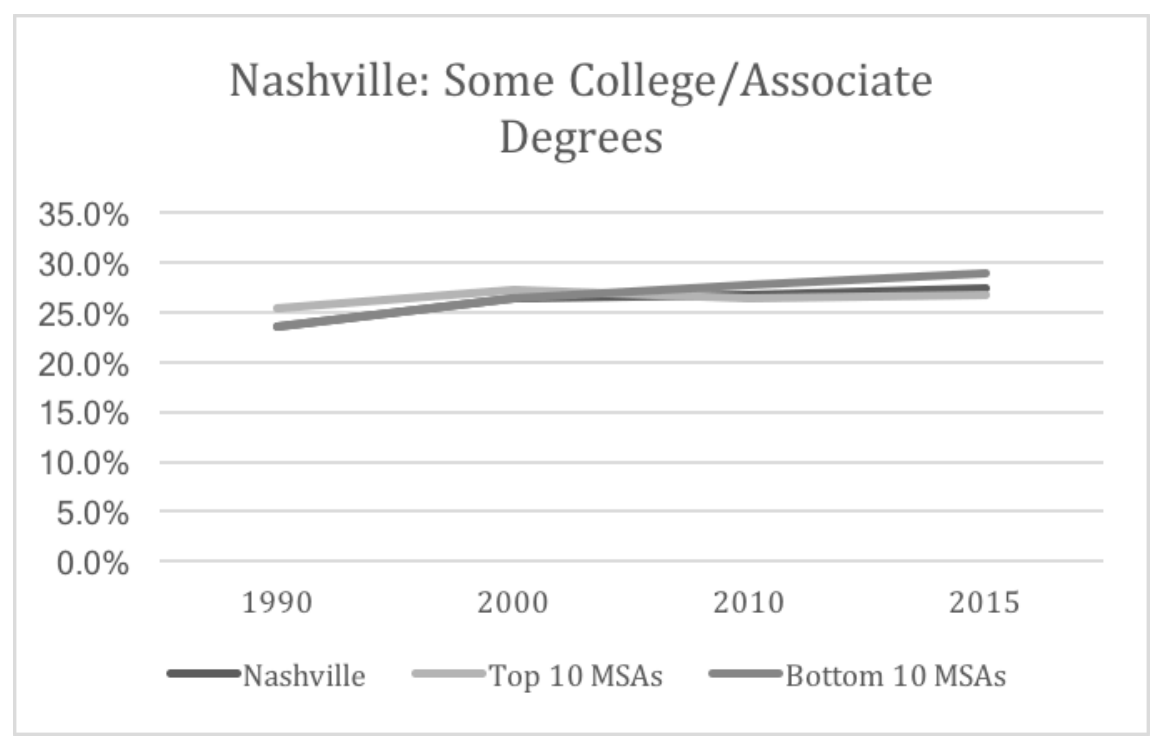

(United States Census 2016a; Minnesota Population Center 2016)

\section{Graph 7.2:}

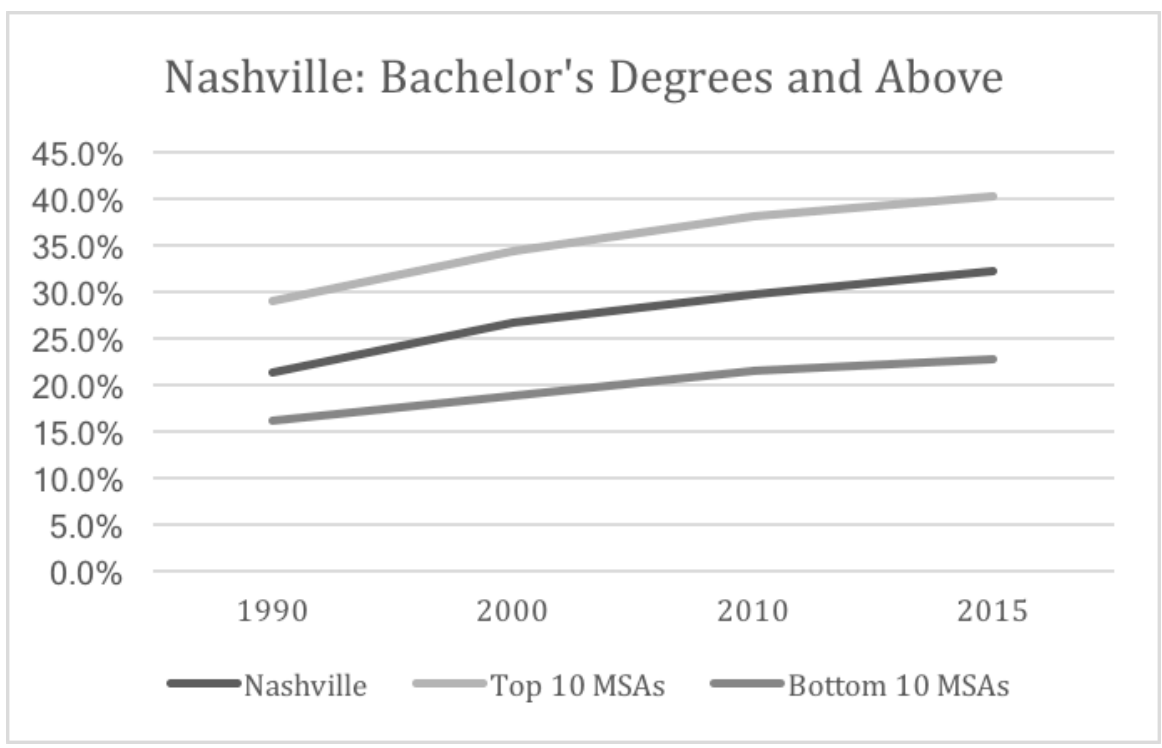

(United States Census 2016a; Minnesota Population Center 2016)

While Nashville has made gains in their educational attainment, slightly outpacing the Top 10 cities average, Nashville's occupational shifts have been very 
standard. Like Indianapolis and Louisville, Nashville has seen its largest occupational percentage gains in the management, business, science, and arts occupations. Nashville's shifts conform to national occupational shifts and help to highlight the effect of automation and globalization.

\section{Table 7.1:}

\begin{tabular}{|r|r|r|r|r|r|}
\hline & $\begin{array}{c}\text { Management, } \\
\text { business, science, } \\
\text { and arts } \\
\text { occupations }\end{array}$ & Service Occupations & $\begin{array}{c}\text { Sales and office } \\
\text { occupations }\end{array}$ & $\begin{array}{c}\text { Natural resources, } \\
\text { construction, and } \\
\text { maintenance } \\
\text { occupations }\end{array}$ & $\begin{array}{c}\text { Production, } \\
\text { transportation, } \\
\text { and material } \\
\text { moving } \\
\text { occupations }\end{array}$ \\
\hline Occupations & $26.80 \%$ & $12.10 \%$ & $34.10 \%$ & $12.20 \%$ & $14.80 \%$ \\
\hline 1990 & \multicolumn{2}{|c|}{$20 \%$} & $25.90 \%$ & $8.00 \%$ & $12.50 \%$ \\
\hline 2015 & $38.00 \%$ & $15.60 \%$ & & & \\
\hline
\end{tabular}

(United States Census 2016a; Minnesota Population Center 2016)

Now that the text has recognized both attainment gains and occupational shifts, the focus now shifts to income. Over the last twenty-five years, median income has remained constant when controlling for inflation, even as attainment had increased. The question as to why the decrease took place is not answered, but the data does present an interesting reality, especially when considering that while median income went down (Graph 7.3), income per capita went up (Graph 7.4). Once again, median household income is the median of all incomes in the MSA while income per capita is an average (calculated by taking all the income made in the MSA and dividing it by the number of people). 


\section{Graph 7.3:}

\section{Nashville Median Household Income (2015 Dollars)}

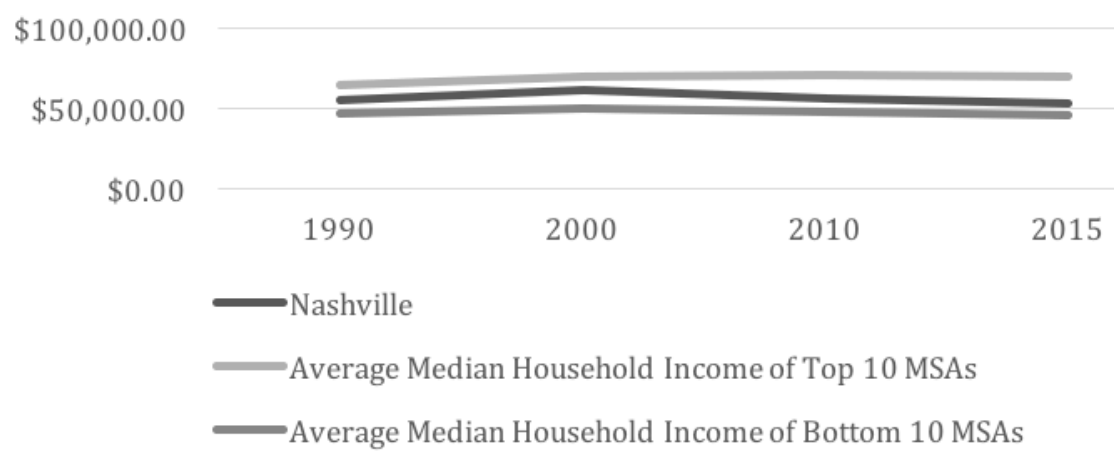

(United States Census 2016a; Minnesota Population Center 2016)

\section{Graph 7.4:}

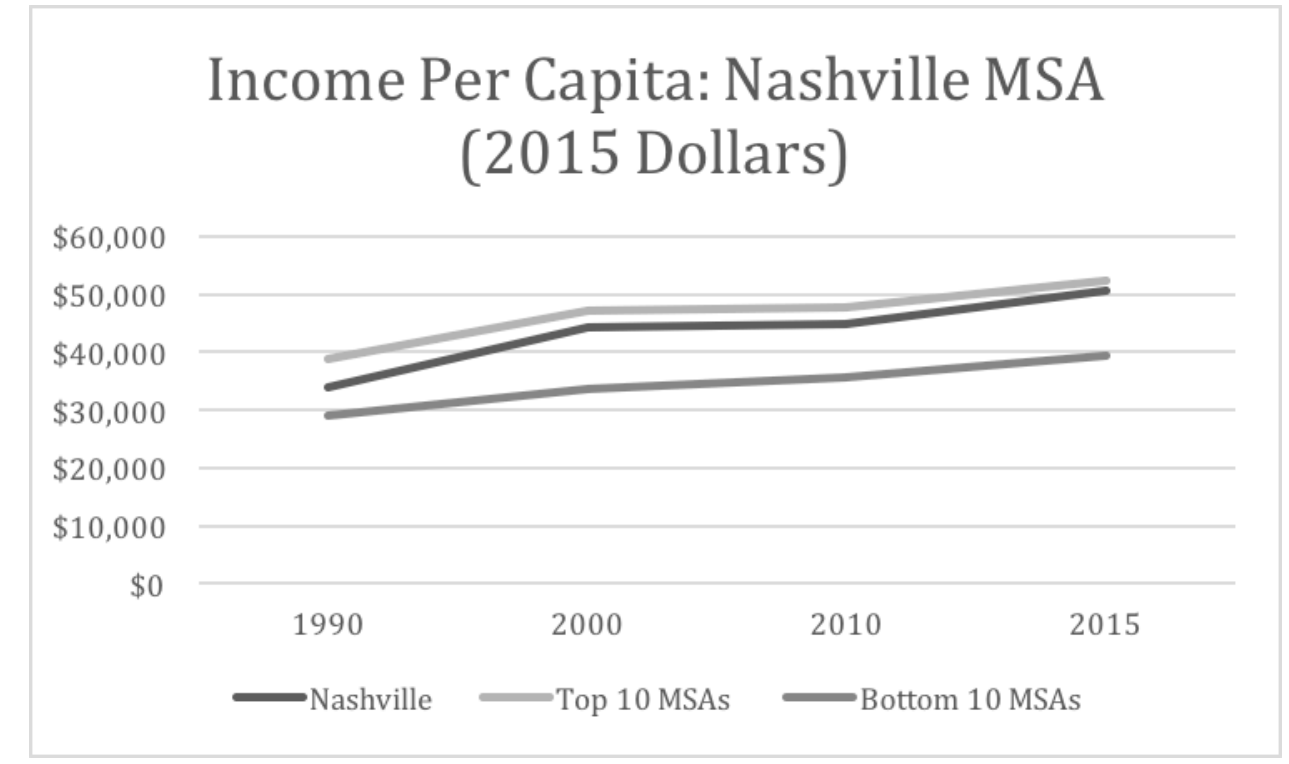

(United States Bureau of Economic Analysis 2017a)

The data presented so far in this chapter are descriptive to understand, as fully as possible, what is going on in the Nashville MSA. While just descriptive, the data provide some of the contexts for local leaders, businesses, and non-profits decision-making, whether they are attainment, occupational changes, or economic-focused. Additionally, 
each graph adds to the conversation on why cities are working to raise human capital. Before answering how Nashville is working to increase human capital, a summary of the impact of state policy in Tennessee on the working going on within Nashville.

\section{State Policy}

The Complete College Tennessee Act of 2010 (CCTA) established a link between the state's economy and the educational system (Tennessee Higher Education Commission 2017). Three of the largest changes were that (1) the funding models for high education became performance-based, (2) the organizational structure of higher education in Tennessee shifted, and (3) there was a more direct focus on degrees that lead to the career paths demanded of by employers. In early 2013, Governor Haslam appointed Randy Boyd, the CEO of Radio Systems Corporation, as his senior advisor for education. Over the next few months, Mr. Boyd and his working group of higher education leaders focused on the need for Tennessee to set a statewide goal for attainment (UT Advocacy 2013). In Fall 2013, Governor Haslam announced Tennessee's “Drive to 55 " with the goal of $55 \%$ of all Tennesseans having a college degree or certificate by 2025 (tnAchieves 2017). Coinciding with this launch, the governor also proposed Tennessee Promise (TN Promise). The program provides a last-dollar scholarship to all Tennessee high school seniors who meet several requirements (GPA, community service, and mandatory meetings) and choose to attend a state community college, a state college of applied technology, or a few select four-year public and private universities (Tennessee Promise 2017; tnAchieves 2017). Mentorship is also a central part of TN Promise by helping students navigate the college access process. Many of these mentors come from the Drive to 55 Alliance partners, which is a collection of private sector 
businesses and nonprofits. On April 15, 2014, the Tennessee Promise Scholarship Act of 2014 was approved by the state legislature (State of Tennessee 2014). In May of 2017 additions to the law took place to include returning adults.

Additionally, two other initiatives exist under the Drive to 55 umbrella Tennessee Reconnect and Tennessee Leap. Tennessee Reconnect helps to ensure more adults complete post-secondary education, while Tennessee Leap works to align post-secondary institutions with the skills and needs of Tennessee employers. The purpose of these three initiatives under the Drive to 55 umbrella is more than just educational. For the state of Tennessee, the Drive to 55 is about the future workforce and economic development of the state (tnAchieves 2017; Tennessee Board of Regents 2017). Governor Haslam himself stated, "We want Tennesseans working in Tennessee jobs. We want Tennesseans to have an opportunity to get a good job and for those in the workplace to be able to advance and get an even better job" (University of Tennessee Advocacy 2013). Governor Haslem's statement highlights the explicit program theory of TN Promise and each of its umbrella initiatives.

The state of Tennessee has set the attainment bar nationally helping to shape a common rationale and language around attainment. For Nashville, during the early formation stage of the Drive to 55, a regional effort called the Middle Tennessee Regional Workforce Alliance (MTRWA) was also getting started; this alliance saw the need to both raise attainment at all levels while aligning education with workforce demands within the Nashville region. The alliance brought together the Tennessee Board of Regents, four workforce investment boards, the Nashville Area Chamber of Commerce, and several community colleges and colleges of applied technology 
(Nashville Chamber of Commerce 2014). The regionalism of the alliance looked beyond governmental jurisdictional boundaries and solidified the need to discuss human capital and workforce demands as a region rather than isolated counties or municipalities.

Thinking regionally is one thing, but bringing together all of the various stakeholders for a collective purpose is different. These qualitative findings center around the work to increase higher education attainment, and because of this focus, much of the great work surrounding K-12 attainment in Nashville is not included. The author does recognize the interconnected nature of $\mathrm{K}-12$ and higher education as part of the educational pipeline, but to focus solely on the stated research questions, much of this data is not covered. It is also important to note, while the metrics used for ranking cities in this research is bachelor's degree and above, the findings focus in this chapter focus on programs and initiatives aimed at growing associates and bachelor's degrees. The following sections discuss the two major strategic focus areas that emerged from interviews in Nashville: college access and workforce alignment.

\section{Strategic Program Focuses}

\section{College access}

The previous two chapters have shown that college access is an important area of work for cities when addressing raising degree attainment. By focusing on Nashville, the data reveal that the work going on in the city centers on college access. While much of this work centers in Davidson County (Nashville Metro), there is still a regional interconnectedness. This common culture around access has developed through tackling access to attainment from a more holistic approach. Three subthemes/ approaches for tackling access emerged from the interview data: cost, mentorship, and matching. The 
state itself has taken the lead with working to address economic access. Tennessee has been at the forefront of states working to break down economic barriers associated with attaining at least an associate's degree. The Nashville stakeholders interviewed recognize that TN Promise is not the end-all solution. Many non-profits who work with lower economic students admit the law's weakness in being only a last dollar scholarship. All those interviewed recognized that when it comes to providing access, TN Promise and its recent revision are a step in the right direction. CCTA and The Drive to 55 have helped in creating a rallying point for stakeholders to come together around access barriers. The implementation of Tennessee Reconnect in Nashville is a further example of recognizing the distinct needs of adults wishing to pursue higher education.

The Middle Tennessee Reconnect Community (MTRC), based out of the Nashville Area Chamber of Commerce, helps adults seeking to earn a college degree. Like Louisville's Degrees Work initiative, MTRC is also a part of the national Graduate! Network, which shares the mission of increasing the number of adults attaining a college degree. MTRC sees itself as "about building the workforce, to meet the changing environment of the (Nashville) region" (MTRC Interview). They do this by engaging with a host of regional partners and community organizations. The organization then trains what they call "Reconnect Ambassadors." The training is a standardized college access-coaching course focused on adults. The Tennessee College Access and Success Network (TCASN) created the training, in collaboration with Lipscomb University. The result of this collaboration has been a standardized tool for training mentors and college coaches who work with adults across Nashville. A certificate program also exists for 
college access professionals and coaches who work with traditional college-going students.

For MTRC, their Reconnect Ambassadors have an assigned geographic space. The staff constantly engage with their ambassadors and see this engagement as an ongoing training process. MTRC also collaborates with the regional career centers to help match prospective students (Reconnectors) to in-demand career paths. TCASN also works with local career centers to provide these groups college access training. MTRC is an organization that believes in both mentorship and matching; this philosophy helps in tying together their two central goals: meeting the demands of the region (a high human capital labor pool) and empowering adults through education. In addition to the focus on mentorship and college coaching, the concept of matching is an important tool in the toolbox for raising attainment in Nashville.

The concept of matching in the literature refers to helping students attend colleges and universities that fit them academically (Roderick, Coca and Nagaoka 2011; Howell and Pender 2016). Matching is especially important for low-socioeconomic and minority students who graduate at higher rates at more selective higher education institutions, but disproportionality fails to apply to selective higher education institutions; this failure supports the need to help match high school students to the most selective school that their academic accomplishments allow (Alon and Teinda 2005). As a result, students are better situated to be successful in college and beyond. Several non-profits in the Nashville area have made matching a central part of their mission; TCASN and the Oasis Center are two of them. 
The Oasis Center is a local nonprofit focused on improving the lives of Nashville's vulnerable and disconnected youth. One of their focuses is the College Access Program. Their goal is to build relationships with high school students in the most challenged public high schools to "do our part to break the cycle of generational poverty" (Oasis Interview). Full-time mentors work to "engage young people in conversations about what's next, build relationships" (Oasis Interview). They do this by helping students discover their passions, understand their worth, and help walk them through post high school graduation. The program does not focus on or buy into the college-for-all model, although many of their students go on to post-secondary institutions. They believe that by helping students to understand their passions and connecting them to the right post-secondary school or career path after high school, better prepare students for future success. Oasis recognizes that the work they do around raising attainment in Nashville is complex but that the work is increasing access to higher education for students. As an organization, Oasis and their College Access Program see their success in helping students see their potential and matching students with the best opportunity for their academic and attainment futures.

Because of (a student's) circumstances, access to things that will improve their life, things they deserve to have access to, they are not always given access... It's important for people to really give young members of our community access to everything they want to explore... We think they deserve real access to those choices, and to be able ... And it's our role to give them access to it, it's our role to share with them the benefits of each and what struggles would come with each. - Oasis Interview

When it comes to access and matching, TCASN works to combat undermatching for Tennessee and Nashville students. Undermatching refers to when a student "attends a post-secondary institution which is less selective than their academic credentials would 
permit," or when a student simply fails to apply for a school even if they are qualified (Tiboris 2014). Through the "TalentED Project," TCASN helps to connect college admission offices to college access professionals. The project has expanded beyond Nashville and Tennessee to be a national network of college access professionals and college admission offices. This type of work is important in creating an infrastructure that helps ensure students are in the best situation for success. TCASN and the Oasis Center see and talk about students as unique individuals who often just lack access to the various forms of capital which help in the navigating the college attainment maze.

Nashville, like many cities across the United States, understands that raising college attainment requires strengthening the existing talent pool. While attracting high attainment individuals is important, Nashville knows that it must work to create equitable access to higher education. The second area of focus for Nashville is workforce development.

\section{Workforce development}

Like Indianapolis and Louisville, Nashville through a variety of means is working to align the demands of industry to the supply of talent. Cities that can adapt quickly and do this are more competitive in their ability to both develop the right human capital. As a city, stakeholders have taken a risk by trying new methods for meeting workforce demands. What this means for Nashville is that their approach to addressing the workforce development is both traditional and innovative, making the city a leader for others to mimic.

In 2012, the Nashville Chamber, Workforce Investment Boards, business leaders, and leadership from various higher education institutions began to come together wanting 
to help meet the city's growing workforce demands. In July 2013, the Middle Tennessee Regional Workforce Alliance formalized the partnership of these various organizations with the mission to prepare and strengthen the Nashville region for growing workforce demands. The solution was the creation of skill panels. These panels focus on IT, healthcare, and advanced manufacturing. On each of the panels were sector business leaders, education providers, and the panels were individually staffed by one of the executive directors of the workforce boards. The initial success of the panels goes back to the Complete College Tennessee Act of 2010. One interviewee stated:

It (the Complete College Tennessee Act of 2010) took a system that was funded on enrollment to a system that was going to be funded on performance, both the persistence of students and graduation rates of the students within the colleges as opposed to how many people are sitting in seats... Part of the legislation required that the colleges and universities align themselves to support the economies that those institutions were servicing. They did not have a strategy to do that. We were essentially proposing a strategy for them to be able to do pilot, if you will, how to better organize themselves to be responsive to business. - Nashville Chamber of Commerce

This quote summarizes how state policy created an atmosphere that made collaboration both practical and beneficial for all stakeholders. Figure 7.1 best summarizes the work addressed by the skill panels. The backbone of the flow chart shows how goals led to strategies, which went to the Governance Board and from there education/training are adapted. The circles surrounding these steps highlight various partners and the outcomes of each step. All of this culminates in the desired results. It is at this stage that workforce alignment meets the increased high human capital. By better connecting the private sector, higher education, and students, the region benefits by 
having a labor pool that is ready to meet the demands of Nashville's regional skill focuses (IT, healthcare, and advanced manufacturing).

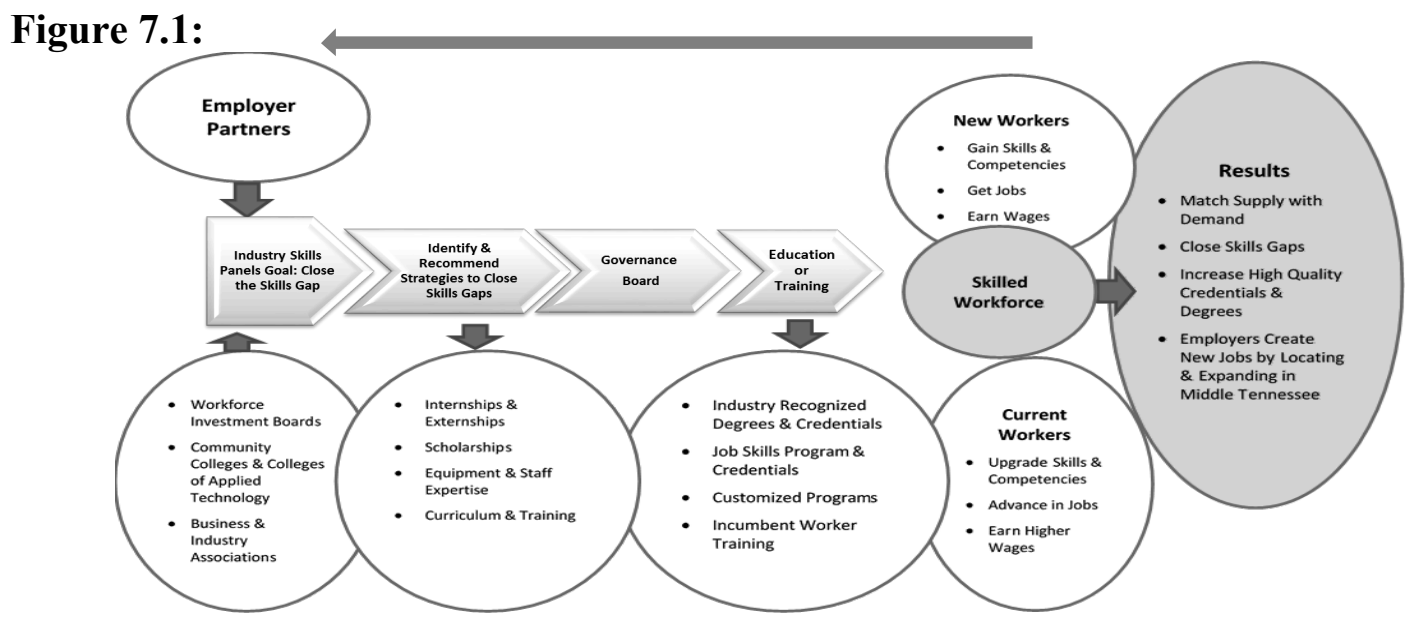

This system is admittedly not perfect. Nashville leaders have and continue to see the skills panel model as a work in progress for both increasing attainment and meeting the demands of industry. One of the main problems with cross-organization collaboration is that if one of the partners undergoes large changes, it affects the larger partnership, which is what has happened with the skills panels. The skills panels at the time of writing this dissertation had not met since December 2015. In 2016, the state of Tennessee under the leadership of Governor Haslem passed the FOCUS Act, which reorganized higher education in Tennessee. This reorganization and shifts in leadership have caused the skills panels to pause their work. During interviews, the Nashville Chamber did emphasize that some of the work started by the skills panels is still ongoing. Skill development work is present beyond these panels within Nashville. Business, nonprofits, and the public-school system are working to emphasize the importance of credential beyond a high school diploma.

Within Metropolitan Nashville Public Schools (MNPS), forty career academies exist to "offer a practical, hands-on approach to learning in a field that interests students, 
ranging from engineering to healthcare. Our goal is to prepare students for college and ultimately to go after their dream jobs" (Academies of Nashville 2017). These academies bring partners into the schools strategically to connect students to the business community in Nashville. The PENCIL Foundation coordinates these partnerships for MNPS.

(PENCIL) does the one-on-one partnerships with the individual academies in the schools, so they actually do a lot of recruiting, a lot of matching, monitoring the partnerships, meeting with them mid-year, making sure everybody's happy, they train the business partners on how to work with schools, they train the schools on how to work with business partners. It is a pretty intensive process. - Alignment Nashville

There are sixteen career clusters across the district. Students can select a program of study within one of the sixteen clusters and where available earn certifications/credentials for a future career. The program model connects to Nashville's higher attainment goals by connecting skills, attainment, and knowledge to jobs earlier in the educational process. Nashville sees the academies, partnerships, and career clusters as occupational pathways for students so that they are the next wave of high attainment talent.

There is no denying that aligning workforce demands is an important emphasis in Nashville. Cities across the country perceive themselves as doing this type of work, but Nashville was able to use statewide policy to develop both a coalition and a strategy around connecting the demand and supply sides of the labor market. This work at the city level, along with state policy, has influenced the curriculum, pedagogy, and delivery of higher education in many of Nashville's community colleges and technical schools. Together, access and workforce alignment play important parts in Nashville's on-going work to strengthen and increase its population with a post-secondary credential. 


\section{Summary}

Cites are searching for the magic solution that would perfectly supply all the talent desired by businesses. Urban scholars, practitioners, and politicians regularly propose innovative solutions for this and other problems faced by cities. Members of the growth machine in every city look to localities, seen as successful, for ideas, strategies, and policy. In the last decade, Nashville has been a city often looked to by national and regional policymakers seeking a prescription to their own city's economic problems. If one asks leaders in Nashville, this praise has not caused the city to take their foot off the gas. Instead, the recent growth and notoriety received by the city have only fueled the desire to maintain the city's momentum and extend it even more. The aspirations of the city of Nashville are high; like Indianapolis and Louisville, the Nashville region sees its future success tied to the ability to prepare and attract a labor pool that meets the needs of the business community. As a result, Nashville is working to connect and align two major American institutions, higher education and the private business sector.

The next chapter brings together the findings from the three case study cities and works to tie their efforts to the existing literature. Also, the following chapter uses interview data to answer the secondary research questions as to why cities see this work as important to understand both their motivation and aspiration. 


\section{CHAPTER VIII: COLLECTIVE FINDINGS}

Data collected as part of the previous three chapters showed that Indianapolis, Louisville, and Nashville have three strategic focuses: developing, retaining, and attracting high human capital. Collectively, the research refers to these strategies and the stakeholders working to execute them as a city's human capital system. These strategies and the stakeholders tackling them are interconnected and in many ways dependent on one another. Where cities differ is in the weight they place on each of the three main strategies. In keeping with the research design (presented in Chapter 3), this chapter draws cross conclusions from the three case studies and answers the sub research question regarding why cities are working to increase their human capital.

To summarize what amounts to a wide breadth of work taking place in the case study cities, this research concludes that there are three major strategic focuses. These foci and the organizations that work to achieve them make-up a city's human capital system. Figure 8.1 provides a diagram to illustrate an example of a city's human capital system. 
Figure 8.1:

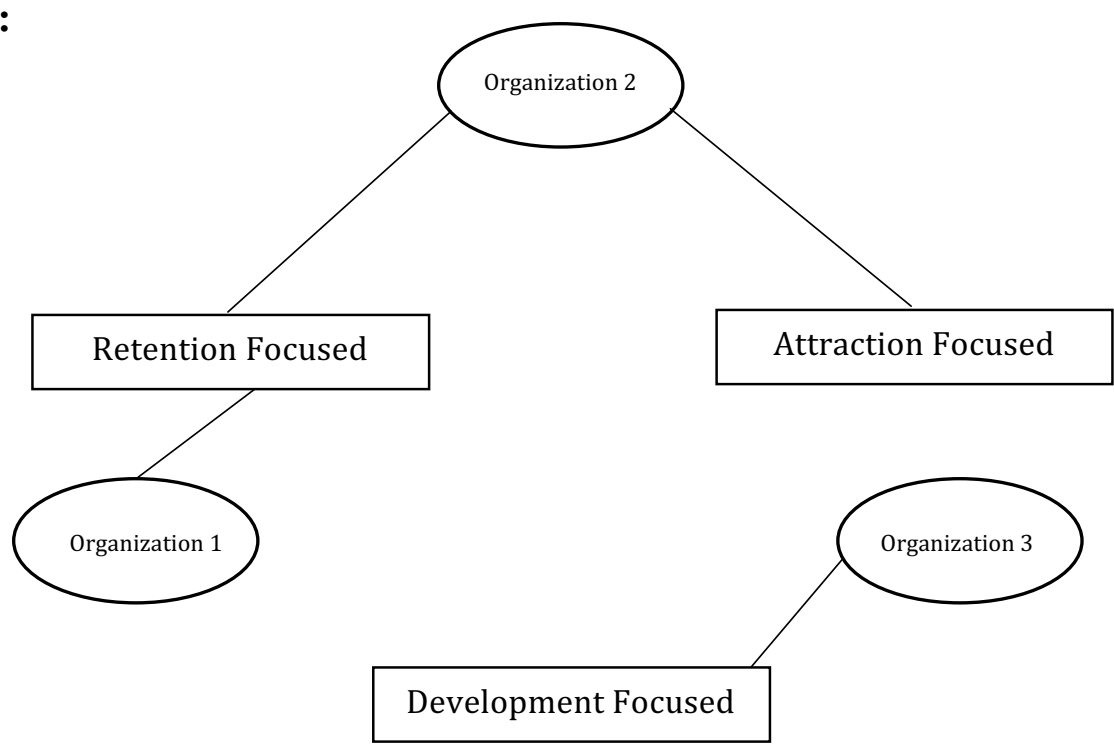

The figure is quite simple. It shows the three strategic foci and three organizations seeking to fulfill one or more of the three foci (denoted by the solid lines connecting them). The term "organizations" is all-encompassing covering such areas as higher education institutions, nonprofits, city government, chambers of commerce, and others. Additionally, the figure shows a less networked grouping of organizations. What the figure illustrates, as a result, is that connections within the human capital system only come about through sharing a common focus. What the case studies showed though was that organizations often develop formal and informal relationships with organizations with common and different foci. Figure 8.2 denotes these relationships using dashed lines.

While commonalities in strategic focus areas exist all three cases, no overarching prescription or formula for cities wishing to raise their human capital exists. Each city looks at others through the benchmarking process, looking for the practices that fit their particular needs. Because of this, these collective findings look 
deeper than programmatic similarities and instead focus on how cities, as a collection of people, organizations, and institutions, are meeting their goals of increasing their human capital.

\section{Figure 8.2:}

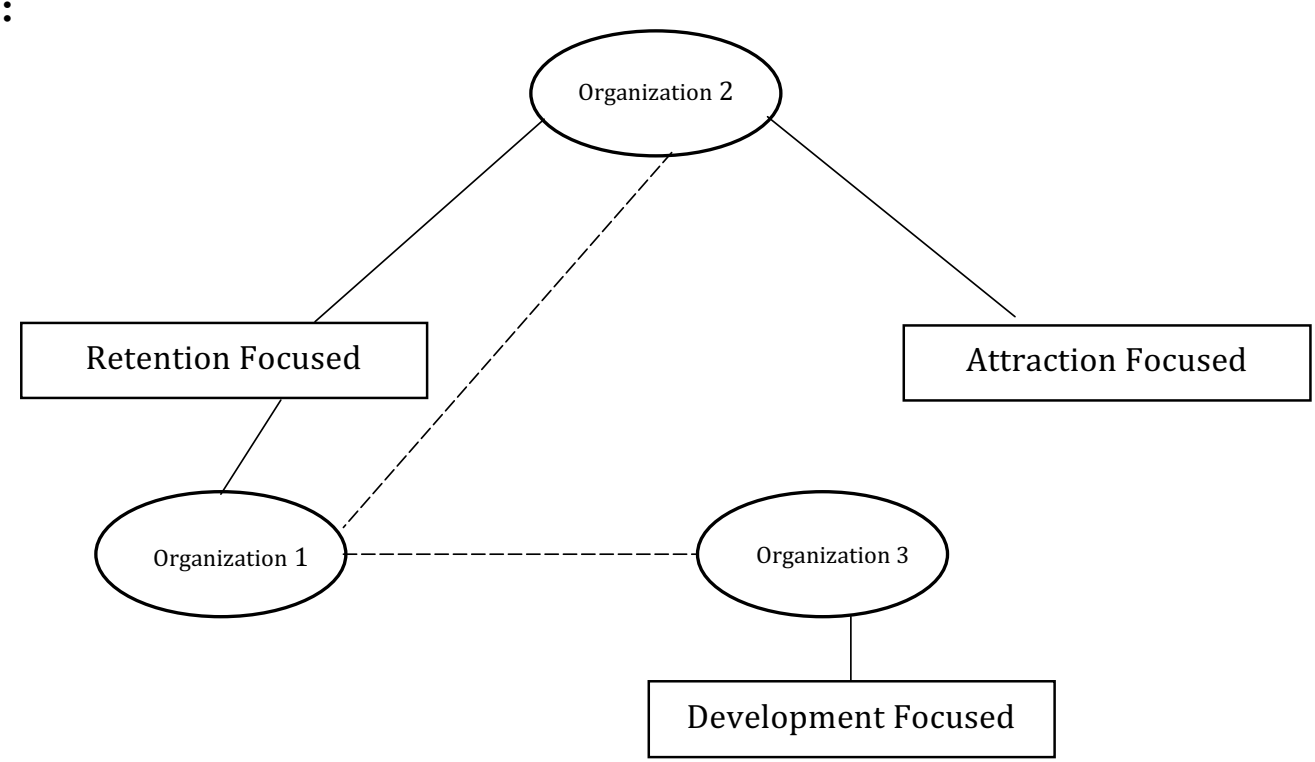

Above all, the findings show that cities see enhancing their human capital systems as mutually reinforcing and communally beneficial. The maintenance and formation of human capital systems are discussed through two different lenses: organizational collaboration and regional complexity. The first lens discussed is organizational collaboration. Each of the organizations spoke the important role of working with organizations across and within focuses in their respective city. One organization in Nashville stated it this way, "if we don't collaborate, we're all spending money. Collectively, we can get a whole lot more done than we can individually" (Nashville- Middle Tennessee Workforce Development Board). While money and funding was one rationale for organizational collaboration, other organizations discussed the need to collaborate to create unity: 
There needs to be a more unified voice. Sometimes it takes a while but I think that everyone here is just, I don't know. We believe in one another. We know their personal relationships. We believe we don't want that person to fail and that's the way I think a lot of the leadership here that is succeeding is approaching these situations. I want to succeed, but I don't want it to be at the expense of another organization, and I don't. -Indianapolis- Indy Chamber

For cities, collaboration serves as a means of making their human capital system efficient and focused. Cities and the stakeholders within their human capital system recognize that, like any structure or system, if efficiently constructed, resources will cover a wider breadth and depth of problems - and opportunities. Part of this work also helps to minimize overlap between organizations and programs. There also exists a sense of shared ownership. Organizations exhibit the traits of mutual reinforcement through this process by leaning on one another for their success as well as the success of the collective.

As it pertains to the development portion of the human capital system, cities recognize that "with workforce development and higher education, we can't completely operate in silos. There's always going to be collaboration" (IndianapolisIndyHub). The silos metaphor was common. In the area of developing high human capital, stakeholders discuss the concept of collaboration by discussing demand and supply. In all three case studies, cities and their stakeholders discussed the changing demands of industry.

Demand shifts in the labor market have created a culture of perceived collaboration to ensure that the focus of human capital development is on the right forms and areas of credentialing. "We are paying close attention to that to make sure that we're aligning any of our talent initiatives to where we actually see the needs are" 
(Indianapolis- EmployIndy). All three cities perceive themselves as doing this type of alignment work where providers of higher education credentials collaborate both directly and indirectly with industry. Such work extends into government policy, where both state and city governments are working to be the intermediaries for collaboration and cooperation. Some of this collaboration is due to WIOA. While states and cities receive discretion by the federal government through WIOA, the law does create a common statutory approach for aligning workforce development with local industry demands. Across all three cities, K-12, higher education providers, workforce boards, and chambers of commerce are working to align all portions of the development pipeline to meet the needs of industry for economic development (I discuss the purposive rationale later in this chapter).

All three case study cities believe that it is important to align development initiatives early in the educational process. While the focus of this research was on higher educational attainment, cities recognize that the development pipeline is a building process. This development pipeline serves an important function of pushing them to examine and create pathways for industry to be involved in the K-12 process, to help students explore their professional interest, and to equip students with the knowledge and skills demanded in the labor force.

We've really been able to bring in business partners in a way that has an influence. Industry certifications is something we've been very intentional about increasing as well as post-secondary early college credit. I know that this coming year that is something that our high school team will be extremely focused is getting those passage rates up for both. - Nashville- Alignment Nashville

We did a strategic planning session with the board, and they identified as their number one goal to try to work on alignment issues, 
particularly between high school and what employers wanted but also the community college. Their perception was if we could get these systems to work better and be better aligned, we don't have to keep trying to fix things on the back end. - Louisville- KentuckianaWorks

To do the work of alignment intermediary organizations exist between the schools and industry. These intermediary organizations help translate the language of industry into actionable steps and processes that meet K-12 statutory curriculum requirements. Intermediaries also exist to do the same work between higher education and industry, but in all three cities, this collaborative work has been difficult due to lag time. "Timing of when people complete certificates or credentials or degrees and when jobs are available often don't line up" (Indianapolis- Ascend Indiana). To shift curriculum within higher education (the supplier of high human capital) takes months if not years to see a return.

We first did it in the traditional way. Go to the community college as a partner. They do work keys profile. Takes them a couple of months to profile the job. Then they create a curriculum. Then they hire a faculty person. Then we try to find people that want to get into a training. Then they take a six- or eight-month training. Then, when you're done, we have, like, 10 people. We were trying to fill what we thought were hundreds of jobs. - Louisville- KentuckianaWorks

It is up to future researchers and scholars to have a discussion to determine whether aligning higher education with industry serves the institution's function; for now, it is a reality. Of particular interest to this research is that because of lag time, cities and their stakeholders can bypass traditional bureaucratic higher education providers. To bypass these traditional providers cities are creating their own curriculum and/or certificate programs a finding that has impacts far beyond these cases. The shift where organizations on behalf of a human capital system are forming their credentials may signal a deconstruction of traditional credentialed labor. 
The data regarding development strategies suggest that the further along in the attainment pipeline an initiative is, the faster and more adaptive it must be. Collaboration between organizations at the K-12 level looks different than it does at higher education; there is a higher sense of immediacy when it comes to working across sectors and institutions as it pertains to traditional and adult learners seeking to gain a credential beyond high school. Cities are working to both meet the immediate needs of high human capital labor while also ensuring that the next generation of learners is prepared to step in to meet the market demands of their economies. By setting local and state attainment goals, the various stakeholders within the human capital system have a common rallying point.

We have built a common table. It's not it's larger and more impactful to me than any one project or any one strategic piece of our agenda... For six plus years, leaders of $\mathrm{U}$ of $\mathrm{L}$, of the city, of JCPS, of nonprofit organizations within community have been at a common table, speaking a common language around common goals consistently, not once a year. They're working on this all the time. - Louisville- 55,000 Degrees

Creating a common table/common language requires a collective mindset. While briefly mentioned above, growth machine theory states that this happens due to a mutually reinforcing desire to grow. As cities work to increase the percentage of their population with high human capital, competing businesses, organizations, and institutions are rallying together by creating an embedded network of stakeholders. When this takes place as part of development initiatives, higher education attainment serves both its long-held individual empowerment function but also a collective cohesion function for the actors within a locality's human capital system (which is discussed more as it pertains to regionalism later in this chapter). Development is not 
the only strategic focus for cities as they work to raise human capital. Cities are also investing in keeping talent from leaving and attracting new individuals to the local workforce.

While retention and attraction efforts were a common theme among all three case cities, the degree of investment and the scope differ. It is clearer from an institutional perspective who is in charge of developing talent; it is less clear who is in charge of ensuring high human capital individuals do not leave and who is attracting high human capital. The the organizations on behalf of their respective cities see attraction and retention as going hand in hand.

We are not doing a lot different for the retention than we are doing for the attraction. So, if we can inspire people who are here to stay here and to make sure they know there are opportunities for them after college or the next jobs here for them is here as well. Then we will retain them. - Louisville- Greater Louisville Inc.

We focus intentionally on that retention piece first knowing that until we had a really strong community, and there was a strong community, but a strong recognized community, that people wanted to stay here and there was a really vibrant community, that attraction would be somewhat futile. - Indianapolis- IndyHub

We brought in Stephanie into Nashville to better understand what that meant for Nashville and why people were relocating in large numbers, young people moving to Nashville. We really began a workforce development initiative at that time that was primarily focused around attraction and retention of young professionals. We did a lot of college recruiting along with business, and then we also created a young professional network. Both of those activities are present today. Nashville- Nashville Chamber of Commerce

Through branding, market research, developing community, and highlighting professional growth opportunities cities are implementing plans to retain and attract high human capital. The case cities are particularly interested in branding themselves as a destination for what they define as "young professionals" which is a 
demographic that is roughly between the ages of 20-35 with at least an associate's degree. Attracting and retaining this group is necessary for these cities' long-term economic success. When organizations spoke about retaining and attracting high human capital, they discussed the need to transform the physical environment. As an example, one representative noted:

From a larger perspective, we've done a lot of things to try to increase the overall visibility and attractiveness of the region. We've worked with many development corporations to help revitalize neighborhoods ... That are housing options that have been placed and available for young professionals who are bringing talent and skills to the region. Indianapolis- Indy Chamber

This research does not dig into how the drive to retain and attract human capital ties to the physical changes taking place in urban spaces. These findings do point to the belief by these cities to the mindset of 'if you build it [the infrastructure] they will come.' As the findings of this study attest, developing high human capital takes time. To create a Cradle to Career pipeline like the one Louisville did, or bringing in industry to K-12 like Nashville, requires long-term buy-in from multiple partners and stakeholders. Efforts to prioritize retaining and attracting talent increases the overall size of the labor pool and fills short-term gaps in labor demand. While rarely discussed as operating together, studying a city's human capital system requires a model that looks at all three components together: development, retention, and attraction. Before explaining this more, a discussion on the spatial and regional dynamics of aspiring knowledge cities is detailed here.

While the case studies share the commonality of organizational collaboration, when it comes to communal thinking, cities also share the reality of regional complexity. Due to the number and various functions of both the inside and outside 
entities which are a part of the system, to do this work at a regional level is difficult. The interview data showed that when cities attempt to work regionally through partnering organizations, they meet various quantities and types of hurdles. Variation between cities can is best understood by comparing human capital systems within their nested configuration.

Richard Hill and Kuniko Fujita first used this phrase to discuss societal hierarchies (Hill and Fujita 2003). To study and compare a city's human capital system, the phrase 'nested configuration' supplies a means for discussing how various levels of society are bound and therefore influence one another. In studying a city's human capital system, this means recognizing how the ties between the city, its' state, its' nation-state, and its' region of the world affect the system. While each of the cities in this study share common strategic focuses, and each city is a consolidated city, all three nests in different configurations. Cities experience a different level of influence from the various ties. Additionally, cities are not just nested or influenced from the outside. A city's internal histories, configurations, and circumstances are influenced from within, which helps cities to affect the rest of their nested configuration or as Hill and Fujita state, "causality runs back and forth among levels of society" (Hill and Fujita 2003). The nested nature of cities creates a complex web of social, political, and economic actors seeking to affect a city's human capital system from outside and inside. Indianapolis and Nashville, bring state capitals are nested differently within their state policy framework than Louisville. Organizations within Indianapolis and Nashville talked about the advantage of having the capital in 
such proximity. The findings suggest that this proximity did not hinder each of the cities, but rather helped extend the culture of human capital growth to the state level.

Using the nested framework, one can see how regionalism affects a human capital system due to the complexity of multi-jurisdictions and overlapping influencers/ stakeholders. This discussion was not explicit in the interview findings. As organizations discuss their work, they emphasize their particular hurdles to regionalism.

We did that in 2004, there was a commuting chart that was done, and if you looked at it is was all of the arrows coming into Davidson County. Really nothing going out. 2007 you started to see, when we did the first study, you started seeing some areas going out. By the time we got the last study done in 2014, of the middle Tennessee region, it was a hodge-podge. Lines coming in, lines going across. And you just pick that slide up and say, this is your workforce. You really need to be looking at radius, more than anything else. Because people are traveling about, between 20 and 30 miles a day to go to work. And they're leaving Wilson County going to Rutherford County. They're leaving Rutherford County going to Williamson County. And they're leaving Williamson County going up to Davidson County. Maury County into Williamson County. So, we need to be doing this collectively, not independently. And once you look at the chart, you can't really say well that's not true. Well, yeah it is true. Just look at it. And that stopped a lot of that. Because I told my mayors was, yes, I serve a lot of Rutherford County residences, how many of them come in to work in Davidson County every day? So, who benefits? Nashville- Middle Tennessee Workforce Development Board

This quote from Nashville explains the regional identity process that took place within their human capital system over the past decade. The Middle Tennessee Workforce Development Board states that as stakeholders began to understand the growing interconnected nature of the region, a more unified voice developed around holistically tackling the deficits in the city's human capital system. Collaboration 
required stakeholders having both the physical proof and buy-in that such work would be mutually beneficial to create cohesion around the region's human capital system.

Cohesion, as stated above, cemented a regional need for collaboration across organizations. What differed across the cities was the discussed degree of embeddedness across the MSA. State policy played a role in dictating this scale. While all three states have attainment goals, the state of Tennessee's, due to the largescale promotion of the Drive to 55 and Tennessee Promise, stood out as an initiative that empowered the Nashville MSA with a shared vision for multiple jurisdictions and regional organizations. With the entire MSA nested in a similar hierarchy, and the Drive to 55 created a motivation for a regional network of organizations embedded together (through relationships and policy), Nashville provides the strongest example of regionalism thinking for the city's human capital system. State, regional, or city goals centered on strengthening a city's human capital system provide a target for collaboration and regionalism. As a result, these efforts create a sense of shared ownership around a common aspiration. These findings have not answered the motivations for the goals and desires in the first place. Therefore, before offering a more comprehensive model for studying and benchmarking urban human capital systems, the following section shows how the case studies confirm growth machine theory by understanding the various motivations of increasing attainment as a means of strengthening a city's human capital system.

This research started by discussing hypermobile capital and growth machine theory as rationales for hypothesizing both the how and why of a city's human capital system. Once again, growth machine theory states that cities are centers of economic 
activity and that at their core they have a desire to grow. Growth machine theory states that a collective desire to grow, causes policy and stakeholders to rally behind various preconditions for growth. To do this, the various groups, organizations, and individuals develop a structure known as mutual reinforcement. Such a structure provides opportunities for various actors to lean on, collaborate, and support one another. These formal and informal structures create networks of actors, focused on meeting a precondition for growth, such as high human capital.

The findings presented in the previous section of this chapter support the theory through the mutually reinforcing nature of the human capital system. Stakeholders that take part in the human capital system conform to the structure and behavior described as a growth machine. Part of that behavior is the use of a common language centered on growth as a central purpose of strengthening a city's human capital system. Through collaboration and shared goals, stakeholders have created both formal and informal reinforcing systems. Found within all three human capital systems were seven common stakeholders:

- City government

- Chambers of Commerce

- Workforce Development Boards

- Community Foundations

- Public School Systems

- Higher Education Providers

- College Access Non-profits

Alone, this list is not enough to answer why cities are developing and investing in their systems; but it does point to the interaction of two larger societal institutions, the economy, and education. This interaction is central to understanding why cities are working to develop, retain, and attract high human capital. Previous 
chapters have touched on the growing demand for individuals with high human capital. While the demand-supply interaction between the nation's economy and education is not new, how these institutions talk about human capital offers an answer to what cities gain from strengthening their human capital. The findings here point to two, non-exclusive reasons why so much work is taking place to strengthen the human capital systems of cities: economic growth and equitable mobility.

Cities identified regional economic growth as a driver for the investment in their human capital systems. Going even further by making the connection between competitiveness and the accumulation of human capital.

The most important thing we can do as a region, the most important thing that can continue to grow our economic opportunity is to get really talented people to locate here. - Indianapolis- Indy Chamber

There's clearly an economic development drive to this. That's a huge part of, over the last 10, 15 years, such a shift from location and cost of business to human talent as being the core to what makes your economy function. Skills, education are key to a community's ability to compete in the global economy, the 21 st-century economy, even if we cut off trade. It's still about skills and human talent. - Louisville55,000 Degrees

Stakeholders within human capital systems use market-driven language to justify the investment in developing, retaining, and attracting talent. The marketdriven justification creates a shared language of competition which drives both the demand and supply sides of the human capital system. Additionally, they spoke of an ongoing shift taking place not just in the domestic economy but the global economy, as it relates to labor demands. Here, these mutually reinforcing members of a human capital system state their level of connectedness to the global network. When a human capital system makes this connection, they also recognize that the shifts are taking 
place at the macroeconomic level and affect labor shifts within their city - a shift that differs in impact across each city. Collectively, the cities share a common desire not just to raise attainment, but that attainment growth should target market demands.

The issue is, sometimes we just don't produce enough people with the specific knowledge or skills for the jobs... The basic challenge, the gap between open jobs and local talent continues to widen. Indianapolis- Ascend Indiana

Failing to meet human capital production demands is influencing the ability of cities to grow in the twenty-first century economy. Cities are strategizing and prioritizing their development, retention, and attraction efforts to meet the knowledge and skills they see industry demanding.

Ultimately, we invest public and private funding to ensure that our residents have the skills that they need to take advantage of the jobs not only of today but also in the future. Then concurrently, we really need to ensure that our employers in the regional market have the talent supply chain that they need to be able to continue to undergird our economy. -Indianapolis- EmployIndy

There is a connection between the work taking place to raise attainment and the desire to grow economically. Cities are formalizing the connection between attainment and growth through their efforts to be adaptive and open to shifting economic conditions. A way cities perceive themselves as doing this is through providing individuals with information about market demands so that providers of higher education credentials and their students align their work with local demands. Lag time, as discussed previously, slows down the ability of cities to respond in a manner that meets constant economic changes, which hinders a city's ability to compete in the macroeconomy. Intra-city collaboration through the creation of more integrated human capital systems has served as a means for how cities themselves are 
working to be more competitive. Through the nurturing of an integrated and focused human capital system, cities and the stakeholders within their systems can be more than just mutually reinforcing; they also can be more adaptive in meeting human capital demands.

By increasing attainment and, as a result, meeting the demands for higher human capital, cities do more than just meet short-term economic demands; they also make themselves a more attractive location for any industry seeking that very human capital system.

The idea is that it raises a lot of the boats in the community. We can attract businesses. We have a more educated workforce, meaning hopefully, we'll have lower unemployment and higher civic engagement and those types of things. - Louisville- 55,000 Degrees

Strengthening a city's human capital system has both individual and communal benefits. Cities state that by increasing human capital through the development, retention, and attraction of individuals, they can nurture a climate that is positive for industry. Phrased differently, cities recognize that human capital is a precondition for economic growth in the knowledge economy. The relationship between the individual and the community continues to arise, which is rooted in the very function of the American educational system. To various degrees, cities recognize that equitable mobility is important for strengthening and increasing citywide human capital.

We will not attract and retain talent unless we offer up for a part of our population who are not integrated into our community, who are not connected to opportunity. We're not going to be able to thrive. Even though my quality of life is fine as a white-collar professional, at some point, the increase in violence, the increase in destabilizing, our community will have ramifications, and you'll see more flight. Indianapolis- EmployIndy 
Organizations, as city actors, discussed that raising human capital for economic growth and equitable mobility as an important feature of working in concert with one another. Leaders from all three cases identified that increases in citywide human capital could not come at the cost of further disenfranchising underprivileged portions of the population.

We have so much poverty in this time, and I think with any community that has a large population of people living in poverty, in generational poverty... but because of those circumstances, access to things that will improve their life, things they deserve to have access to, they're not always given access. But nobody is really giving them true access to it. And so I think that's our role, and I think that's why it's important. It's important for people to really give young members of our community access to everything they want to explore. Nashville- Oasis Center

As part of their development foci, all three cities have strategies for creating equitable access to higher education. Each city stated that their human capital efforts would help empower individuals by supplying additional channels for economic mobility. Equitable rationales for human capital policy and strategies meet both the individual and collective function of education while also meeting the growing precondition of high human capital for economic growth.

The organizations stated that growing the economy and creating equitable access to higher education were two of their main reasons for investing in their human capital systems. Due to shifts in the global labor market, cities have recognized that to be competitive they must nurture and align their human capital systems to meet the changing needs of the economy. At the city level, stakeholders are collaborating and coming together for a mutually beneficial investment to enhance human capital by developing, retaining, and attracting individuals with 
higher post-secondary credentials. The ultimate goal of the efforts is to develop, retain, and attract business. To grow business, cities desire to make their human capital systems effective and efficient producers and consumers of the human capital deemed important to the twenty-first-century economy.

Efforts to enhance citywide human capital through developing, retaining, and attracting individuals with high attainment is not unique to these three cases. Nationwide efforts such as the Talent Dividend Network (TBN) show that cities and national groups (Lumina Foundation, CEO's for Cities, and others), recognize the importance of investing in a citywide human capital system. The concluding chapter of this study discusses the need for more research on human capital systems. Based on the study's findings, a network approach for examining human capital systems is proposed. Additionally, policy changes are recommended which address supporting the current human capital paradigm, as well as recommendations that seek to rethink human capital. 


\section{CHAPTER IX: CONCLUSION}

Due to the rise of knowledge-based capitalism, the United States has experienced an increased demand for higher education credentials. During this same time, the power of cities has increased in both domestic and global economies due to policy and global flows. In their attempt to be central nodes in the economy, cities compete for the various preconditions associated with economic growth, one of which is high human capital. The competition for higher and higher human capital have converged to create a reality where cities fight to meet the demands of a twenty-first-century knowledge society. A result of this, the convergence is that two large societal institutions, education and the economy, are pulled together; this relationship requires researchers to examine how institutions such as education adapt to address changes in both the domestic and global economies.

Recognizing a rise in demand for high human capital, and that cities - and their human capital systems - play various roles in meeting this labor demand, this study asked how cities work to increase the percentage of their population with a post-secondary credential. The findings presented in previous chapters suggest that cities focus on developing, retaining, and attracting individuals with such credentials. To do this, those who make up the human capital system of a city come together to increase attainment as a precondition for growth. The actors/stakeholders within human capital systems stretch from traditional educational nonprofits to chambers of commerce, and local government. It is through a mutually benefiting network of stakeholders that collaboration creates a shared language, which ties together the economy and education. Additionally, when 
asked why raising human capital was important, the research found two rationales: economic growth and equitable mobility.

Underpinning these findings is the reality of competition. Cities perceive themselves as competing with one another for a larger share of economic growth, using the ability to compete as a justification for modifying and justifying their role in the drive for higher education attainment. Human capital systems -through their desire to raise attainment- have bought into and use the language of competition to help spearhead the demand for high human capital. Organizations and the various stakeholders who comprise human capital systems have accepted the language of competition and tied their work to the larger growth machine. The literature suggests that global flows push high human capital as a precondition for growth beyond geographic boundaries wherein the culture of capitalism makes competition a foundational rationale for raising human capital in the current market.

A problem exists with this line of thinking. To gain a competitive advantage, an actor must outgain those already ahead of them. No gain in competitive advantage takes place if all actors, who are competing, gain at the same rate. What this means for cities is that if they wish to compete in the race to raise human capital, they must do so at a rate that exceeds their identified competitors. In examining the great divergence (Chapter 4), findings revealed that on average this notion of exceeding competitors is not happening overall - and has not happened in the recent decades. As a result, cities have held their "place" in the competition. What this means, is that cities remain stratified based on their human capital and that this stratified system is fairly rigid. Like education itself, which 
both creates mobility pathways and stratifies society for individuals, these findings point to the same reality for cities.

The importance of Chapter 4 is that it highlights the problem with fixating on one precondition such as human capital. Cities who historically have been places of high human capital in the United States tend to remain places with high attainment, a fact supported by prior research, which shows that high attainment cities are outpacing low attainment cities (Moretti 2013). The macro level repercussions for this ongoing divergence are broad. While it is important in the growing knowledge economy to have a large pool of high human capital, using competitive economic rationales fails to recognize that relatively, cities rarely make large competitive leaps when looking solely at human capital. While now and then cities increase attainment at a faster rate than others do, this is not the norm. Instead, efforts to increase attainment as a form of human capital are an attempt by cities to remain steady to not lose or fall behind in the growing knowledge-based economy. One major problem exists with this line of performance benchmarking: by only measuring human capital using formalized credentials, scholars and practitioners have lost sight of less formal modes of human capital development.

While easy to quantify and measure, researchers and practitioners need to question efforts that look solely at attainment as a means of measuring the talent and skills of a localities labor pool. With the emergence of MOOCs (massive open online classes) and creation of company-specific training programs. Both higher education and industry are creating pathways for knowledge and skill expansion, which will go unaccounted for if human capital is measured using traditional metrics. Within the traditional measures of attainment, there also exists a stratified reality. A person attains 
status only at higher and higher levels. As larger percentages attain a post-secondary credential, those at the "bottom" of the strata (e.g., less degree attainment) will see their degree worth less and less. Simply put, this is degree inflation. While education provides a means of economic and personal empowerment, looking forward one can expect to receive less of an economic and status value through attainment as larger shares of the population achieve a post-secondary credential. In effect, this means that a failure to address the inherent inequalities created by higher education will result in the education system that stratifies as much as it empowers. These indicators will require the United States to reimagine how it educates and prepares individuals for the changing economy. The policy recommendation section below proposes ideas and solutions for addressing this problem.

Away from the macro trend findings presented in Chapter 4, the case studies and their collective results highlight the need to move beyond just the study of program efforts to raise human capital. From a perspective of both researchers and practitioners, cities use a broad program level brush to increase their measures of attainment. These increases are centered mainly on the three focuses of a human capital system as identified throughout this study (develop, retain, and attract). Often, organizations focus on one of the three strategic focuses and fail to account for how their efforts affect the larger human capital system of the city. A failure to recognize the level of connectivity is not an indictment of the human capital system stakeholders. Often strapped for resources, the work of stakeholder organizations centers more on survival than systematic citywide efficiency. 
Future research should focus on how cities work to come together through the mutual reinforcement process to meet their own individual goals as well as the collective goal of citywide attainment growth. To do this, research must focus on the network of human capital systems both at the organizational and individual levels. Such research will help in identifying best practices at the system level rather than focusing solely on programming. Additionally, by studying how the city prioritizes development, retention, and attraction, researchers can gain a deeper understanding of the interaction and interconnected nature of the focuses. Research in this area also will shed light on the spillover effect of global flows as a means of creating a shared language of growth across social and economic institutions. Further research on human capital systems can also help to close gaps in regionalism literature regarding the shifting geospatial labor market of American cities. Also, future researchers should examine the effects both positive and negative of being a state capital when studying a city's human capital system.

Each of the cities highlights a different complexity for studying cities at the regional level. All three case cities, while near one another at a national level, sit coupled in a unique geographic and political situation. Louisville, for example, straddles two states; individuals cross back and forth daily for work, shopping, and other daily activities. The research showed that stakeholders within the city's human capital system are working to collaborate across state lines through unifying efforts aimed at meeting the cities regional labor demands. While Nashville and Indianapolis sit completely within their respective states, they too have their regional challenges. Understanding how cities work to break down barriers for regional collaboration within their human systems will provide best practice examples for seeing beyond jurisdictional lines; benchmarking and 
research such as this sees a metropolitan statistical area as more than just geographic space but as a place of complex social and economic ties. The complexity associated with regionalism is not new to urban scholars. Nevertheless, as the geography of jobs shifts, it is important to examine how cities and their human capital system stakeholders adjust to compete in the domestic and global economies.

As cities fight for larger pieces of the economic pie, they also fight for the various preconditions that scholars and practitioners state are essential for becoming more central to the economy. While the findings of this study showed that growth was a key driver for human capital development, retention, and attraction, what emerged from the data was the impact of both federal and state policies. With this in mind, the following section proposes several broad policy recommendations aimed at helping to support the efforts of a city's human capital system.

\section{Policy Recommendations}

In the previous chapter, the term nested-configuration described how the various levels of hierarchy influence the city. Where federal policy changes affect policy at lower levels and the internal experiences of a city, inform their interactions with the hierarchy. Recognizing the nested nature of cities, this section starts with federal policy recommendations focused on national workforce development and education. From there recommendations on how states can both formally and informally support human capital development, retention, and attraction. Finally, recommendations regarding the creation and sustainment of human capital systems at the city level.

The Workforce Innovation and Opportunity Act of 2014 brought together three departments of the United States government for more effectively meeting the changing 
demands on America's workforce. Since its passage, Congress has cut funding to workforce boards, handcuffing the progress to better train and equip America's workforce to meet industry demands. For cities to continue their work in developing talent that aligns with the demands of their particular market, the U.S. federal government must look at growing the budget for WIOA. Doing so will not only help in meeting the current gaps in the labor market, but such funding will increase the number of individuals who can access the educational and workforce training need for both collective and individual growth. Simply adding funding is not enough. Additionally, policymakers must reassess the state allocation formula for WIOA funding. Relying simply on unemployment measures for calculating funding fails to help workforce development boards and their services to enhance the human capital of a locality fully.

Beyond WIOA, the federal government must address the economic burden taken on by enrolling in higher education. If the function of higher education is both collective and individual, then the federal government must ensure all Americans no matter their geography, gender, sexuality, race, ethnicity, and/or socioeconomic background have an equitable pathway to gaining the knowledge and skills demanded by the knowledge economy of the twenty-first century. Addressing access is not a policy option but rather a policy requirement in the college for all era, especially as individuals begin to experience the effects of credential inflation. Individual states have begun to recognize this and have taken it upon themselves to address the financial barriers associated with higher education attainment.

Federalism supplies states the power to pass legislation and policies that they see as beneficial for them both economically and socially. Like cities, states often use the 
language of competition as a stated rationale for many policies. Recognizing that one of the strongest measures of economic competitiveness is high human capital, several states have passed legislation making two-year and four-year college attainment more affordable. In this research, Nashville benefited from the various initiatives and policies that have made community college free within the state of Tennessee. By leading at the state level, state governments are helping the individuals wishing to gain a higher education credential while also taking the burden off their localities who themselves maybe seeking to lower the economic burden of higher education for students. Leadership at the state level, as shown in the Nashville case study, permeates down to individual and organizational level. As more and more states begin to pass legislation, which partially or entirely breaks down, the economic barriers tied to higher education; those who fail to do so maybe left behind in the human capital race.

Above all, cities must continue to lead when it comes to college affordability. For cities specifically, they must work to create regional, multi-jurisdictional collaboration across their entire human capital system. To create this level of collaboration will require constructing a human capital system that does more than just plug current holes but also must work to bring together stakeholders around a forward-thinking vision. Innovation has the potential to increase the rate of human capital accumulation rather than just simple duplication of other efforts attempted by cities. Cities who seek to increase human capital within the current national landscape should push back at isomorphic pressures from national funding entities, while also considering the impacts of policy diffusion. To be competitive, cities (especially those not at the top of the MSA attainment rankings) should measure beyond attainment percentages and measure attainment growth rates. 
Cities able to increase attainment at higher rates have the potential to move permanently ahead of their competitors. Additionally, cities that sit in supportive and aligned nested configurations will be better equipped to meet both the demand and supply sides of the attainment race. What all of these recommendations share in common, is that they abide by the current paradigm, which would only further the college for all culture.

There is no doubt that education provides one of the strongest mobility pathways for any individual. Education as an institution sits near the heart of the American dream. At each level of attainment, individuals gain status and on average see higher economic returns for their labor. The college for all era shifted the discourse and pushed policy to focus on sending every student to two- or four-year higher education institutions. In effect, this approach pushes aside vocational and technical pathways. Going forward policymakers at all levels should revisit traditional vocational and technical training pathways as a means of supplying individuals with the skills and knowledge that are in demand and for growing the economy (Newman and Winston 2016). To do this, policymakers, industry, and education providers will need to develop innovative approaches that are outside of the existing educational paradigm. Taking this from policy formation to implementation requires the political will and buy-in by individuals that current education and workforce policy fails to meet the needs of both the individual and collective.

\section{Limitations}

This research focused on three cities in one region of the United States, possibly limiting the potential to generalize beyond this geographic space. One may also comment on the overall sample, inferring that these cities are not truly reflective nationally. 
However, the goal in pulling from the Talent Dividend Network is for cities to self-select. This self-selection was important because it signaled that these cities had desired, at one point in time, to compete and grow their human capital for some purpose. Lastly, with any snowball sample, relationship bias is a possibility. Questions regarding the centrality of the networks in each city are also valid but do not take away from the existence of human capital systems. Additionally, this research does not see the organizations discussed as peripheral to the work taking place in their respective human capital systems. Researchers will need to conduct deep network analysis of cities to discuss the varying sizes, scopes, and level of centrality for human capital systems.

\section{Summary}

This study sought to answer both how and why U.S. cities are working to raise the percentage of their population with higher educational attainment as a form of human capital. The three case studies showed that cities perceive themselves as working to develop, retain, and attract individuals, for increasing the percentage of their population with at least an associate's degree. Cities, through their various stakeholders, prioritize these three strategies at different levels and use varying programs and initiatives to accomplish them. All three cities showed the formation of what the findings call human capital systems. These networks of organizations and individuals create both informal and formal collaboration across one or more of the three strategic focuses.

While the research only looked at three cities, the findings regarding human capital systems and their roles as part of modern urban growth machines might provide insights for conducting future studies. Future research needs to affirm this belief, but due to the national networks that connect the various cities, along with the isomorphic tendencies associated with mimicry, it is rational to hypothesize similar human capital 
system structures. The findings suggest that the difference between cities is in the weight placed on the three strategic focuses (development, retention, and attraction), along with the programs used to accomplish those ends. Therefore, as future research examines human capital systems, the author sees the framework as applicable to cities and localities of all sizes.

Going forward, practitioners and the academy should focus on the evaluation of city human capital systems. Further research needs to examine the centrality of these networks in cities, and the effects of isomorphism on human capital systems. Research must examine systematic best practices that look beyond programming. Additionally, scholars need to understand the impact that social institutions have on one another; this research would help to understand how institutions such as the urban, industry, and global finance are transforming education and vice-versa.

The findings of this dissertation highlight how the changing domestic and global economies are pressuring changes in education. When addressing how various institutions affect education broadly, it also is wise to consider how knowledge cities influence the balance between higher education being both a tool for individual advancement and a means for economic growth. As the demand and supply for high human capital continues to evolve, practitioners, academics, and policymakers will need to work together to be proactive to meet the various needs of human capital systems. 


\section{REFERENCES:}

Abrahamson, Mark. 2004. Global Cities. Oxford: Oxford University Press.

Academies of Nashville. 2017. “Academies of Nashville: Making Learning as Practical as Possible.” Retrieved June 4, 2017 (http://www.mnps.org/academies-ofnashville/).

Adelman, Robert M. 2004. "Neighborhood Opportunities, Race, and Class: The Black Middle Class and Residential Segregation." City and Community 3(1): 43-64.

Agtmael, Antoine W. van. and Fred Bakker. 2016. The Smartest Places on Earth: Why the Rustbelts Are the Emerging Hotspots of Global Innovation. New York: Public Affairs.

Alon, Sigal and Marta Tienda. 2005. "Assessing the "Mismatch" Hypothesis: Differences in College Graduation Rates by Institutional Selectivity." Sociology of Education 78: 294-315.

Appadurai, Arjun. 1996. Modernity at Large: Cultural Dimensions of Globalisation. Minneapolis: University of Minnesota Press.

Armstrong, Elizabeth A. and Laura T. Hamilton. 2013. Paying for the Party. Cambridge, MA: Harvard University Press.

Audretsch, David B., Diana Heger, and Tobias Veith. 2015. "Infrastructure and Entrepreneurship.” Small Business Economics 44 (2):219-230.

Audretsch, David B., and Erik Lehmann. 2005. "Does Knowledge Spillover Theory of Entrepreneurship Hold for Regions?” Research Policy 34(8):1191-1202. 
Bagachi-Sen, Sharmistha. 1995. "Structural Determinants of Occupational Shifts for Males and Females in the U.S. Labor Market." The Professional Geographer 47(3): 268-279.

Barnhardt, Cassie L. 2017. "Higher Education: Handbook of Theory and Research: Published Under the Sponsorship of the Association for Institutional Research (AIR) and the Association for the Study of Higher Education (ASHE).” Pp. 181257 in Philanthropic Foundations' Social Agendas and the Field of Higher Education. Cham: Springer International Publishing.

Barro, Robert. 2001. "Human Capital and Growth.” American Economic Review 91(2): $12-17$.

Bartik, Timothy J. 2011. Investing in Kids: Early Childhood Programs and Local Economic Development. Kalamazoo, MI: Upjohn Institute for Employment Research.

Basolo, Victoria. 2003. "U.S. Regionalism and Rationality." Urban Studies 40(3): 447462.

Baum, Sandy, Jennifer Ma and Kathleen Payea. 2010. "Education Pays, 2010: The Benefits of Higher Education for Individuals and Society." College Board Advocacy and Policy Center.

Bauman, Kurt and Camille L. Ryan. 2016. "Educational Attainment in the United States: 2015.” Retrieved July 27, 2017 (https://www.census.gov/content/dam/Census/library/publications/2016/demo/p20 578.pdf).

Becker, Gary. 1975. Human Capital. Chicago, IL: Chicago University Press. 
Becker, Gary. 1993. Human Capital: A Theoretical and Empirical Analysis with Special Reference to Education. Chicago, IL: University of Chicago Press.

Been, Vicki, Josiah Madar, and Simon McDonnell. 2014. "Urban Land-Use Regulation: Are Homevoters overtaking he Growth Machine?". Journal of Empirical Legal Studies 11(2):227-265.

Benner, Chris and Manuel Pastor. 2012. Just Growth: Inclusion and Prosperity in America's Metropolitan Regions. New York: Routledge.

Bok, Derek. 2013. Higher Education in America. Princeton, NJ: Princeton University Press.

Bowles, Samuel and Herbert Gintis. 2011. Schooling in Capitalist America. New York: Basic Books.

Brenner, Neil. 2000. The Urban Question: Reflections on Henri Lefebvre, Urban Theory and the Politics of Scale. International Journal of Urban and Regional Research 24(2): 361-378.

Burgess, Ernest W. 1984. "The Growth of the City: An Introduction to a Research Project.” Pp. 47-62 in The City, edited by Robert E. Park and Ernest W. Burgess. Chicago, IL: University of Chicago Press.

Cain, Colleen. 2014. "Negotiating with the Growth Machine: Community Benefits Agreements and Value Conscious." Sociological Forum 29(4): 937-958.

Calvino, Italo. 1978. Invisible Cities. Orlando, FL: Harcourt Publishing. Carlino, Gerald. 1995. "Do Education and Training Lead to Faster Growth Cities?" Business Review of the Federal Reserve Bank of Philadelphia January Issue:1522. 
Carnevale, Anthony P., Tamara Jayasundera and Artem Gulish. 2016. America's Divided Recovery: College Haves and Have-Nots. Center on Education and the Workforce. Washington D.C.: Georgetown University. Retrieved July 1, 2016 (https://cew.georgetown.edu/wp-content/uploads/Americas-Divided-Recoveryweb.pdf).

Carrillo, Fracisco. 2004. "Capital Cities: A Taxonomy of Capital Accounts for Knowledge Cities." Journal of Knowledge Management. 8(5): 28-46.

Clark, Cal, Johnny Green and Keenana Grenell. 2001. 'Local Regimes: Does Globalization Challenge the Growth Machine.” Policy Studies Review 18(3): 4962.

Clarke, Thomas. 2001. "The Knowledge Economy.” Education+Training 43(4): 189196.

Collins, Patricia Hill. 2009. “The New Politics of Community.” American Sociological Review 75(1):7-30.

COSMOS Corporation. (1983). Case Studies and Organizational Innovation” Strengthening the Connection. Bethesda, MD: Author.

Cox, Kevin R. 1993. "The Local and the Global in the New Urban Politics: A Critical Review." Environment and Planning D: Society and Space 11:433-448.

Cox, Kevin R. 1999. "Ideology and the Growth Coalition.” Pp. 21-26 in The Urban Growth Machine: Critical Perspectives Two Decades Later, edited by Andrew E. G. Jonas and David Wilson. New York: State University of New York Press. Craig, Ryan. 2015. College Disrupted: The Great Unbundling of Higher Education. New York, NY: Palgrave Macmillan. 
Domina, Thurston. 2006. "Brain Drain and Brain Gain: Rising Educational Segregation in the United States, 1940-2000." City and Community 5(4): 387-407.

Dreier, Peter, John Mollenkorf, and Todd Swanstrom. 2001. Place Matters: Metropolitics for the Twenty-first Century. Lawrence, KS: University Press of Kansas.

Duggal, Vijaya G., Cynthia Saltzman, and Lawrence R. Klein. 2007. “Infrastructure and Productivity: An Extension to Private Infrastructure and it Productivity.” Journal of Econometrics 140(2): 485-502.

Employment and Training Administration. 2014a. “The Workforce Innovation and Opportunity Act.” United States Department of Labor: (https://www.doleta.gov/wioa/Docs/WIOA-Factsheet.pdf).

Employment and Training Administration. 2014b. “The Workforce Innovation and Opportunity Act.” United States Department of Labor: (https://www.doleta.gov/wioa/Docs/WIOA_GovernLeadership_FactSheet.pdf).

Ergazakis, Kostas, Kostas Metaxiotis and John Psarras. 2004. “Towards Knowledge Cities: Conceptual Analysis and Success Stories." Journal of Knowledge Management 8(5): 5-15.

Ergazakis, Kostas, Kostas Metaxiotis and John Psarras. 2006. “An Emerging Pattern of Successful Knowledge Cities' Main Features.” Pp. 3-15 in Knowledge Cities, edited by Francisco Javier Carrillo. Oxford: Butterworth-Heinemann.

Everett, Bethany G., Richard F. Rogers, Robert A. Hummer, and Patrick M. Krueger. 2011. "Trends in educational attainment by race/ ethnicity, nativity, and sex in the United States, 1989-2005.” Ethnic and Racial Studies 34(9): 1543-1566. 
Felbinger, Claire L. and James E Robey. "The Rise of Regional Cluster-Based Economic Development Strategies.” Policy Studies Review 18(3): 63-79.

Florida, Richard. 2002. The Rise of the Creative Class. New York, NY: Basic Books.

Florida, Richard. 2005. Cities and the Creative Class. New York, NY: Routledge.

Frenkel, Amnon, Edward Bendit and Sigal Kaplan. 2013. "Residential location choice of knowledge-workers: The role of amenities, workplace and lifestyle.” Cities 35:3341.

Garreau, Joel. 1994. "Edge Cities.” American Demographics 16(2): 24.

Geiger, Roger L. 2011 “The Ten Generations of American Higher Education.” Pp. 37-68 in American Higher Education in the Twenty-First Century, edited by Philip Altbach, Patricia J. Gumport, and Robert O. Berdahl. Baltimore: John Hopkins University Press.

Gibson, Chris and Lily Kong. 2005. "Cultural Economy: A Critical Review.” Progress in Human Geography 29(5): 541-561.

Glaeser, Edward L. 1994. "Cities, information, and Economic Growth.” Cityscape 1(1):947.

Glaeser, Edward L., Jose A. Scheinkman, and Andrei Shleifer. 1995. "Economic Growth in a Cross-Section of Cities.” Journal of Monetary Economics 36(1): 117-143.

Glyde, Gerald P. 2016. "Underemployment: Defintion and Causes.” Journal of Economic Issues 11(2): 245-260.

Goldin, Claudia and Lawrence F. Katz. 2008. The Race Between Education and Technology. Cambridge, MA: Harvard University Press. 
Gottlieb, Paul D. and Michael Fogarty. 2003. "Educational Attainment and Metropolitan Growth." Economic Development Quarterly 17(4): 325-336.

Greene, Francis J., Paul Tracey, and Marc Cowling. 2007. "Recasting the City into City Regions: Place Promotion, Competiveness Benchmarking and the Quest for Urban Supremacy." Growth and Change 38(1):1-22.

Graduate Network. 2015. "About the Network” http://graduate-network.org/about-us/. Hanlon, Bernadette. 2009. “A Typology of Inner-Ring Suburbs: Class, Race, and Ethnicity in U.S. Suburbia." City and Community 8(3): 221-246.

Hanushek, Eric A., Dean t. Jamison, Eliot A. Jamison, and Ludger Woessmann. 2008. "Education and Economic Growth." Education Next 8(2):62-70.

Hanushek, Eric A., Jens Ruhose, and Ledger Woessmann. 2016. "It Pays to Improve School Quality." Education Next 16(3): 16-24.

Harvey, David. 2005. A Brief History of Neoliberalism. Oxford: Oxford University Press. Haughwout, Andrew. 1999. "State Infrastructure and the Geography of Employment." Growth and Change 30 (4):549-566.

Hill, Richard and Kuniko Fujita. 2003. "The Nested City: Introduction.” Urban Studies 40(2): 207-217.

Howell, Jessica S. and Matea Pender. 2016. "The Cost and Benefits of Enrolling in an Academically Matched College." Economics of Education Review 51(3): 152168.

Huggins, Robert. 2009. "Regional Competitive Intelligence: Benchmarking and Policymaking.” Regional Studies 44(5):639-658. 
Huggins, Robert and Hiro Izushi. 2009. "Regional Benchmarking in a Global Context: Knowledge, Competitiveness, and Economic Development." Economic Development Quarterly 23(4):275-293.

International Trade Administration. 2017. "MSA 2015 (Full Year) Exports". United States Department of Commerce. Retrieved February $28^{\text {th }} 2017$ : http://tse.export.gov/metro/MetroMapDisplay.aspx?ReportID=1\&Referrer=Select Reports.aspx\&DataSource=Metro\&ReportOption=Map

Jonas, Andrew E.G. and David Wilson. 1999. "The City as a Growth Machine Critical Reflections Two Decades Later.” Pp. 3-20 In The Urban Growth Machine: Critical Perspectives Two Decades Later, edited by Andrew E.G. Jonas and David Wilson. New York, NY: State University of New York Press.

Kalmijn, Matthijs and Gerbert Kraaykamp. 1996. "Race, Cultural Capital, and Schooling: An Analysis of Trends in the United States." Sociology of Education 69(1): 22-34. Kania, John and Mark Kramer. 2011. "Collective Impact”. Stanford Social Innovation Review 9(1):36-41.

Krugman, Paul. 1996. "Making Sense of the Competiveness Debate." Oxford Review of Economic Policy 12:17-35.

Kuo, Frances E. and William C Sullivan. 2001. “Aggression and Violence in the Inner City: Effects of Environment via Mental Fatigue.” Environment and Behavior 33(4): 543-571.

Krupat, Edward. 1985. People in Cities: The Urban Environment and Its Effects. New York, NY: Cambridge University Press.

Labaree, David. 2010. Someone Has to Fail. Cambridge, MA: Harvard University Press. 
Ladd, Helen F. 2012. "Presidential Address: Education and Poverty: Confronting the Evidence." Journal of Policy Analysis and Management 31(2): 203-227.

Jensen, Leif and Slack Tim. 2003. "Underemployment in America: Measurement and Evidence." Community Psychology 32(1): 21-31.

Living Cities. 2014. “Talent Dividend Final Report.” Retrieved May 22, 2017 (https://www.livingcities.org/resources/280-talent-dividend-final-report)

Lang, Robert. 2002. Edgeless Cities. New York: Brookings Institution Press.

Lipman, Pauline. 2011. The New Political Economy of Urban Education: Neoliberalism, Race, and The Right to the City. New York: Routledge.

Livingstone, D.W. 1999. "Lifelong Learning and Underemployment in the Knowledge Society: A North American Perspective.” Comparative Education 35(2): 163-186. Livingstone, D.W. 2004. The Education-Jobs Gap: Underemployment or Economic Democracy. Toronto: Garamond Press.

Livingstone, D.W. 2009a. "Prior Empirical Research on Education-Job Matching.” Pp. 30-50 In Education and Jobs: Exploring the Gaps, edited by D.W. Livingstone. Toronto: University of Toronto Press.

Livingstone, D.W. 2009b. "Starting with The Education-Jobs Gap” Pp. 51-63 In Education and Jobs: Exploring the Gaps, edited by D.W. Livingstone. Toronto: University of Toronto Press.

Louisville Metro Government. 2014. “Cradle to Career: Louisville.” Retrieved July 19, 2017

(https://louisvilleky.gov/sites/default/files/safe_neighborhoods/vii_b_cradletocare erlouisville_0_5.pdf). 
Louisville Metro Government. 2017. "Degrees Work to Help Workers Finish College Degree.” Retrieved July 21, 2017 (https://louisvilleky.gov/news/degrees-workhelp-workers-finish-college-degree).

Marcotte, David E. 2010. "The Earnings Effect of Education at Community Colleges." Contemporary Economic Policy 28(1): 36-51.

Martinez, Samuel David. 2006. “A Comparative Framework for Knowledge Cities.” Pp. 17-30 in Knowledge Cities edited by Francisco Javier Carrillo. Oxford: Butterworth-Heinemann.

Maynard, Douglas C. and Daniel C. Feldman. 2011. Underemployment: Psychological, Economic, and Social Challenges. New York: Springer.

Mayor's Educational Roundtable. 2010. "Greater Louisville Education Commitment." Retireved October 18, 2017 (http://www.55000degrees.org/wpcontent/uploads/2012/05/Greater-Louisville-Education-Commitment.pdf).

McClendon, David, Janet Chen-Lan Kuo and R. Kelly Raley. 2014. "Opportunities to Meet: Occupational Education and Marriage Formation in Young Adulthood." Demography 51:1319-1344.

Minnesota Population Center. 2016. National Historical Geographic Information System: Version 2.0. Minneapolis, MN: University of Minnesota 2011.

Molotch, Harvey. 1976. "The City as a Growth Machine: Toward a Political Economy of Place." American Journal of Sociology 82: 309-332.

Molotch, Harvey. 1993. "The Political Economy of Growth Machine" Journal of Urban Affairs 15: 29-53. 
Molotch, Harvey. 1999. “Growth Machine Links: Up, Down, and Across.” Pp. 247-265 in The Urban Growth Machine: Critical Perspectives Two Decades Later. Edited by Andrew E.G. Jonas and David Wilson. New York: State University of New York Press.

Moretti, Enrico. 2013. The New Geography of Jobs. New York: Houghon Mifflin Hacourt Publishing Company.

Nashville Chamber of Commerce. 2014. "The Nashville Region is Red Hot: Nashville Area Chamber of Commerce Annual Report.” Retrieved May 22, 2017 (https://s3.amazonaws.com/nashvillechamber.com/PDFs/2014-NashvilleChamber-Partnership-Annual-Report.pdf).

National Commission on Excellence in Education. 1983. A Nation At Risk. Retrieved January 30, 2017 (https://www2.ed.gov/pubs/NatAtRisk/risk.html).

National Education Association. 1957. Higher Education in a Decade of Decision. Washington, D.C.: National Education Association of the United States and the American Association of School Administrators.

Neal, Zachary P. 2013. The Connected City. New York: Routledge.

Newman, Katherine S. and Hella Winston. 2016. Reskilling America: Learning to Labor in the Twenty-First Century. New York: Metropolitan Books.

Olson, Keith W. 1973. "The G.I. Bill and Higher Education: Success and Surprise.” American Quarterly 25(5): 596-610.

Olssen, Mark and Michael A. Peters. 2007. "Neoliberalism, Higher Education and the Knowledge Economy: From the Free Market to Knowledge Capitalism.” Journal of Education Policy 20 (3): 313-345. 
Organization for Economic Co-operation and Development (OECD). 1996. "The Knowledge Based Economy.” Organization for Economic Co-operation and Development: Paris.

Payne, Charles M. 2013. So Much Reform So Little Change: Persistence of Failure in Urban Schools. Cambridge, MA: Harvard Education Press.

Peck J. and A. Tickell. 2002. “Neoliberalizing Space”. Pp. 33-57 in Spaces of Neoliberalism: Urban Restructuring in North America and Western Europe edited by Neil Brenner and Nik Theodore. Oxford: Blackwell.

Putnam, Robert D. 2015. Our Kids: The American Dream in Crisis. New York: Simon and Schuster.

Rauch, James E. 1993. "Productivity Gains from Geographic Concentration of Human Capital: Evidence from the Cities." Journal of Urban Economics 34:380-400.

Rausch, Stephen and Cynthia Negrey. 2006. "Does The Creative Engine Run? A Consideration of the Effect of Creative Class on Economic Strength and Growth.” Journal of Urban Affairs 28(5): 473-489.

Reid, M Jeanne and James L. Moore III. 2008. “College Readiness and Academic Preparation for Postsecondary Education.” Urban Education 43(2): 240-261.

Reisinger, Mark E. 2003. "Sectoral Shifts and Occupational Migration in the United States." The Professional Geographer 55(3): 383-395.

Robinson, Jennifer. 2006. Ordinary Cities. New York: Routledge. Roderick, Melissa, Vanessa Coca, and Jenny Nagaoka. 2011. "Potholes on the Road to College: High School Effects in Shaping Urban Students' Participation in College 
Application, Four-year College Enrollment, and College Match." Sociology of Education 84(3):178-211.

Romer, Paul. 1986. "Increasing Returns and Long-run Growth.” Journal of Political Economy 94(5):1002-1037.

Romer, Paul. 1990. “Endenous Technical Change.” Journal of Political Economy 98: 71102.

Saatcioglu, Argun and John L. Rury. 2012. "Education and Changing Metropolitan Organization of Inequality: A Multilevel Analysis of Secondary Attainment in United States, 1940-1980." Historical Methods: A Journal of Quantitative and Interdisciplinary History 45(1): 21-40.

Sander, William and William Testa. 2015. "Parents education, school age children and household location in American Cities." Papers in Regional Science 94(3): 573595.

Sassen, Saskia. 1994. Cities in a World Economy. Thousand Oaks, CA: Pine Forge Press.

Sassen, Saskia. 2005. "The Global City: Introducing a Concept.” The Brown Journal of World Affairs 6(2): 28-43.

Savitch, H. V., David Collins, Daniel Sanders, and John Markham. 1993. "Ties that Bind: Central Cities, Suburbs, and the New Metropolitan Region.” Economic Development Quarterly 7(4): 341-357.

Sawhill, Isabel V. and Stephanie Owen. 2013. “Should Everyone Go to College?” Center on Children and Families. Washington DC: Brookings Institution.

Sax, Linda J. 2008. The Gender Gap in College. San Francisco, CA: Jossey-Bass. 
Seiter, Stephan. 2003. "Endogenous Growth: One Phenomenon, Two Interpretations." Pp. 27-39 in Growth Theory and Growth Policy, edited by Harald Hagemann and Stephan Seiter. New York: Routledge.

Simmel, Georg. 1950. “The Metropolitan \& Mental Life.” Sociology of Georg Simmel: 409-424.

Simon, Curtis. 1998. "Human Capital and Metropolitan Employment Growth.” Journal of Urban Economics 43:223-243.

Simon, Curtis and Clark Nardinelli. 2002. "Human Capital and the Rise of American Cities 1900-1990.” Regional Science and Urban Economics 32:59-96.

Spencer, James. 2015. Globalization and Urbanization: The Global Urban Ecosystem. Landham, MD: Rowman \& Littlefield.

Spring, Joel. 2008. "Research on Globalization and Education.” Review of Educational Research 78(2):330-363.

State of Tennessee. Public Chapter NO. 900: Tennessee Promise Scholarship Act of 2014. S. Bill No. 2491. Regular Session 2014. Retrieved May 21, 2017 (http://www.tn.gov/sos/acts/108/pub/pc0900.pdf).

Stone, Clarence. 1989. Regime Politics: Governing Atlanta. Lawrence, KS University Press of Kansas.

Strohush, Vitaliy and Justin Wanner. 2015. "College Degree for Everyone?" International Advances in Economic Research 21(3):261-273.

Stroper, Michael. 1997. The Regional World: Territorial Development in a Global Economy. New York: Guilford Press. 
Talent Dividend Network (TDN). 2010. “About Talent Dividend Network.” Retrieved June. 26, 2016 (http://www.talentdividendnetwork.com/about/About.aspx).

Tavernise, Sabrina. 2012. “A Gap in College Graduates Leaves Some Cities Behind.” Retrieved May 15, 2017 (http://www.nytimes.com/2012/05/31/us/as-collegegraduates-cluster-some-cities-are-left-behind.html).

Tennessee Board of Regents. 2017. “Governor's Drive to 55.” Retrieved May 21, 2017: (https://www.tbr.edu/initiatives/governors-drive-55).

Tennessee Higher Education Commission. 2017. “Complete College TN Act of 2010.” Retrieved May 22, 2017 (https://www.tn.gov/thec/topic/complete-college-tn-act).

Tennessee Promise. 2017. “About: Tennessee Promise.” Retrieved May 21, 2017 (http://tnpromise.gov/about.shtml).

Thelin, John R. 2011. A History of American Higher Education. Baltimore: John Hopkins University Press.

Timberlake, Jeffrey M. and John Iceland. 2007. "Change in Racial and Ethnic Residential Inequality in American Cities, 1970-2000." City and Community 6(4): 335-365.

Tiboris, Michael. 2014. "What's Wrong with Undermatching." Journal of Philosophy of Education 48(4): 646-664.

tnAchieves. 2017. "Drive to 55." Retrieved May 21, 2017 (https://tnachieves.org/aboutus/drive-to-55).

Trippl, Michaela and Gunther Maier. 2010. “Knowledge Spillover Agents and regional Development." Papers in Regional Science 89(2):229-233.

Tsai, Chun Li, Ming-Cheng Hung, and Kevin Harriott. 2010. "Human Capital Composition and Economic Growth.” Social Indicators Research: An 
International and Interdisciplinary Journal for Quality-of-Life Measurement 99(1): 41-59.

United States Census Bureau. 1998. "Population of the 100 Largest Urban Places: 1900." Retrieved November $16^{\text {th }}, 2016$ :

(https://www.census.gov/population/www/documentation/twps0027/tab13.txt).

U.S. Census Bureau a.; American Community Survey, 2016 American Community

Survey 5-Year Estimates, Table S0501; generated by Brandon McReynolds; using American FactFinder; http://factfinder2.census.gov; (20 December 2016).

U.S. Census Bureau b.; American Community Survey, 2016 American Community Survey 5-Year Estimates, Table DP03; generated by Brandon McReynolds; using American FactFinder; http://factfinder2.census.gov; (20 December 2016).

United States Bureau of Economic Analysis. 2017a. "Per Capita Real GDP by Metropolitan Area," Retrieved February 28, 2017

(https://bea.gov/iTable/iTable.cfm?reqid=70\&step=1\&isuri $=1 \&$ acrdn=7\#reqid $=7$ $0 \&$ step $=10 \&$ isuri $=1 \& 7003=1000 \& 7035=1 \& 7004=$ naics $\& 7005=1 \& 7006=x x \& 70$ $36=-1 \& 7001=21000 \& 7002=2 \& 7090=70 \& 7007=2015 \& 7093=$ levels $).$

United States Bureau of Economic Analysis. 2017b. "CA1 Personal Income Summary:

Personal Income, Population, Per Capita Personal Income.” Retrieved February 27, 2017 (https://www.bea.gov/newsreleases/regional/lapi/lapi_newsrelease.htm). United States Department of Education. 2007. “Carl D. Perkins Career and Technical Education Act of 2006.” Retrieved June 22, 2017 (https://www2.ed.gov/policy/sectech/leg/perkins/index.html). 
United States Department of Education, National Center for Education Statistics. (2015). Digest of Education Statistics, 2013. National Center for Education Statistics, NCES 2015-011. Washington, D.C.: Government Printing Office.

United States Bureau of Labor Statistics. 2016. "Employment Projections.” Retrieved December 20, 2016: https://www.bls.gov/emp/ep_chart_001.htm.

United States Department of Transportation. 2015a. "Major Freight Corridors.” Retrieved September 22, 2016

(http://ops.fhwa.dot.gov/Freight/freight_analysis/nat_freight_stats/mjrfreightcorri dors.htm).

United States Department of Transportation. 2015b. “Top 25 U.S. International Trade Freight Gateways by Value of Shipments.” Retrieved Sept. 22, 2016 (http://ops.fhwa.dot.gov/Freight/freight_analysis/nat_freight_stats/topftgvalue201 1.htm).

United States Government. 1947. "Higher Education for American Democracy: Volume 1, A Report on the President's Commission on Higher Education.” Washington, D.C.: U.S. Government Printing Office.

United States Office of Management and Budget. 2013. Revised Delineations of Metropolitan Statistical Areas, Micropolitan Statistical Areas, and Combined Statistical Areas, and Guidance on Uses of the Delineations of These Areas (OMB BULLETIN NO. 13-01). Washington D.C.: The Executive Office of the President, Office of Management and Budget. 
University of Tennessee Advocacy. 2013. "Governor Bill Haslam Launches Drive to 55 Initiative." Retrieved May 21, 2017 (http://advocacy.tennessee.edu/2013/09/04/drive-to-55-initiative/).

Viedma, Jose Maria. "CICBS: A Methodology and a Framework for Measuring and Managing Intellectual Capital of Cities: A practical Application in the City of Mataró." Journal of Knowledge Management Research and Practice: 13-23.

Wagner, Fritz W., Timothy E. Joder and Anthony J. Mumphrey, eds. 2003. Human Capital Investment for Central City Revitalization. New York: Routledge. Weber, Max. 1921. "The Nature of the City. ” Pp. 23-46 In The City edited by Max Weber. Glencoe, Illinois: Free Press.

Wolf, Alison. 2003. "Education and Growth." New Economy 10(1):10-15.

Yater, George H. 1979. Two Hundred Years at the Falls of the Ohio: A History of Louisville and Jefferson County. Louisville, KY: The Heritage Corporation. Yin, Robert K. 2014. Case Study Research: Design and Methods. Thousand Oaks, CA: SAGE Publications. 


\section{APPENDICES:}

Appendix I. Interview Question Guide

The following are questions for the interview portion of "The Knowledge Economy:

Increasing Human Capital on the U.S. I-65 Corridor".

Questions are in a working order and may be rearranged:

1. Can you tell me about what your organizations - what does the organization do and what are its areas of focus?

2. Tell me about your role in the organization.

3. What does your organization do in support of higher education?

4. Why does you organization work to promote higher education?

5. How do you and your organization choose what to focus on?

6. What are several of the higher educational initiative your organization is working on?

7. Whom do you collaborate with on your various educational programs/initiatives?

8. Is there anything else you wish to share about your organization? 


\section{Appendix II. Final Talent Dividend Standings}

Talent Dividend - Overall Ranking

Talent Dividend: Final Rankings

\begin{tabular}{|c|c|c|c|c|c|c|c|c|c|c|}
\hline City & AA.2010 & BA+.2010 & AA.2013 & BA+.2013 & POP 2010 & POP 2013 & $\begin{array}{ll}++ & \text { Pts } 2010 \\
\end{array}$ & Pts 2013 & Pct. Inc. & Rank \\
\hline Akron, $\mathrm{OH}$ & 1,147 & 9,346 & 1,414 & 11,218 & 705,474 & 705,686 & 2,812 & 3,380 & $20.2 \%$ & 61 \\
\hline Portland-Vancouver-Beaverton, OR-WA & 6,054 & 13,408 & 9,468 & 15,306 & $2,232,177$ & $2,314,554$ & 1,473 & 1,732 & $17.6 \%$ & 2 \\
\hline Omaha-Council Bluffs, NE-IA & 2,390 & 5,883 & 2,972 & 7,064 & 868,087 & 895,151 & 1,631 & 1,910 & $17.1 \%$ & 3 \\
\hline Tulsa, OK & 3,195 & 2,190 & 4,102 & 2,439 & 939,826 & 961,561 & 806 & 934 & $15.9 \%$ & 4 \\
\hline Syracuse, NY & 2,243 & 8,939 & 2,488 & 10,393 & 662,972 & 661,934 & 3,035 & 3,516 & $15.9 \%$ & 5 \\
\hline Tampa-St. Petersburg-Clearwater, FL & 9,288 & 17,652 & 12,013 & 20,389 & $2,788,961$ & $2,870,569$ & 1,599 & 1,839 & $15.0 \%$ & 6 \\
\hline Chattanooga, TN-GA & 1,101 & 2,687 & 1,448 & 3,058 & 529,107 & 541,744 & 1,224 & 1,396 & $14.1 \%$ & 7 \\
\hline Orlando-Kissimmee, $\mathrm{FL}$ & 10,592 & 14,408 & 13,429 & 16,992 & $2,139,372$ & $2,267,846$ & 1,842 & 2,091 & $13.5 \%$ & 8 \\
\hline Richmond, $V A$ & 2,040 & 8,926 & 2,621 & 10,239 & $1,260,299$ & $1,296,680$ & 1,578 & 1,781 & $12.9 \%$ & 9 \\
\hline Columbia, SC & 1,027 & 7,595 & 1,406 & 8,642 & 769,655 & 793,779 & 2,107 & 2,355 & $11.7 \%$ & 10 \\
\hline Houston-Sugar Land-Baytown, TX & 11,633 & 21,067 & 15,460 & 24,098 & $5,975,153$ & $6,340,014$ & 900 & 1,004 & $11.6 \%$ & 11 \\
\hline Louisville-Jefferson County, KY-IN & 2,723 & 7,698 & 3,228 & 8,695 & $1,285,964$ & $1,312,039$ & 1,409 & 1,571 & $11.5 \%$ & 12 \\
\hline Memphis, TN-MS-AR & 2,007 & 5,512 & 2,606 & 6,038 & $1,317,887$ & $1,333,175$ & 989 & 1,101 & $11.4 \%$ & 13 \\
\hline Sarasota-Bradenton-Venice, FL & 1,500 & 1,299 & 1,693 & 1,521 & 703,545 & 732,535 & 582 & 646 & $11.0 \%$ & 14 \\
\hline Raleigh-Cary, NC & 1,969 & 8,350 & 2,735 & 9,685 & $1,137,351$ & $1,214,516$ & 1,641 & 1,820 & $10.9 \%$ & 15 \\
\hline Honolulu, HI & 2,599 & 7,274 & 3,383 & 8,074 & 956,256 & 983,519 & 1,793 & 1,986 & $10.7 \%$ & 16 \\
\hline El Paso, TX & 3,456 & 4,010 & 4,208 & 4,428 & 807,041 & 831,036 & 1,422 & 1,572 & $10.6 \%$ & 17 \\
\hline Jackson, MS & 1,971 & 4,345 & 2,454 & 4,735 & 540,285 & 548,499 & 1,973 & 2,174 & $10.2 \%$ & 18 \\
\hline Baltimore-Towson, MD & 5,791 & 24,831 & 7,393 & 27,100 & $2,715,312$ & $2,770,738$ & 2,042 & 2,223 & $8.9 \%$ & 19 \\
\hline Cleveland-Elyria-Mentor, $\mathrm{OH}$ & 5,431 & 9,884 & 6,363 & 10,416 & $2,075,690$ & $2,064,725$ & 1,214 & 1,317 & $8.5 \%$ & 20 \\
\hline Indianapolis-Carmel, IN & 2,983 & 9,452 & 4,368 & 10,018 & $1,760,678$ & $1,823,479$ & 1,243 & 1,338 & $7.7 \%$ & 21 \\
\hline Philadelphia, PA & 12,222 & 59,562 & 13,134 & 64,866 & $5,971,397$ & $6,034,678$ & 2,200 & 2,367 & $7.6 \%$ & 22 \\
\hline Pittsburgh, PA & 6,401 & 23,849 & 6,405 & 25,857 & $2,356,658$ & $2,360,867$ & 2,296 & 2,462 & $7.2 \%$ & 23 \\
\hline Milwaukee-Waukesha-West Allis, WI & 2,843 & 13,268 & 3,118 & 14,305 & $1,556,549$ & $1,569,659$ & 1,887 & 2,021 & $7.1 \%$ & 24 \\
\hline Charlotte-Gastonia-Concord, NC-SC & 3,816 & 8,873 & 4,438 & 9,966 & $1,824,468$ & $1,926,538$ & 1,182 & 1,265 & $7.0 \%$ & 25 \\
\hline Los Angeles-Long Beach-Santa Ana, CA & 31,668 & 97,594 & 36,593 & 105,678 & $12,844,070$ & $13,131,431$ & 1,766 & 1,888 & $6.9 \%$ & 26 \\
\hline Harrisburg-Carlisle, $P A$ & 2,061 & 4,517 & 2,398 & 4,805 & 550,262 & 557,711 & 2,016 & 2,153 & $6.8 \%$ & 27 \\
\hline McAllen-Edin burg-Mission, TX & 1,828 & 3,378 & 2,294 & 3,650 & 779,271 & 815,996 & 1,102 & 1,176 & $6.7 \%$ & 28 \\
\hline Washington-Arlington-Alexandria DC-VA & 9,745 & 47,867 & 13,170 & 52,524 & $5,610,484$ & $5,893,875$ & 1,380 & 2,006 & $6.7 \%$ & 29 \\
\hline Boston-Quincy, MA & 7,263 & 70,740 & 8,211 & 77,257 & $4,564,054$ & $4,684,299$ & 3,259 & 3,474 & $6.6 \%$ & 30 \\
\hline Knoxville, TN & 1,080 & 7,535 & 1,581 & 8,004 & 699,200 & 714,813 & 2,310 & 2,461 & $6.5 \%$ & 31 \\
\hline Detroit-Livonia-Dearborn, MI & 11,192 & 17,716 & 13,905 & 17,893 & $4,291,400$ & $4,294,983$ & 1,086 & 1,157 & $6.5 \%$ & 32 \\
\hline Hartford-West Hartford-East Hartford, C & 2,499 & 12,891 & 2,897 & 13,579 & $1,214,014$ & $1,215,211$ & 2,330 & 2,473 & $6.2 \%$ & 33 \\
\hline Rochester, NY & 4,058 & 12,367 & 4,301 & 13,138 & $1,054,726$ & $1,058,122$ & 2,730 & 2,890 & $5.9 \%$ & 34 \\
\hline Baton Rouge, LA & 1,117 & 7,470 & 1,365 & 7,976 & 804,472 & 820,159 & 1,996 & 2,111 & $5.8 \%$ & 35 \\
\hline Nashville-Davidson-Murfreesboro-Franklin, TN & 2,466 & 13,716 & 2,696 & 15,251 & $1,594,760$ & $1,674,151$ & 1,875 & 1,983 & $5.8 \%$ & 36 \\
\hline Fargo, ND-MN & 54 & 4,223 & 67 & 4,757 & 209,400 & 223,490 & 4,059 & 4,287 & $5.6 \%$ & 37 \\
\hline Chicago-Naperville-Joliet, IL & 19,010 & 75,143 & 23,171 & 78,318 & $9,477,247$ & $9,544,149$ & 1,786 & 1,884 & $5.5 \%$ & 38 \\
\hline Charleston-North Charleston-Summerville, SC & 1,274 & 4,794 & 2,018 & 5,085 & 667,719 & 712,220 & 1,627 & 1,711 & $5.2 \%$ & 39 \\
\hline Providence-New Bedford-Fall River, Rl-M & 4,521 & 16,318 & 4,765 & 17,181 & $1,601,798$ & $1,604,291$ & 2,320 & 2,439 & $5.1 \%$ & 40 \\
\hline Minneapolis-St. Paul-Bloomington, MN-WI & 9,052 & 26,365 & 10,705 & 28,022 & $3,286,157$ & $3,390,431$ & 1,880 & 1,969 & $4.7 \%$ & 41 \\
\hline St. Louis, MO-IL & 7,344 & 27,925 & 9,068 & 28,532 & $2,530,488$ & $2,542,495$ & 2,497 & 2,601 & $4.2 \%$ & 42 \\
\hline Buffalo-Niagara Falls, NY & 3,853 & 15,319 & 4,319 & 15,704 & $1,135,314$ & $1,134,115$ & 3,038 & 3,150 & $3.7 \%$ & 43 \\
\hline Lakeland, FL & 1,360 & 1,555 & 1,584 & 1,595 & 603,452 & 623,009 & 741 & 766 & $3.4 \%$ & 44 \\
\hline Dayton, $\mathrm{OH}$ & 3,382 & 7,800 & 3,688 & 7,947 & 844,082 & 844,221 & 2,249 & 2,320 & $3.1 \%$ & 45 \\
\hline Madison, WI & 2,883 & 10,402 & 3,465 & 10,912 & 569,562 & 590,341 & 4,159 & 4,284 & $3.0 \%$ & 46 \\
\hline Wichita, KS & 1,339 & 4,324 & 1,667 & 4,341 & 624,077 & 629,550 & 1,600 & 1,644 & $2.7 \%$ & 47 \\
\hline Denyer-Aurora, CO & 5,366 & 17,755 & 7,014 & 18,618 & $2,553,829$ & $2,697,476$ & 1,601 & 1,640 & $2.5 \%$ & 48 \\
\hline Albany-Schenectady-Troy, NY & 3,952 & 13,795 & 4,374 & 14,012 & 870,913 & 877,905 & 3,622 & 3,690 & $1.9 \%$ & 49 \\
\hline Oklahoma City, OK & 3,336 & 13,296 & 4,393 & 13,718 & $1,257,883$ & $1,319,677$ & 2,379 & 2,412 & $1.4 \%$ & 50 \\
\hline San Diego-Carlsbad-San Marcos, CA & 8,276 & 25,264 & 9,722 & 25,762 & $3,104,182$ & $3,211,252$ & 1,894 & 1,907 & $0.7 \%$ & 51 \\
\hline Little Rock-N.Little Rock-Conway,AR & 1,587 & 5,355 & 1,568 & 5,584 & 702,230 & 724,385 & 1,751 & 1,758 & $0.4 \%$ & 52 \\
\hline Youngstown-Warren-Boardman, $\mathrm{OH}-\mathrm{PA}$ & 948 & 2,698 & 783 & 2,692 & 565,217 & 555,506 & 1,122 & 1,110 & $-1.1 \%$ & 53 \\
\hline Manchester-Nashua, NH & 1,327 & 1,597 & 1,154 & 1,670 & 547,406 & 550,834 & 826 & 816 & $-1.2 \%$ & 54 \\
\hline Grand Rapids-Wyoming, MI & 2,560 & 3,651 & 2,605 & 3,614 & 774,116 & 792,871 & 1,274 & 1,240 & $-2.7 \%$ & 55 \\
\hline Stockton, CA & 4,078 & 1,838 & 3,266 & 2,142 & 687,489 & 704,379 & 1,128 & 1,072 & $-5.0 \%$ & 56 \\
\hline Columbus, $\mathrm{OH}$ & 3,735 & 18,915 & 4,452 & 17,854 & $1,840,734$ & $1,902,404$ & 2,258 & 2,111 & $-6.5 \%$ & 57 \\
\hline
\end{tabular}




\section{CURRICULUM VITA \\ Brandon Scott McReynolds}

\section{Education}

December 2017

Ph.D. in Applied Sociology

Test Areas: Public Policy (Major) \& Education (Minor)

"Knowledge Cities: How the I-65 Corridor is Increasing Human

Capital"

University of Louisville, Louisville KY

May 2014

\section{M.A. in Sociology}

"Informal Study Groups: Gender \& Group Homophily"

University of Louisville, Louisville KY

December 2012

\section{Employment}

July 2016- Present

\section{B.S. in Political Science and Public Policy}

University of Louisville, Louisville KY

\section{Graduate Researcher at the University of Louisville Center for Environmental Policy and Management}

Conduct research that supports a variety of grants focused on communities affected by various environmental and social issues. The center also is contracted to do an annual State of the Metropolitan Housing Report.

August 2013- April 2014

\section{Graduate Teaching Assistant - (Sociology 210)}

Worked alongside a faculty member to instruct and administer a class, which looked at the historical construction of race along with the current state of race in the United States.

January 2013- August 2013

\section{AmeriCorps VISTA at GLI: Louisville Chamber of Commerce \& 55,000 Degrees \\ Worked on citywide educational initiatives the examined college access issues in the Louisville community. Job responsibilities also included research to help guide city programs that were intended to increase the percentage of citizens with associate and bachelor degrees.}




\section{Fellowships and Awards}

August 2014- June 2016

\section{University of Louisville Doctoral Fellowship}

This two-year fellowship allows the recipient to concentrate on graduate coursework with no other commitments while receiving a stipend and all tuition expenses.

August 2013- April 2014

\section{Graduate Teaching Assistantship}

Assistantship paid tuition as well as a regular monthly stipend for

Teaching teaching responsibilities.

August 2013- April 2014

\section{Graduate Teaching Assistant for Race in the U.S}

Worked alongside a faculty member to instruct and administer a class, which looked at the historical construction of race along with the current state of race in the United States. Main obligations of the position included facilitating two, one-hour discussion sessions

Professional Reports per week, grading and office hours.

2017

2016

\section{Papers Under-Review}

\section{State of Metropolitan Housing Report 2017}

A report created for the Metropolitan Housing Coalition by the Center for Environmental Policy and Management. Report examined multiple measures studying access to affordable housing with a special focus on Louisville's rental market.

\section{State of Metropolitan Housing Report 2016}

A report created for the Metropolitan Housing Coalition by the Center for Environmental Policy and Management. Report examined multiple measures studying access to affordable housing with a special focus on aging, and disabled populations.

Heberle, Lauren, Joseph Schilling, Brandon McReynolds and Steve Sizemore. "HUD's Sustainable Communities Initiative 2010 - 2016: An Emerging Model of Placed-Based Federal Policy and Collaborative Capacity Building" Cityscape (Has been preselected for a forthcoming special edition).

Presentations

October 2017

June 2017

\section{Mid-South Sociological Association- Chattanooga, TN}

Presented research on how Nashville, and the state of Tennessee, are working to meet their workforce demands.

\section{Optimal Aging Conference- Louisville, KY}


Presented on research around affordable housing and access to affordable housing for aging, and disabled populations.

March 2017

April 2016

March 2015

North Central Sociology Conference- Indianapolis, IN

Presented preliminary findings focusing on how Louisville, Kentucky, is working to increase human capital.

Southern Sociological Society Annual Conference- Atlanta, GA Presented on working paper entitled "A Coal Miner's Education: An Analysis of Coal Mining's Impact on Educational Attainment in Appalachian Region".

\section{Southern Sociological Society Annual Conference- New}

\section{Orleans, LA}

Presented the research findings of thesis entitled "Informal College

Study Groups: Gender and Group Homophily".

\section{Community Involvement}

January 2017- Present

Founder and President of Friends of Limestone

Started at non-profit that educates individuals about the impact limestone has on the Kentucky economy. Primary responsibility is to oversee the Board of Directors, and the team, which execute the

June 2016- Present day-to-day operations of the organization.

\section{Young Professional Association of Louisville (YPAL)} Ambassador

Work on a team to retain and attract individuals to Louisville's largest young professional association. YPAL provides programming and services to retain and network the City of Louisville's young professional talent.

April 2016- Present

\section{Americana Community Center Ambassador}

Work with the organization to support the mission of Americana, which is to create both programming for and awareness of the

November 2015- Present immigrant and refugee community in Louisville.

Nativity Academy of Louisville, Associate Board Member The Nativity Academy of Louisville is an independent Catholic middle school, which serves underprivileged students from throughout the community. This board helps to support and advocate for the mission of the Nativity Academy of Louisville.

October 2014- April 2015

American Cancer Society Cancer Action Network

Volunteer on behalf of the American Cancer Society with the primary duties of working with the organization's state leadership 
to advocate for issues pertaining to the prevention and treatment of cancer during the 2015 Kentucky Legislative Session.

March 2014- August 2014

\section{American Cancer Society Event Committee}

Served on a local committee, which was in charge of organizing a major fundraising event in the Louisville area that benefited the mission of the American Cancer Society.

\section{Service to University of Louisville}

October 2015- Present

University of Louisville Committee for Responsible Business Practices

Committee gathers pertinent business practice information, conducts benchmark studies, and makes recommendations to the University leadership.

July 2014- Present

\section{School of Interdisciplinary and Graduate Studies Student Ambassador \\ Works with office of Graduate Studies to recruit new students to the university.}

September 2016- June 2017

\section{University of Louisville Task Force on Tuition and Fees}

Committee oversees all university, department and auxiliary fees, along with tuition and recommends to university leadership

March 2016- July 2016 changes for the fiscal year.

Hiring Committee University of Louisville Vice-President for Strategic Enrollment Management and Student Success Serve on the committee and provide perspective on candidates for this university leadership position.

March 2016- May 2016

University of Louisville Executive Vice President \& University Provost, Search Committee

The committee is comprised of students, faculty, staff and local business leaders who are tasked with finding the chief academic officer for the university.

May 2015- May 2016

Speaker for the University of Louisville Student Senate

The job of Senate Speaker involves leading over fifty Senators who represent students from each college within the university. In this role the Senate Speaker is in charge of conducting meetings and serving as the liaison between the Student Senate and the May 2015- May 2016 university.

External Vice President for University of Louisville Graduate Student Council 
The responsibilities of the External Vice President encompass a multitude of different task but most importantly the position requires that the student represent graduate student interest on a variety of university committees.

May 2015- May 2016

\section{University Student Aid Committee}

Serve as the student representative on the committee to review and December 2014- June 2017 discuss any student aid proposals from across the university.

\section{University SACS Reaffirmation: Student Services Subcommittee}

Represent graduate and professional students university wide as it relates to ensuring the student voice is heard during the reaffirmation process of the University of Louisville's accreditation.

December 2014- December 2016

First Year Initiatives Essay Contest Judge

Judge and score submitted essays for the University of Louisville's

Teaching annual essay contest.

August 2013- April 2014

\section{Graduate Teaching Assistant for Race in the U.S (Sociology} 210)

Worked along side a faculty member to instruct and administer a class, which looked at the historical construction of race along with the current state of race in the United States. Main obligations of the position included facilitating two, one-hour discussion sessions

Professional Development per week, grading and office hours.

August 2013- April 2014

Graduate Teaching Academy

- Regular workshops designed around developing a pedagogical teaching style and preparing future academics to teach.

Awards and Recognition

- Upon completion, received a certificate for graduate teaching

Featured Graduate Student (2017) - University of Louisville

College of Arts and Sciences

City Finest Awardee (2017) - Cystic Fibrous Foundation of

Kentucky and West Virginia

YPAL Member of the Month (2017) - Young Professional

Association of Louisville

Volunteer of the Year Award (2014) - Mid-South Division of the

American Cancer Society

Outstanding Service Award (2014) - University of Louisville

Sociology Department 
The Michael Mardis Award for Excellence (2014) - University of Louisville Student Government Association

Committed Mentor Award (2014) - University of Louisville Student Government Association

\section{Current Memberships}

American Sociological Association

Association for the Study of Higher Education

North Central Sociological Association

Southern Sociological Association

\section{Recommendations}

Available upon request 